UDK 902

ISSN 1330-0644

VOL 35/2018.

ZAGREB, 2018.

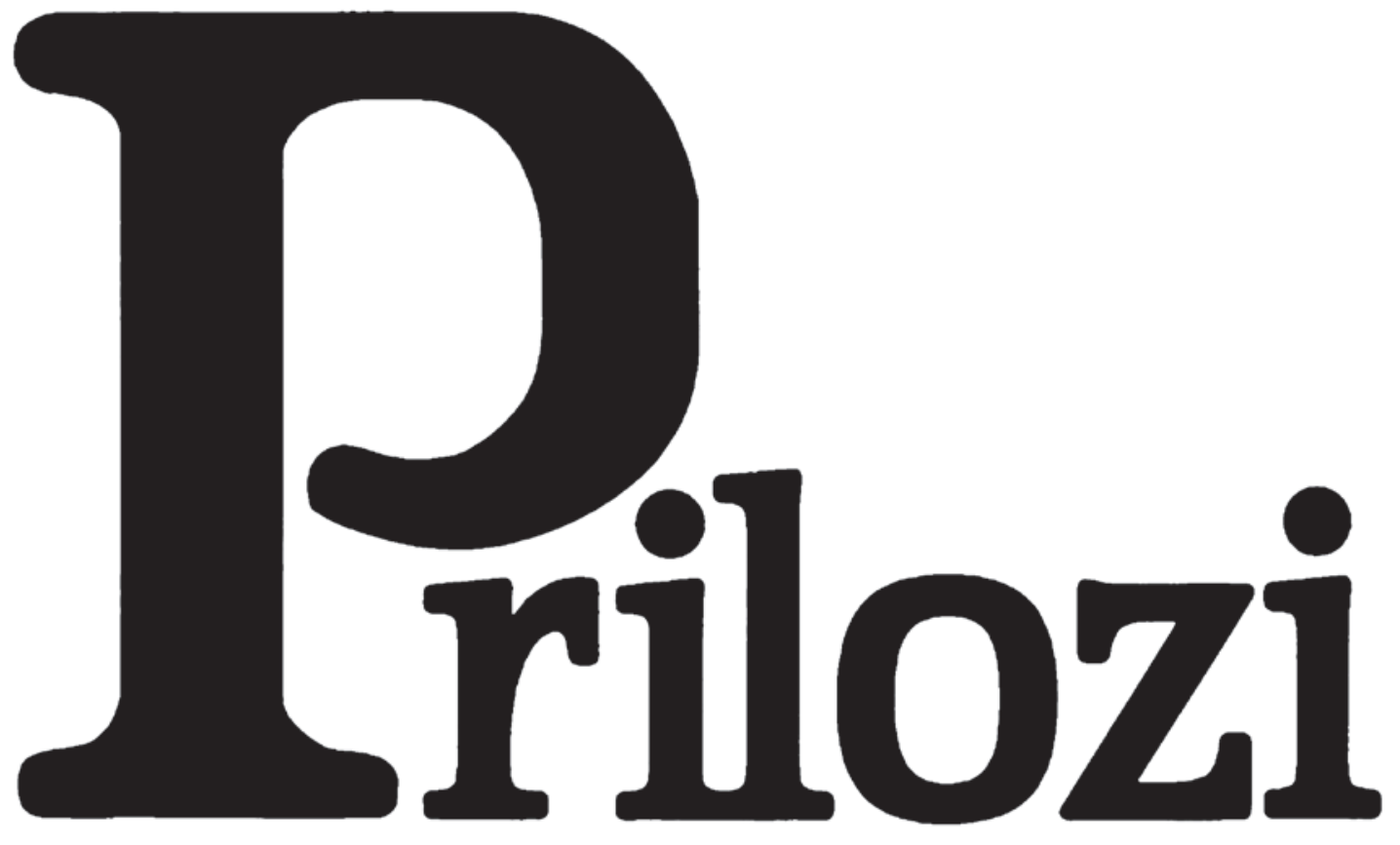

Instituta za arheologiju u Zagrebu 
Pril. Inst. arheol. Zagrebu, 35/2018

Str./Pages 1-328, Zagreb, 2018.
Ovaj rad licenciran je pod Creative Commons Attribution By 4.0 međunarodnom licencom / This work is licenced under a Creative Commons Attribution By 4.0 International Licence
Izdavač/Publisher

INSTITUT ZA ARHEOLOGIJU

INSTITUTE OF ARCHAEOLOGY

Adresa uredništva/Address of the editor's office Institut za arheologiju/Institute of archaeology HR-10000 Zagreb, Ulica Ljudevita Gaja 32

Hrvatska/Croatia

Telefon/Phone ++385/(0)1 6150250

Fax $++385(0) 16055806$

e-mail: urednistvo.prilozi@iarh.hr

http://www.iarh.hr

Glavni i odgovorni urednik/Editor in chief

Marko DIZDAR

Uredništvo/Editorial board

Marko DIZDAR, Snježana KARAVANIĆ, Viktória KISS (Budapest, HUN) (prapovijest/Prehistory), Goranka LIPOVAC VRKLJAN (antika/Antiquities), Tajana SEKELJ IVANČAN, Katarina Katja PREDOVNIK (Ljubljana, SLO), Natascha MEHLER (Wien, AUT), Juraj BELAJ, Tatjana TKALČEC (kasni srednji vijek i novi vijek/Late Middle Ages and Modern era), Predrag NOVAKOVIĆ (Ljubljana, SLO) (metodologija/Methodology)

Izdavački savjet/Editorial advisory board

Dunja GLOGOVIĆ (Zagreb), Ivor KARAVANIĆ (Zagreb), Laszlo KÓVACS (Budapest, HUN),

Kornelija MINICHREITER (Zagreb), Mladen RADIĆ (Osijek), Aleksandar RUTTKAY (Nitra, SK), Ivančica SCHRUNK (Minneapolis, USA), Željko TOMIČIĆ (Zagreb), Ante UGLEŠIĆ (Zadar)

Prijevod na engleski/English translation

Edward BOSNAR, Kristina BRKIĆ, Nikola CESARIK, Ivan DRNIĆ, Ana ĐUKIĆ, Nataša ĐURĐEVIĆ, Emanuele FALCONE, Stašo FORENBAHER, Marija KOSTIĆ, Danijel LONČAR, Marko MARAS, Tina MILAVEC, David ŠTRMELJ

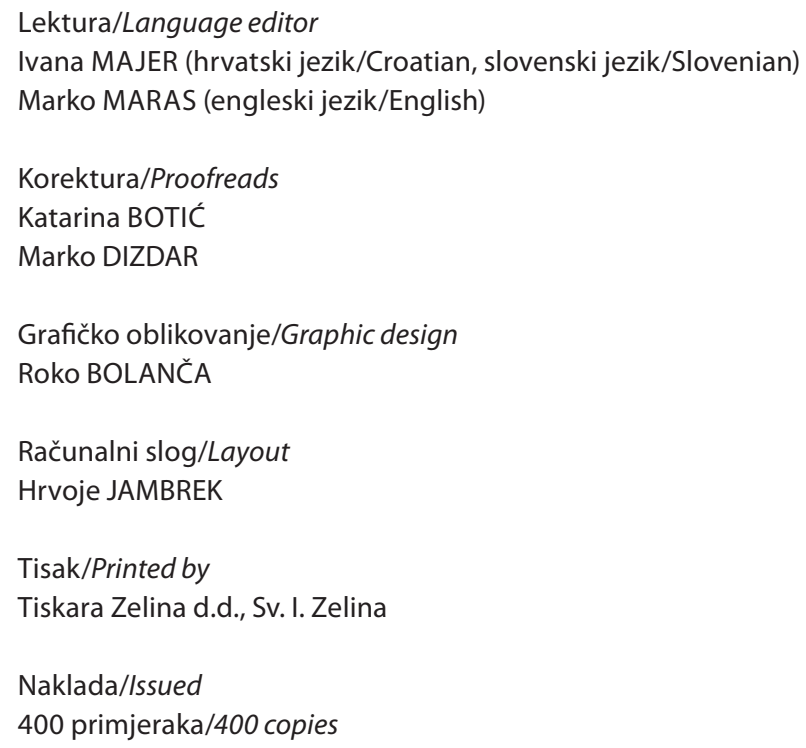

Prilozi Instituta za arheologiju u Zagrebu uključeni su u sljedeće indekse/ Prilozi Instituta za arheologiju u Zagrebu are included in following indices:

DYABOLA - Sachkatalog der Bibliothek - Römisch-Germanische Kommission des Deutschen Archaeologischen Instituts, Frankfurt a. Main

Clarivate Analytics services - Emerging Sources Citation Index

CNRS/INIST - Centre National de la Recherche Scientifi que/L'Institut de I'Information Scientifi que et Technique, Vandoeuvre-lès-Nancy

EBSCO - Information servises, Ipswich

ERIH - European Reference Index for the Humanities, European Science Fundation, Strasbourg SciVerse Scopus - Elsevier, Amsterdam 
Pril. Inst. arheol. Zagrebu, 35/2018

Str./Pages 1-328, Zagreb, 2018.

Sadržaj

\section{Izvorni znanstveni radovi}

DARIO VUJEVIĆ STIPAN DILBER

Izvor - špilja Ričina u Buškome jezeru. Prvi tragovi paleolitika na području zapadne Hercegovine

IVAN DRNIĆ

KONSTANTINOS P. TRIMMIS

ALEXANDRA HALE

RICHARD MADGWICK

KELLY REED

ANTONELA BARBIR

MARIN MAĐERIĆ

Assemblages from Marginal Spaces: The results of the excavations in Mala (Nova) Pećina near Muć and the Neolithic of Dalmatinska Zagora

HRVOJE KALAFATIĆ

BARTUL ŠILJEG

KRUGOVI PARNJACI: novi uvidi u neolitičke

obrasce naseljavanja

113 STAŠO FORENBAHER

Ljubljana i Cetina: lončarski stilovi 3. tisućljeća prije Krista na prostoru istočnoga Jadrana

ZVONKO BOJČIĆ

DARIA LOŽNJAK DIZDAR

TOMISLAV HRŠAK

Nove spoznaje o kronologiji groblja Batina -

Sredno na početku starijega željeznog doba

KORNELIJA A. GIUNIO

NIKOLA CESARIK

DAVID ŠTRMELJ

Šest baza počasnih statua iz Jadera

\section{Contents}

\section{Original scientific papers}

DARIO VUJEVIĆ
STIPAN DILBER

The Ričina spring cave in Buško Jezero. The first traces of the Palaeolithic in the western Herzegovina region

IVAN DRNIĆ

KONSTANTINOS P. TRIMMIS

ALEXANDRA HALE

RICHARD MADGWICK

KELLY REED

ANTONELA BARBIR

MARIN MAĐERIĆ

Nalazi iz marginalnih prostora: Rezultati istraživanja Male (Nove) pećine pokraj Muća i neolitik

Dalmatinske zagore

HRVOJE KALAFATIĆ

BARTUL ŠILJEG

TWIN CIRCLES: new insights in the Neolithic settlment pattern

\section{STAŠO FORENBAHER}

Ljubljana and Cetina: Pottery Styles of the Third Millennium BC in the Eastern Adriatic

\section{ZVONKO BOJČIĆ \\ DARIA LOŽNJAK DIZDAR}

TOMISLAV HRŠAK

New knowledge about the chronology of The Batina - Sredno cemetery at the beginning of the Early Iron Age

KORNELIJA A. GIUNIO

NIKOLA CESARIK

DAVID ŠTRMELJ

Six Honorary Statue Bases from Iader 
219 MIRKO RAŠIĆ

JOSIPA BARAKA PERICA

Starokršćanski kompleks u Docima kod Vitine: rezultati revizijskih arheoloških istraživanja

239 TINA MILAVEC

The elusive early medieval glass: remarks on vessels from the Nin - Ždrijac cemetery, Croatia

\section{Pregledni rad}

251 ANA ĐUKIĆ

Prapovijesne glačane kamene izrađevine sjeverozapadne Hrvatske

291 MARIN ZANINOVIĆ

Kako sam ustanovio postojanje grčkoga katastra (chora) u Starigradskom polju

299 ANA AZINOVIĆ BEBEK

Novovjekovna arheologija u Hrvatskoj - problemi metodologije, terminologije i imena
MIRKO RAŠIĆ

JOSIPA BARAKA PERICA

The early Christian complex in Doci, Vitina: the results of the revised archaeological research

\section{TINA MILAVEC}

Izmikajoče se zgodnjesrednjeveško steklo: komentar k posodam z grobišča Nin-Ždrijac, Hrvaška

\section{Report}

\author{
ANA ĐUKIĆ \\ Prehistoric polished stone implements from \\ northwestern Croatia
}

MARIN ZANINOVIĆ

How I identified a Greek cadastre (chora) on the Stari Grad Plain

ANA AZINOVIĆ BEBEK

Early Modern Archaeology in Croatia - Problems of Methodology, Terminology and Nomenclature 


\title{
Prapovijesne glačane kamene izrađevine sjeverozapadne Hrvatske
}

\section{Prehistoric polished stone implements from northwestern Croatia}

\author{
Pregledni rad \\ Prapovijesna arheologija \\ Report \\ Prehistoric archaeology \\ UDK/UDC 903.21(497.5-16)"634/636" \\ Primljeno/Received: 18. 12. 2017. \\ Prihvaćeno/Accepted: 02. 07. 2018.
}

\author{
ANA ĐUKIĆ \\ Zeleni put 10 \\ HR-10292 Laduč \\ adukic21@gmail.com
}

\begin{abstract}
Glačano kameno oruđe vrlo je važna vrsta pokretnoga arheološkog materijala s prapovijesnih lokaliteta. U fundusu Arheološkoga muzeja u Zagrebu čuva se oko 220 neobjavljenih predmeta te vrste s područja sjeverozapadne Hrvatske. U ovome radu ti će predmeti biti tipološki, kronološki i prostorno analizirani, s ciljem proširenja spoznaja o razdobljima neolitika i eneolitika na spomenutome području. lako su nalazi u muzej stizali odvojeno i bez podataka o kontekstu pronalaska, i to početkom 20. stoljeća, njegova brojnost i tipološka raznolikost svjedoče o intenzivnom naseljavanju toga prostora u spomenutim razdobljima. Nalazi potječu sa 71 lokacije, a podijeljeni su u osam tipoloških cjelina koje su zatim kronološki određene. Prema tipološkim obilježjima i usporedbama s drugim, dobro datiranim nalazima, dio analiziranih nalaza pripisan je neolitičkima starčevačkoj, linearnotrakastoj i sopotskoj kulturi ili bakrenodobnima lasinjskoj, retzgajarskoj i vučedolskoj kulturi, s napomenom da prema nekim obilježjima dio nalaza može biti datiran u brončano te rano željezno doba. Osim tipološke analize glačanih kamenih izrađevina, cilj ovog rada jest i utvrđivanje arheološke topografije proučavanoga prostora te izrada plana za buduće terenske preglede i arheološka istraživanja.
\end{abstract}

Ključne riječi: glačano kameno oruđe, kameno oruđe s abrazivim svojstvima, neolitik, eneolitik, sjeverozapadna Hrvatska, Hrvatsko zagorje

Polished stone tools are a highly important kind of movable archaeological material from prehistoric sites. The Archaeological Museum in Zagreb keeps about 220 unpublished finds of this kind from the territory of northwestern Croatia. This paper brings the typological, chronological and spatial analysis of these finds, with the aim of expanding knowledge on the Neolithic and Copper Age periods on the discussed territory. Although the material made its way to the Museum on different occasions at the beginning of the 20th century, with no data on the context of discovery, the number of finds and their typological diversity testify to the intensive settling of the area in the aforementioned periods. The material originated from 71 locations and was divided into eight typological groups that were then chronologically defined. Based on the typological characteristics and comparisons to other, well-dated finds, some of these finds were ascribed to the Neolithic Starčevo, Linear Pottery and Sopot, the Copper Age Lasinja, Retz-Gajary and Vučedol cultures, noting that some of the traits indicate a part of the material could be dated to the Bronze and the Early Iron Age. In addition to the typological analysis of polished stone tools, the aim was to establish the archaeological topography of the studied area and to create a plan for future field surveys and archaeological research.

Key words: polished stone tools, stone tools with abrasive properties, Neolithic, Copper Age, northwestern Croatia, Hrvatsko Zagorje

\section{UVOD}

U Arheološkome muzeju u Zagrebu u tijeku je revizija građe s Pretpovijesnoga odjela koja obuhvaća analiziranje predmeta te provjeravanje podataka o mjestu pronalaska i nabavi predmeta za fundus Muzeja. Tijekom revizije nalaza s prostora sjeverozapadne Hrvatske pojavio se već poznati problem glačanoga kamenog oruđa koje čini velik dio ukup-

\section{INTRODUCTION}

The Archaeological Museum in Zagreb is currently conducting a revision of the material from the Prehistoric Department that includes the analysis of the finds and the checking of the data on the place of discovery and the modes in which the finds were acquired by the Museum. The revision of the finds from northwestern Croatia revi- 
ne građe.' Iz ovoga je rada izlučen dio predmeta poznat kao zbirka Pečornik i dodatnih pet predmeta koji su prethodno objavljeni (Balen-Letunić 1981: 5-17; Pavišić 1990). Predmeti su tipološki analizirani i datirani do mjere do koje su njihove karakteristike dopuštale. Precizna kronološka atribucija većine analizianih predmeta nije moguća s obzirom na to da se uglavnom radi o slučajnim nalazima bez arheološkoga konteksta. Ipak, bit će predložene okvirne odrednice utemeljene na tipovima i varijantama izrađevina, vrsti sirovina koje su korištene za njihovu izradu² te usporedbama s drugim lokalitetima gdje je arheološki kontekst poznat i dobro datiran.

Pod pojmom glačanoga kamenog oruđa obuhvaćeni su svi predmeti koji su mogli služiti za bilo kakvu vrstu posla (Antonović, Đorđević 2003: 47) te koji su primarno oblikovani tehnikom udaranja i lomljenja sirovine, a zatim su dodatno brušeni i glačani (Karavanić, Balen 2003: 50) uz pomoć ručnih i/ili statičnih glačalica (Antonović 2003: 51). Među analiziranim nalazima definirano je osam kategorija. Okvirne datacije lokacija prema tipu glačanih kamenih predmeta predložene su na kraju rasprave (tab. 12). Analiza tehnologije izrade glačanoga kamenog oruđa važna je jer pridonosi utvrđivanju svakodnevnih aktivnosti na nalazištu, sagledavanju društvenih odnosa i načinu života populacija te njihova odnosa prema okolišu (Biró 1994: 159-161; Marciuš 2017: 26).

\section{TOPOGRAFIJA NALAZIŠTA}

U radu su obrađeni i prezentirani glačani kameni nalazi sa 71 lokacije te nalazi s područja Hrvatskoga zagorja (karta 1). Muzejske inventarne knjige i arhiv iznjedrili su podatke potrebne za okvirno kartiranje nalazišta, osobito za mjesta s čestim toponimima, a u svrhu određivanja lokacija za buduće terenske preglede i istraživanja. Većina zastupljenih lokacija nalazi se u Krapinsko-zagorskoj ${ }^{3}$ i Varaždinskoj županiji, ${ }^{4}$ ali neke su i u Karlovačkoj, ${ }^{5}$ Zagrebačkoj, ${ }_{1}^{6}$ Koprivničko-križevačkoj ${ }^{7}$ i Sisačko-moslavačkoj županijii ${ }^{8}$ te u Gradu Zagrebu. ${ }^{9}$

1 Ovom prilikom zahvaljujem dr. sc. Jacqueline Balen, voditeljici Pretpovijesnoga odjela Arheološkoga muzeja u Zagrebu, na ustupanju materijala za potrebe izrade ovoga rada.

2 Ovom prilikom zahvaljujem pokojnome dr. sc. Hrvoju Posiloviću iz Zavoda za geologiju Hrvatskoga geološkog instituta, koji je pregledao dio materijala, a neke predmete i detaljno analizirao (P-6473, P-21297, P-1723, P-1721, P-21323, P-1697, P-1814, P-21349-1, P-21312-9).

3 Bedekovčina, Bojačno Selo, Golubovec, Gotalovec, Hrašćina, Hum, Jalševec, Klenovec, Konjšćina, Kuzminec, Laz, Lobor, Mače, Marija Bistrica, Martinci, Mihovljan, Miljana, Peršaves, Poljanica, Radoboj, Ratkovec, Sutinske Toplice, Sutinsko, Šemnica, Topličica, Vučak, Zajezda i Zlatar.

4 Biškupec, Brezova Gora, Cerje Tužno, Cvetlin, Črnec, Druškovec, Hum Sveti Martin, Ivanec, Jamno, Jazbina, Jerovec, Klenovnik, Koškovec, Kršćenovec, Lepoglava, Novaki, Poljana, Sveti Ilija Obrež, Štefanec, Tkalec i Vinično.

5 Oštri Vrh.

6 Brdovec, Jakovlje, Kloštar Ivanić, Kraljev Vrh, Lipovac, Marija Gorica, Pakasin, Samobor i Sveti Ivan Zelina.

7 Kalinovac, Miholečke Mokrice, Ivanec i Oslavec.

8 Drenov Bok.

9 Cerje, Čulinec, Jakuševec, Kamenski Dol, Kašina, Podsused i Sveti Šimun. ved the long-known problem of the polished stone implements that make up a large portion of the material. ${ }^{1}$ This paper does not include the finds recorded as the Pečornik collection and the additional five finds that have already been published (Balen-Letunić 1981: 5-17; Pavišić 1990). The finds were typologically analysed and dated to the extent allowed by their characteristics. It was impossible to make precise chronological attributions for the majority of the finds analysed herein, seeing as they are mostly chance finds without an archaeological context. However, we will present approximate determinations based on artefact types and variants, the raw materials used for their production, ${ }^{2}$ and comparisons with other sites that have a well-known and dated archaeological context.

The term 'polished stone tool' includes all the artefacts that could have been used for any kind of job (Antonović, Đorđević 2003: 47), and which were primarily shaped by striking and knapping, and were then additionally honed and polished (Karavanić, Balen 2003: 50) by using hand-held and/or static polishers (Antonović 2003: 51). The analysed material was sorted into eight categories. The general dating of the studied locations is presented at the end of the discussion (Tab. 12). The analysis of the technology applied to polished stone tool production is important because it contributes to the reconstruction of everyday activities at a given site, the understanding of social relations, the way of life of past populations, and the way in which they related to the environment (Biró 1994: 159-161; Marciuš 2017: 26).

\section{SITE TOPOGRAPHY}

The paper offers the analysis of the polished stone artefacts from 71 locations and the finds from the territory of Hrvatsko Zagorje (Map 1). Museum inventory books and archives provided the data necessary to map the sites, especially for places with common toponyms, all with the aim of determining the locations for future field surveys and research. Most sites are in the Krapina-Zagorje County ${ }^{3}$ and the Varaždin County, ${ }^{4}$ but some are in the Karlovac, ${ }^{5}$ Zagreb, ${ }^{6}$ Koprivnica-Križevci ${ }^{7}$ and the Sisak-Moslavina counties, ${ }^{8}$ and

1 I would like to thank Jacqueline Balen, $\mathrm{PhD}$, the head of the Prehistoric Department of the Archaeological Museum in Zagreb, for providing me with the material for this paper.

2 I would like to thank the late Hrvoje Posilović, $\mathrm{PhD}$, from the Department of Geology of the Croatian Geological Survey for studying the material and fully analyzing some of the finds (P-6473, P-21297, P-1723, P-1721, P-21323, P-1697, P-1814, P-21349-1, P-21312-9).

3 Bedekovčina, Bojačno Selo, Golubovec, Gotalovec, Hrašćina, Hum, Jalševec, Klenovec, Konjšćina, Kuzminec, Laz, Lobor, Mače, Marija Bistrica, Martinci, Mihovljan, Miljana, Peršaves, Poljanica, Radoboj, Ratkovec, Sutinske Toplice, Sutinsko, Šemnica, Topličica, Vučak, Zajezda and Zlatar.

4 Biškupec, Brezova Gora, Cerje Tužno, Cvetlin, Črnec, Druškovec, Hum Sveti Martin, Ivanec, Jamno, Jazbina, Jerovec, Klenovnik, Koškovec, Kršćenovec, Lepoglava, Novaki, Poljana, Sveti Ilija Obrež, Štefanec, Tkalec and Vinično.

5 Oštri Vrh.

6 Brdovec, Jakovlje, Kloštar Ivanić, Kraljev Vrh, Lipovac, Marija Gorica, Pakasin, Samobor and Sveti Ivan Zelina.

7 Kalinovac, Miholečke Mokrice, Ivanec and Oslavec.

8 Drenov Bok. 


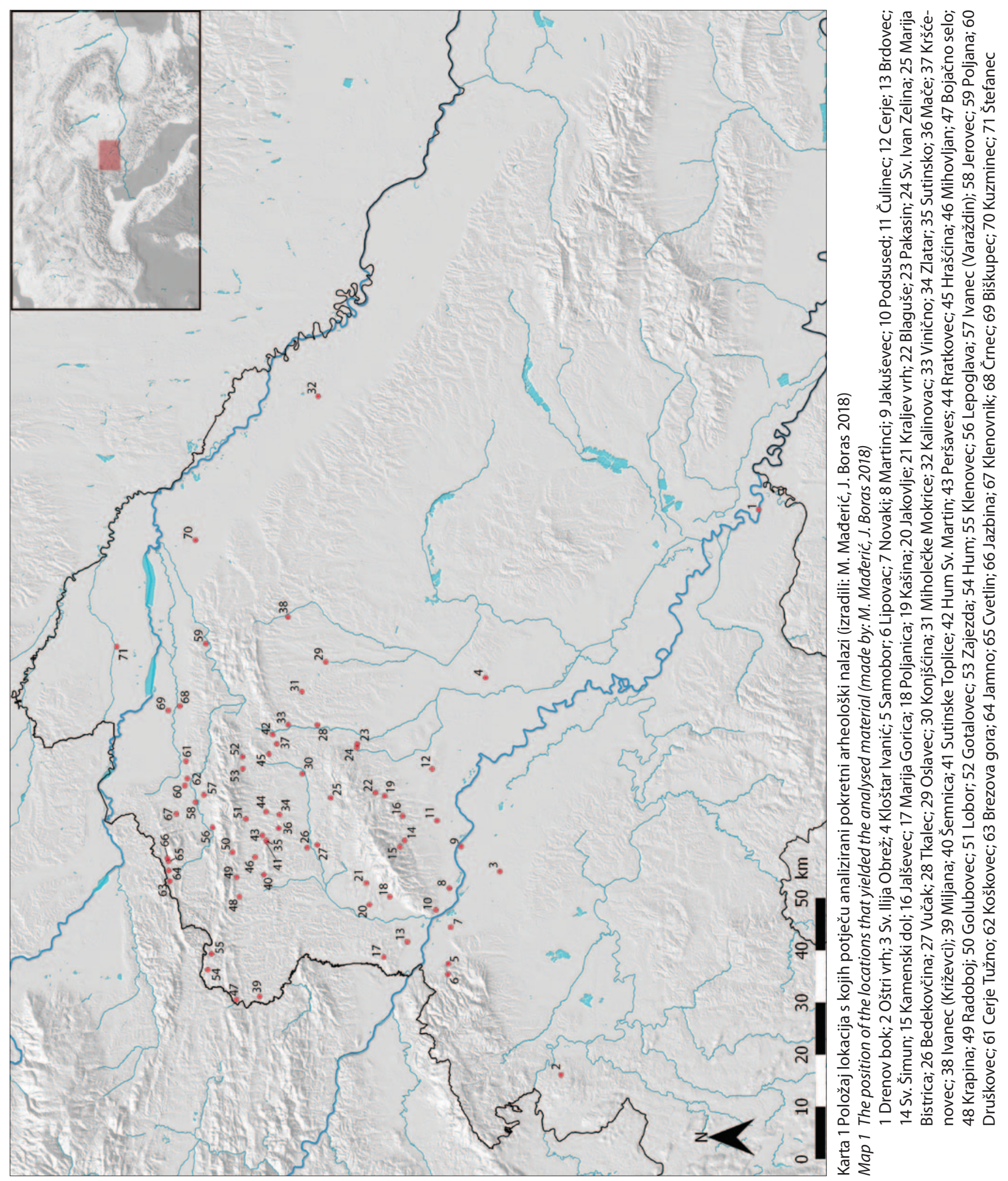


Najjužnija zahvaćena lokacija je Drenov Bok kod Novske, najistočnija Kalinovac kod Đurđevca, najzapadnija Oštri Vrh kod Karlovca, a najsjevernija Štefanec u općini Mala Subotica. Geografski gledano, radi se o vrlo raznolikom reljefnom prostoru u kojemu Hrvatsko zagorje, varaždinska Podravina i Međimurje imaju kontaktnu ulogu prema Alapama, a Posavina prema peripanonskom prostoru, odnosno Dinaridima (Feletar 1986: 4).

\section{TIPOLOŠKO-FUNKCIONALNA ANALIZA GLAČANOGA KAMENOG ORUĐA}

U radu je analizirano 218 predmeta koji su dokumentirani pod 196 inventarnih brojeva. ${ }^{10} \mathrm{~S}$ većine lokacija uključenih $u$ analizu potječe po jedan predmet, a s nekih i njih više (tab. 1).

U prijašnjim objavama analizirana su 53 predmeta iz zbirke Pečornik koji su podijeljeni u tri kategorije - oruđe bez rupe, oruđe s rupom te oštećeni i neprepoznatljivi primjerci (Balen-Letunić 1981: 7). Ovdje analizirana građa podijeljena je u osam kategorija - glačana kamena dlijeta i bradve (14), sjekire trapezastoga oblika (22), čekići (21), sjekire-čekići s rupom za nasad drška (28), sjekire s rupom za nasad drška (21), čekići i sjekire ili sjekire-čekići s rupom za nasad drška (19), žrvnjevi (4) i ostalo (38). Nalazi s nepoznatih lokaliteta (tri), kao i oni s nepoznatih lokaliteta u Hrvatskome zagorju (46), obrađeni su kao zasebne cjeline.

\section{Dlijeta i bradve}

Sva glačana kamena dlijeta i bradve analizirane u ovome radu pripadaju tipu s jednom zaravnjenom stranom i presjekom u obliku slova D. Na svim se predmetima, izuzev P-21296, Drenov Bok, vide tragovi upotrebe na oba kraja.

Dlijeta je sedam, i to sa šest lokacija (tab. 2). ${ }^{11}$ U ovoj kategoriji treba izdvojiti P-18838 iz Klenovca (T. 3: 2) koje je prvotno bilo glačano, a sekundarno dorađivano lomljenjem, vjerojatno zbog toga što je izrađeno od silicificiranoga lapora koji zbog svojih svojstava nije pogodan za obradu glačanjem. Treba izdvojiti i P-15000 iz Kamenskog Dola (T. 4: 1), jer se radi o najvećem predmetu u ovoj kategoriji. Izduženoga je oblika i gotovo trokutastoga presjeka, a određen je kao dlijeto na temelju paralelnih bočnih bridova. $\mathrm{Na}$ predmetu su ustanovljeni tragovi korištenja na oba kraja. Osim prikazanih dlijeta (tab. 2), valja spomenuti i ulomak iz neolitičkoga naselja na Strugači (T. 3: 4) koje je otkriveno rekognosciranjem (Špoljar 2012: 36). Radi se o predmetu Dpresjeka sa zaravnjenim stražnjim krajem. Predmet je dug $7,1 \mathrm{~cm}$, širok 4,7 cm, debljine 2,6 cm i težak 124 grama. Osim ovih, objavljeno je još predmeta ovoga tipa iz Hrvatskog zagorja (Balen-Letunić 1981) te pet predmeta iz čakovečkoga muzeja (Marciuš 2017: 29, kat. br. 28-32).

Među analiziranim nalazima definirano je šest bradvi $s$

10 U većini slučajeva je s lokacije sačuvan po jedan predmet. Ipak, s lokacija Bojačno Selo, Čulinec, Druškovec, Hum, Hum Sv. Martin, Konjšćina, Kuzminec, Lobor, Pakasin, Poljana, Poljanica, Radoboj i Sutinsko potječu po dva, s lokacija Gotalovec, Jazbina, Kašina, Mihovljan i Zajezda po tri, s lokacija Ivanec (Križevci), Klenovec, Koškovec i Mače po četiri, s lokacija Brezova Gora i Drenov Bok po pet, s lokacije Tkalec šest, s lokacije

Jamno 12, s lokacije Marija Bistrica 17 i s lokacije Zlatar 20 predmeta.

11 Klenovec i Tkalec po dva dlijeta, a s ostalih lokaliteta po jedno. in the city of Zagreb. ${ }^{9}$ The southernmost location is Drenov Bok near Novska, the easternmost is Kalinovac near Đurđevac, the westernmost is Oštri Vrh near Karlovac, and the northernmost is Štefanec in the Mala Subotica municipality. Geographically speaking, this is a very versatile area, wherein important roles are played by Hrvatsko Zagorje and the Drava River valley around Varaždin and Međimurje for the contact with the Alps, and by the Sava River valley for the contact with the Pannonian regions, i.e. the Dinarids (Fele$\operatorname{tar}$ 1986: 4).

\section{THE TYPOLOGICAL AND FUNCTIONAL ANALYSIS OF POLISHED STONE IMPLEMENTS}

A total of 218 finds, registered under 196 inventory numbers, were analysed..$^{10}$ Most locations yielded one find, but some contained several (Tab. 1).

Previous publications include 53 finds from the Pečornik collection that were divided into three categories - tools without a hole, tools with a hole, and damaged and unrecognizable finds (Balen-Letunić 1981: 7). The material studied herein was divided into eight categories - polished stone chisels and adzes (14), trapezoidal axes (22), hammers (21), axe-hammers with holes for hafting (28), axes with holes for hafting (21), hammers and axes or axe-hammers with holes for hafting (19), grindstones (4), and other (38). The finds from unknown sites (three), and the finds from unknown sites in Hrvatsko Zagorje (46), were studied as separate units.

\section{Chisels and adzes}

All the polished stone chisels and adzes analysed in this paper are ascribed to the type with one straight side and a D-shaped cross-section. All of the finds, except P-21296, Drenov Bok, display traces of use on both ends.

Seven chisels were defined at six locations (Tab. 2). ${ }^{11}$ Chisel P-18838 from Klenovec (PI. 3: 2) should be emphasized in this category because it was originally polished and subsequently knapped, probably because it is made of silicified marl that is not suitable for polishing. Chisel P-15000 from Kamenski Dol (PI. 4: 1) should also be noted, seeing as it is the largest find in the category. It has an elongated shape and an almost triangular cross-section, and was defined as a chisel based on its parallel lateral sides. The find displays traces of use on both ends. Apart from the represented chisels (Tab. 2), we should also mention a fragment from the Neolithic settlement of Strugača (PI. 3: 4), which was discovered in field surveys (Špoljar 2012: 36). The find has a D-shaped cross-section with a straightened back end. It is $7.1 \mathrm{~cm}$ long, $4.7 \mathrm{~cm}$ wide, $2.6 \mathrm{~cm}$ thick and weighs $124 \mathrm{grams}$. In addition to these, other

9 Cerje, Čulinec, Jakuševec, Kamenski Dol, Kašina, Podsused and Sveti Šimun.

10 In most cases, one find was preserved per location. However, there were two finds in Bojačno Selo, Čulinec, Druškovec, Hum, Hum Sv. Martin, Konjšćina, Kuzminec, Lobor, Pakasin, Poljana, Poljanica, Radoboj and Sutinsko; three finds in Gotalovec, Jazbina, Kašina, Mihovljan and Zajezda; four finds in Ivanec (Križevci), Klenovec, Koškovec and Mače; five finds in Brezova Gora and Drenov Bok; six finds in Tkalec; 12 finds in Jamno; 17 finds in Marija Bistrica and 20 finds in Zlatar.

11 Two chisels each from Klenovec and Tkalec, and one from every other location. 


\begin{tabular}{|c|c|c|c|c|c|c|c|c|c|c|c|c|c|c|c|c|c|c|c|c|c|c|}
\hline 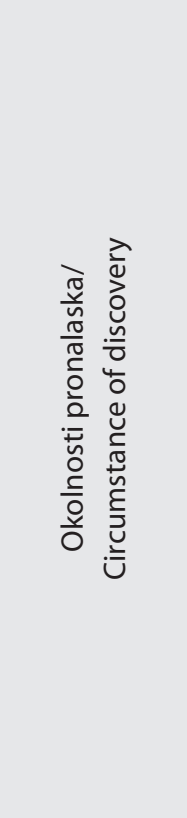 & 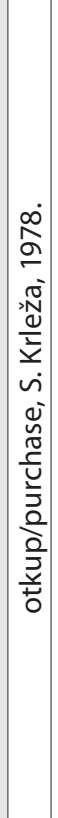 & 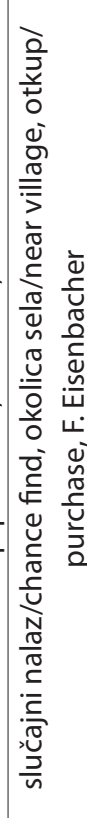 & \begin{tabular}{|c|} 
\\
\\
0
\end{tabular} & 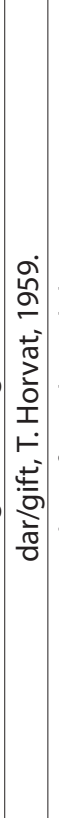 & 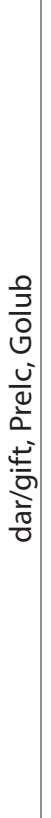 & 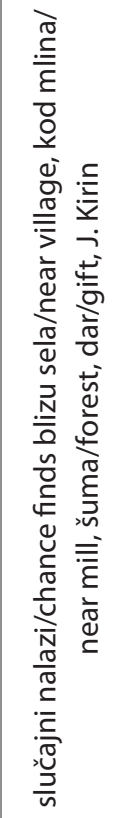 & 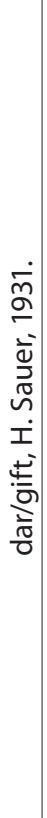 & 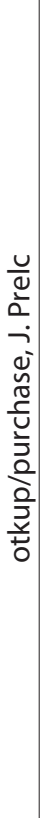 & 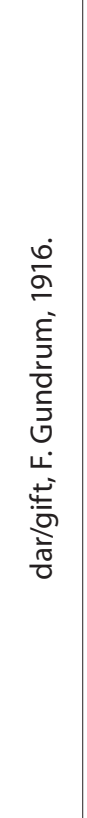 & 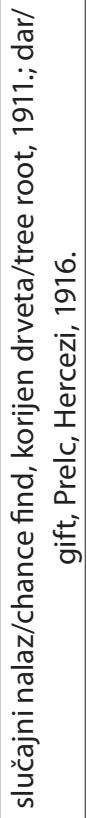 & 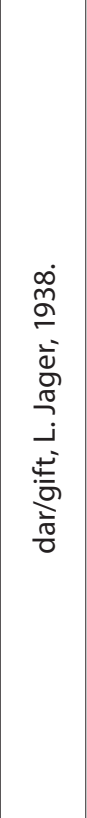 & 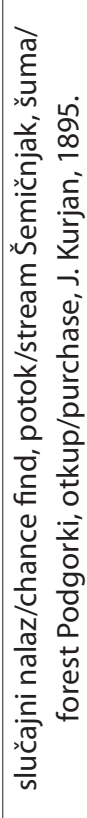 & 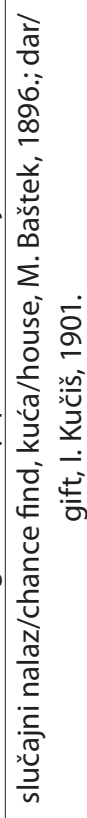 & 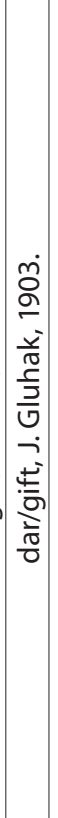 & 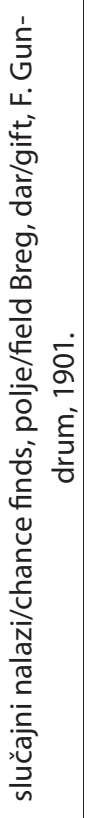 & 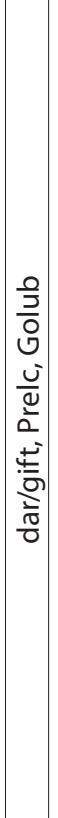 & 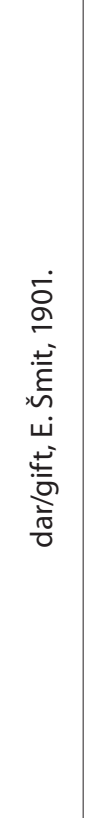 & 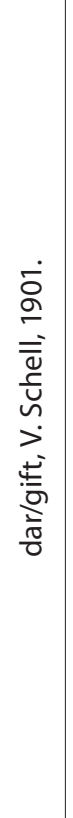 & 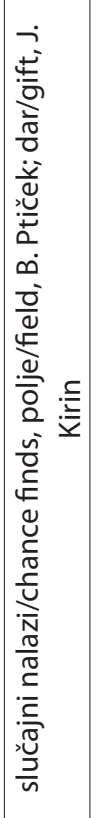 & 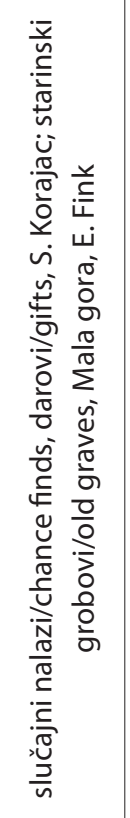 & 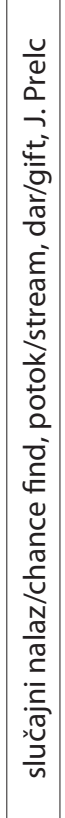 & \\
\hline 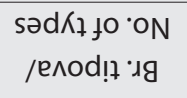 & $\sim$ & - & - & $\sim$ & $\sim$ & $\nabla$ & - & - & - & $N$ & - & - & - & - & $N$ & - & - & $\sim$ & - & $N$ & - & \\
\hline $\begin{array}{l}\text { spuy jo on } \\
\text { /ezejeu 'ג }\end{array}$ & $\sim$ & - & - & $\sim$ & $\nabla$ & $\approx$ & - & - & - & $m$ & - & - & - & - & $N$ & - & - & $\sim$ & $N$ & $N$ & - & \\
\hline 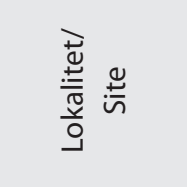 & 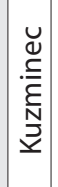 & $\begin{array}{l}\frac{\pi}{0} \\
\frac{\pi}{5} \\
\frac{0}{0} \\
\frac{0}{9}\end{array}$ & 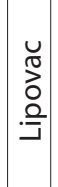 & 亯 & $\sum^{\frac{8}{2}}$ & 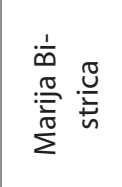 & 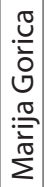 & : & 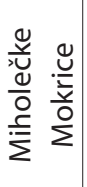 & 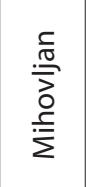 & 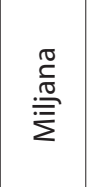 & $\begin{array}{l}\frac{5}{0} \\
\frac{5}{0} \\
2\end{array}$ & $\frac{\stackrel{u}{\Delta}}{\frac{\pi}{n}}$ & 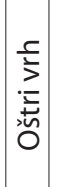 & 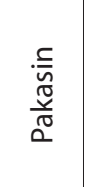 & 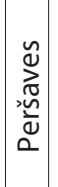 & 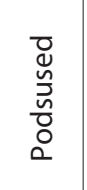 & $\begin{array}{l}\frac{\pi}{\stackrel{0}{0}} \\
\stackrel{\frac{\pi}{0}}{0} \\
\frac{0}{0}\end{array}$ & $\begin{array}{l}\frac{0}{\frac{0}{\pi}} \\
\frac{.0}{\overline{0}} \\
\frac{0}{0}\end{array}$ & $\begin{array}{l}\overline{0} \\
\frac{0}{0} \\
\frac{0}{0} \\
\check{\pi}\end{array}$ & 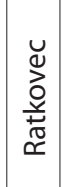 & \\
\hline 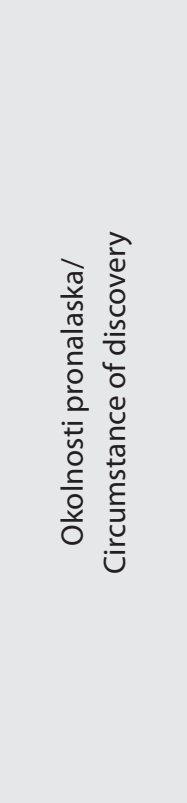 & 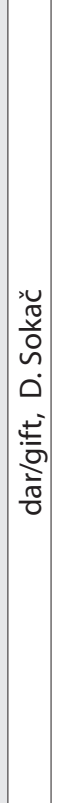 & 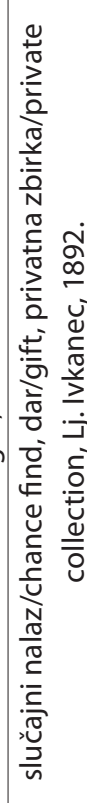 & 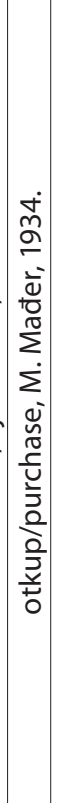 & 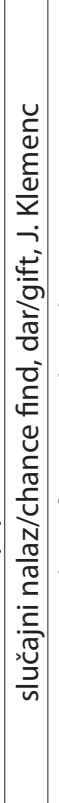 & 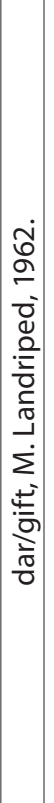 & 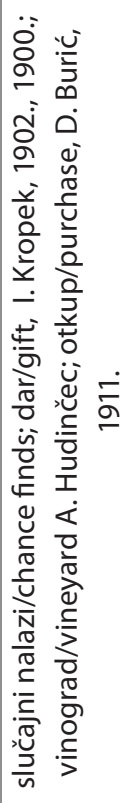 & 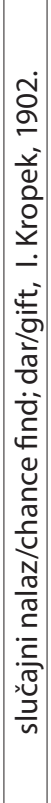 & 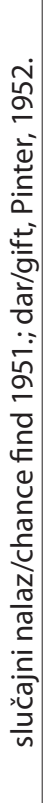 & 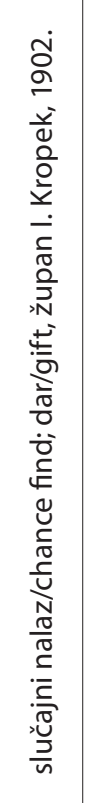 & 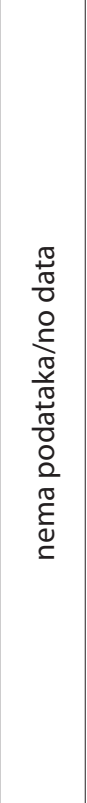 & 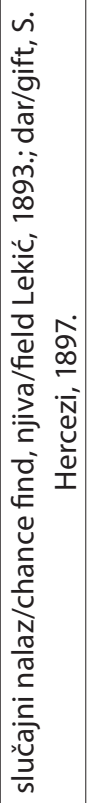 & 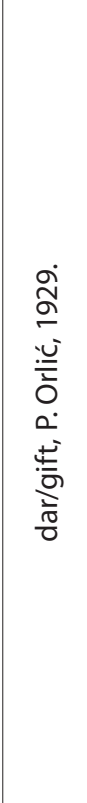 & 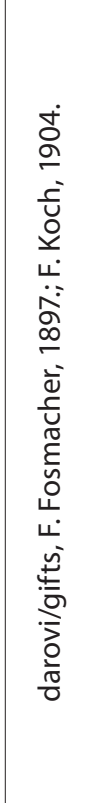 & 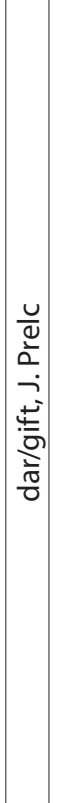 & 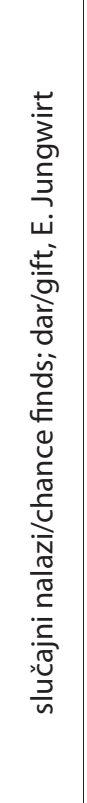 & 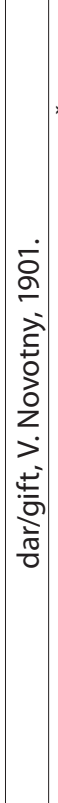 & 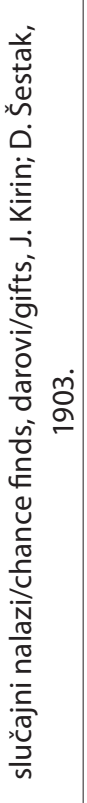 & 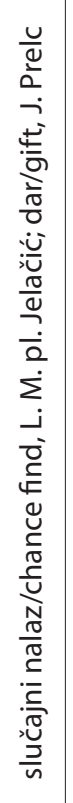 & 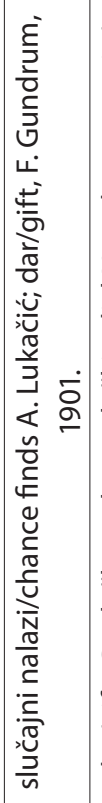 & 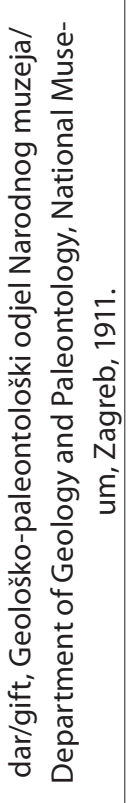 & 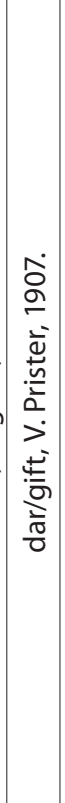 & \\
\hline 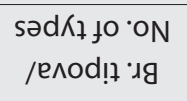 & - & - & - & $\sim$ & - & $\sim$ & - & - & - & - & $\sim$ & $r$ & . & - & $m$ & - & $\sim$ & $\sim$ & $N$ & - & - & \\
\hline $\begin{array}{l}\text { spuy jo on } \\
\text { /ezejeu ' }\end{array}$ & - & 7 & - & $N$ & - & in & -1 & - & - & - & $N$ & in & $N$ & - & $m$ & - & $N$ & $N$ & $\sigma$ & - & - & 7 \\
\hline 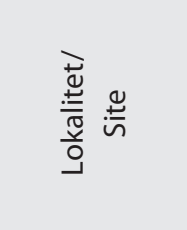 & 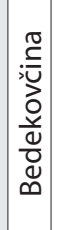 & 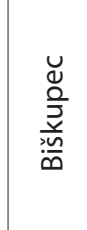 & 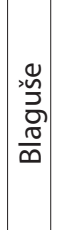 & 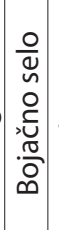 & 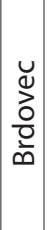 & 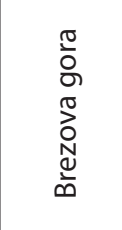 & & 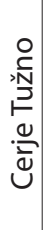 & 号 & $\sum_{\mathscr{U}}^{\mathscr{U}}$ & 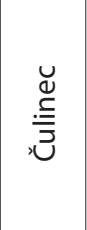 & $\begin{array}{l}\frac{y}{0} \\
0 \\
0 \\
0 \\
0 \\
0 \\
0\end{array}$ & 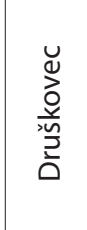 & $\begin{array}{l}0 \\
0 \\
0 \\
0 \\
\frac{0}{3} \\
\\
0\end{array}$ & $\begin{array}{l}\frac{0}{0} \\
\frac{0}{0} \\
\frac{0}{0} \\
0 \\
0\end{array}$ & 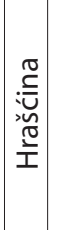 & $\frac{\xi}{3}$ & 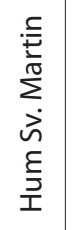 & 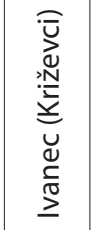 & 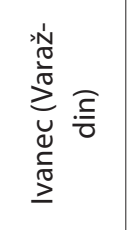 & 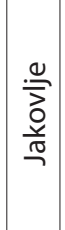 & \\
\hline
\end{tabular}




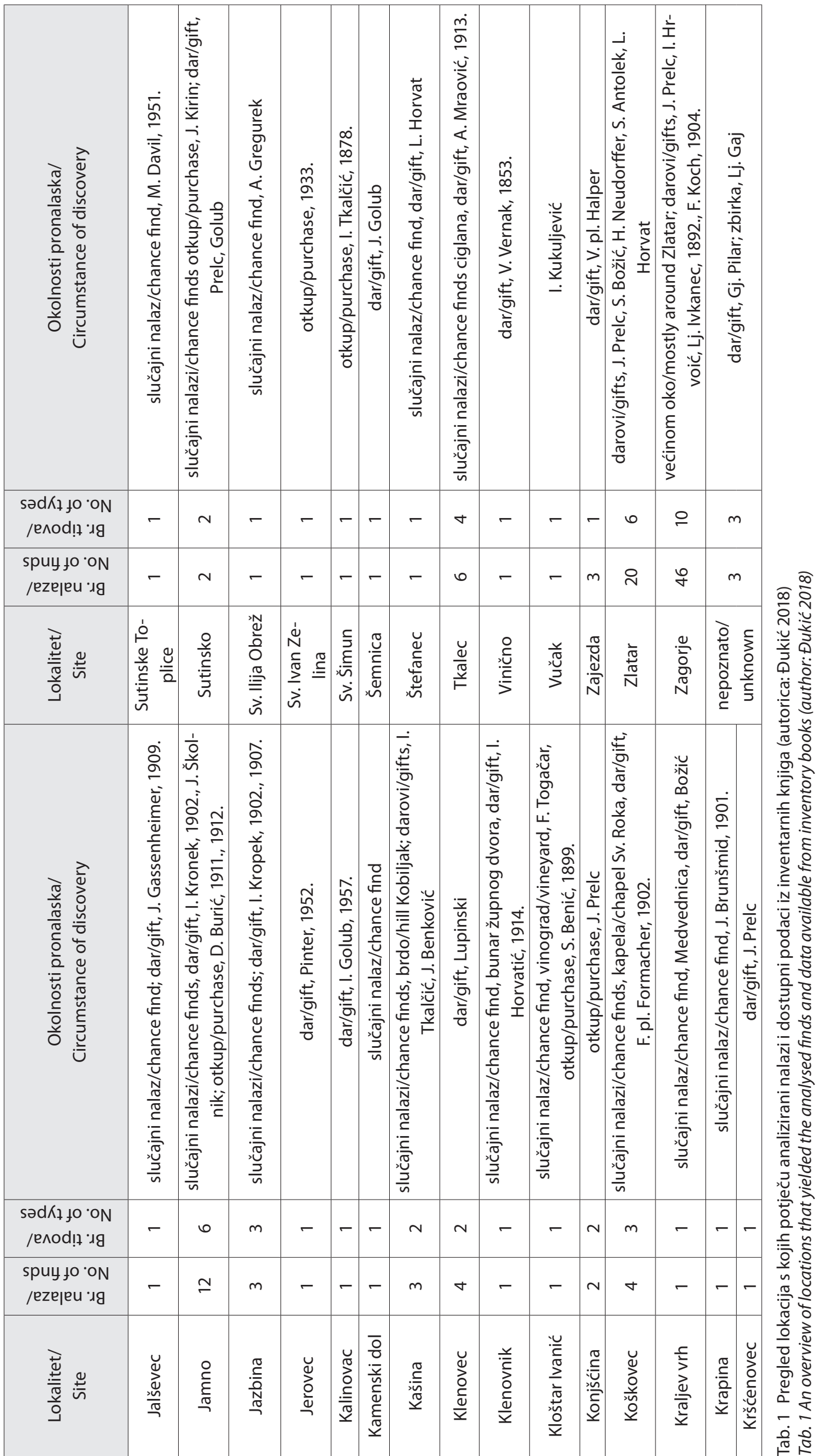


četiri lokacije (tab. 2). ${ }^{12}$ P-21296 iz Drenovog Boka zanimljiv je i zbog toga što je izrađen od rožnjaka trijaske starosti koji bi porijeklom mogao biti s obronaka Papuka. Bradva P-1677 iz Čulinca izrađena je od pješčenjaka kakvih ima na višim dijelovima Medvednice.

\begin{tabular}{|c|c|c|c|c|c|c|}
\hline $\begin{array}{l}\text { Lokalitet/ } \\
\text { Site }\end{array}$ & $\begin{array}{l}\text { Inv. br./ } \\
\text { Inv. no. }\end{array}$ & $\begin{array}{l}\text { Dužina/ } \\
\text { length }(\mathrm{cm})\end{array}$ & $\begin{array}{l}\text { Širina/ } \\
\text { width } \\
(\mathrm{cm})\end{array}$ & $\begin{array}{c}\text { Debljina/ } \\
\text { thickness } \\
(\mathrm{cm})\end{array}$ & $\begin{array}{l}\text { Težina/ } \\
\text { weight }(g)\end{array}$ & $\begin{array}{l}\text { Stanje/ } \\
\text { State }\end{array}$ \\
\hline Čulinec & P-1677 & 11,2 & 4,5 & 2,4 & 167 & veća oštećenja/larger indents \\
\hline \multirow{3}{*}{ Drenov bok } & P-14934 & 8,5 & 4,9 & 2 & 41 & $\begin{array}{c}\text { znatno oštećen/ } \\
\text { significantly damaged (T./PI. 3: 1) }\end{array}$ \\
\hline & P-21296 & 9,8 & 5,9 & 2,5 & 149 & manja oštećenja/smaller indents \\
\hline & P-21299 & 12,9 & 7,3 & 2,6 & 325 & znatno oštećen/significantly damaged (T./PI. 2: 5) \\
\hline Jazbina & P-4224 & 8,8 & 4,8 & 2,8 & 177 & $\begin{array}{c}\text { oštećen stražnji dio/ } \\
\text { back end damaged }\end{array}$ \\
\hline Samobor & P-21318 & 8,7 & 4,7 & 1,6 & 74 & $\begin{array}{c}\text { mala oštećenja/ } \\
\text { small indents (T./Pl. 2:4) }\end{array}$ \\
\hline $\begin{array}{c}\text { Kamenski } \\
\text { dol }\end{array}$ & P-15000 & 27,1 & 4,8 & 3,5 & 655 & $\begin{array}{c}\text { više manjih oštećenja/ } \\
\text { several smaller indents (T./PI. 4: 1) }\end{array}$ \\
\hline \multirow{3}{*}{ Klenovec } & P-18835 & 10,6 & 4,6 & 3,9 & 287 & $\begin{array}{l}\text { niz sitnih oštećenja/ } \\
\text { a line of tiny indents }\end{array}$ \\
\hline & P-18836 & 10,7 & 5,9 & 3 & 324 & sitna oštećenja/tiny indents \\
\hline & $\mathrm{P}-18838$ & 6,4 & 3,9 & 2,8 & 76 & znatno oštećen/significantly damaged (T./PI. 3: 2) \\
\hline $\begin{array}{l}\text { Miholečke } \\
\text { Mokrice }\end{array}$ & P-6753 & 11,1 & 5 & 2,7 & 263 & $\begin{array}{l}\text { sitna oštećenja/tiny indents } \\
\text { (T./PI. 3: 3) }\end{array}$ \\
\hline Poljana & P-4249 & 14,1 & 5,5 & 4 & 489,5 & $\begin{array}{c}\text { mnogo malih oštećenja/ } \\
\text { many small indents }\end{array}$ \\
\hline \multirow{2}{*}{ Tkalec } & P-6653 & 10,7 & 5,1 & 3,9 & 334 & $\begin{array}{l}\text { oštećen prednji dio/ } \\
\text { front end damaged }\end{array}$ \\
\hline & P-6654 & 11,4 & 5,9 & 2,8 & 293 & $\begin{array}{l}\text { mala oštećenja/small indents } \\
\text { (T./PI. 4: 2) }\end{array}$ \\
\hline
\end{tabular}

chisels from Hrvatsko Zagorje have been published (BalenLetunić 1981) together with five finds from Čakovec Museum (Marciuš 2017: 29, kat. br. 28-32).

The analysed material yielded six adzes from four locations (Tab. 2). ${ }^{12}$ Adze P-21296 from Drenov Bok is interesting

Tab. 2 Dimenzije i zatečeno stanje glačanih kamenih dlijeta i bradvi (autorica: Đukić 2017)

Tab. 2 Dimensions and state of polished stone chisels and adzes (author: Đukić 2017)

\section{Trapezaste sjekire}

Ovdje analizirani tip glačanih kamenih sjekira uključuje spljoštene predmete trapezastoga oblika koji se širi prema oštrici, a sužava na stražnjem dijelu, odnosno 22 predmeta s 15 lokaliteta..$^{13}$ Osim ovih nalaza, valja spomenuti dva nalaza iz Sutinskog (Klemenc, Saria 1939: 69), zatim dva iz Kamenog Vrha kod Lepoglave (Šimek 1985: 64) te ulomak trapezaste sjekire iz neolitičkoga lokaliteta Strugača kod Bedekovčine koji je pronađen rekognosciranjem (T. 2: 2; Špoljar 2012: 36-37). Radi se o ulomku oštrice na kojem su vidljiva brojna oštećenja. Predmet je dug $3 \mathrm{~cm}$, širok $3,3 \mathrm{~cm}$, debljine 1,4 cm i težak 21 gram. Objavljeno je dodatnih devet sjekira ovoga tipa (Balen-Letunić 1981; Škiljan 2009b: 5, br. 4, br. 7). Sjekira iz Jamnog (P-4218; T. 2: 1), izrađena je od filita, metamorfne stijene koje ima gotovo na svim planinama, pa treba pretpostaviti da je sirovina donešena s najbližega ležišta. Sjekire iz Marije Bistrice (P-1807; T. 1: 5) i Črneca (P14931) izrađene su od bazalta, sjekira iz Huma (P-1804; T. 1:

12 Najviše njih, tri, potječe s lokacije Drenov Bok.

13 Najviše predmeta ovoga tipa, njih pet, potječe s lokacije Jamno, tri predmeta su iz Brezove gore, a dva iz Druškovca. S preostalih 12 lokacija sačuvana je po jedna sjekira ovoga tipa. because it is made of Triassic chert that might have originated from the slopes of the Papuk Mountain. Adze P-1677 from Člinec is made of sandstone that can be found on the higher parts of the Medvednica Mountain.

\section{Trapezoidal axes}

The type of polished stone axes analysed herein includes flat items of trapezoidal shape that widens towards the blade and narrows towards the back end - a total of 22 finds from 15 locations. ${ }^{13}$ Apart from these, two were found at Sutinsko (Klemenc, Saria 1939: 69), two at Kameni Vrh near Lepoglava (Šimek 1985: 64), and one was found in the field survey of the Neolithic settlement of Strugača near Bedekovčina (PI. 2: 2; Špoljar 2012: 36-37). The latter is a blade fragment with numerous visible indentations. The find is 3 $\mathrm{cm}$ long, $3.3 \mathrm{~cm}$ wide, $1.4 \mathrm{~cm}$ thick and weighs 21 grams. Additional nine axes of this type have been published (Balen-Letunić 1981; Škiljan 2009b: 5, no. 4, no. 7). The axe from Jamno (P-4218; PI. 2: 1) is made of phyllite, a metamorphic rock that is present on almost all mountains, so it can be

12 Most of them, three, were found at Drenov Bok.

13 Most of them, five, were found at Jamno, three were found at Brezova Gora, and two at Druškovec. Each of the remaining 12 locations yielded one axe of this type. 
3) od pješčenjaka, a sjekira iz Ivanca kod Varaždina (P-6367) od gnajsa, metamorfne stijene koje, kao i bazalta i pješčenjaka, ima na Medvednici. Osim ovih, na području općine Radoboj pronađeno je još kamenih sjekira: uz potok Radobojšicu kod župne crkve (Ljubić 1890: 119; Kozina 2007: 45; Špoljar 2015: 96, 101), u vinogradu u Šokotu (Špoljar, Šincek 2013: 31; Špoljar 2014: 28; 2015: 96, 102, sl. 16) te na položaju Horvati - Gradine (Špoljar, Šincek 2013: 29-30; Špoljar 2014: 28; 2015: 96, 101, sl. 15), no radi se isključivo o površinskim slučajnim nalazima. Jedna trapezasta sjekira pronađena je assumed that it came from the nearest available source. The axes from Marija Bistrica (P-1807; PI. 1: 5) and Črnec (P14931) are made of basalt, the axe from Hum (P-1804; PI. 1: 3 ) of sandstone, and the axe from Ivanec near Varaždin ( $P$ 6367) of gneiss, a metamorphic rock that can be found on the Medvednica just like basalt and sandstone. Furthermore, the Radoboj municipality yielded several stone axes: the Radobojšica stream near the parish church (Ljubić 1890: 119; Kozina 2007: 45; Špoljar 2015: 96, 101), the vineyard in Šokot (Špoljar, Šincek 2013: 31; Špoljar 2014: 28; 2015: 96, 102, Fig. 16), and the Horvati - Gradine position (Špoljar, Šincek 2013:

\begin{tabular}{|c|c|c|c|c|c|c|}
\hline $\begin{array}{l}\text { Lokalitet/ } \\
\text { Site }\end{array}$ & $\begin{array}{l}\text { Inv. br./ } \\
\text { Inv. no. }\end{array}$ & $\begin{array}{l}\text { Dužina/ } \\
\text { length }(\mathrm{cm})\end{array}$ & $\begin{array}{c}\text { Širina/ } \\
\text { width }(\mathrm{cm})\end{array}$ & $\begin{array}{c}\text { Debljina/ } \\
\text { thickness } \\
(\mathrm{cm})\end{array}$ & $\begin{array}{l}\text { Težina/ } \\
\text { weight }(g)\end{array}$ & $\begin{array}{l}\text { Stanje/ } \\
\text { State }\end{array}$ \\
\hline \multirow{3}{*}{ Brezova gora } & P-4216 & 5,7 & 4 & 1,6 & 66 & bez oštećenja/no damage \\
\hline & P-6399 & 6,7 & 5,7 & 1,3 & 104 & $\begin{array}{l}\text { oštećen stražnji dio/back end damaged } \\
\text { (T./PI. 2: 1) }\end{array}$ \\
\hline & P-6451 & 5,2 & 4 & 1,6 & 59 & sitna oštećenja/tiny indents \\
\hline Črnec & P-14931 & 6,5 & 3,8 & 1,6 & 64 & $\begin{array}{r}\text { oštećen stražnji dio/ } \\
\text { back end damaged }\end{array}$ \\
\hline \multirow{2}{*}{ Druškovec } & P-14945 & 5 & 3,9 & 1,4 & 32 & $\begin{array}{l}\text { oštećen stražnji dio/back end damaged } \\
\text { (T./PI. 1: 4) }\end{array}$ \\
\hline & P-21295 & 6,7 & 4,9 & 2,1 & 97 & $\begin{array}{l}\text { znatno oštećen/ } \\
\text { highly damaged } \\
\end{array}$ \\
\hline Golubovec & P-1712 & 8,8 & 5,2 & 2,5 & 198,5 & $\begin{array}{l}\text { oštećen stražnji dio/ } \\
\text { back end damaged }\end{array}$ \\
\hline Hum & P-1804 & 5 & 4,7 & 1,6 & 53 & $\begin{array}{l}\text { oštećen stražnji dio/back end damaged } \\
\text { (T./PI. 1: 3) }\end{array}$ \\
\hline $\begin{array}{c}\text { Ivanec } \\
\text { (Križevci) }\end{array}$ & P-4242 & 3 & 5,2 & 1,8 & 45 & $\begin{array}{c}\text { ulomak sječiva/blade fragment, oštećen/ } \\
\text { damaged }\end{array}$ \\
\hline $\begin{array}{c}\text { Ivanec } \\
\text { (Varaždin) }\end{array}$ & P-6367 & 8,1 & 4,4 & 2,6 & 129 & $\begin{array}{l}\text { oštećen stražnji dio/ } \\
\text { back end damaged }\end{array}$ \\
\hline \multirow{5}{*}{ Jamno } & P-4218 & 13 & 6,6 & 1,6 & 213 & $\begin{array}{l}\text { oštećena oko oštrice/damaged around the } \\
\text { blade (T./PI. 1: 1) }\end{array}$ \\
\hline & P-4219 & 7,5 & 4,6 & 2 & 101,5 & $\begin{array}{l}\text { jako oštećen stražnji dio/ } \\
\text { back end highly damaged }\end{array}$ \\
\hline & $\mathrm{P}-4220$ & 10,6 & 7,2 & 3 & 332 & $\begin{array}{l}\text { jako oštećen stražnji dio/ } \\
\text { back end highly damaged }\end{array}$ \\
\hline & $\mathrm{P}-4221$ & 10 & 6,4 & 3,2 & 346 & $\begin{array}{l}\text { oštrica nije očuvana/ } \\
\text { blade not preserved }\end{array}$ \\
\hline & P-6472 & 8,3 & 5,9 & 1,7 & 124 & $\begin{array}{l}\text { oštrica nije očuvana/ } \\
\text { blade not preserved }\end{array}$ \\
\hline Jazbina & P-5777 & 8,9 & 5,5 & 1,6 & 147 & $\begin{array}{c}\text { sitna oštećenja/tiny indents } \\
\text { (T./PI. 1: 2) }\end{array}$ \\
\hline Kuzminec & P-18832 & 5,4 & 5,4 & 1,8 & 98 & $\begin{array}{c}\text { sitna oštećenja/tiny indents } \\
\text { (T./PI. 2: 3) }\end{array}$ \\
\hline Lepoglava & P-1684 & 8,9 & 4,8 & 2 & 117 & sitna oštećenja/tiny indents \\
\hline $\begin{array}{l}\text { Marija } \\
\text { Bistrica }\end{array}$ & P-1807 & 5,3 & 3,5 & 1,2 & 29 & $\begin{array}{l}\text { stražnji dio oštećen/back end damaged } \\
\text { (T./PI. 1:5) }\end{array}$ \\
\hline Oslavec & P-4239 & 7,8 & 5,5 & 2,7 & 187 & bez oštećenja/no damage \\
\hline Pakasin & P-4246 & 4,8 & 4,9 & 1 & 44,5 & $\begin{array}{c}\text { veći dio oštećen/ } \\
\text { larger part damaged }\end{array}$ \\
\hline Tkalec & P-6655 & 5,7 & 3,3 & 1,3 & 44 & mala oštećenja/small indents \\
\hline
\end{tabular}

Tab. 3 Dimenzije i zatečeno stanje glačanih kamenih sjekira trapezastoga oblika (autorica: Đukić 2017)

Tab. 3 Dimensions and state of trapezoidal polished stone axes (author: Đukić 2017) 
i u kontekstu srednjovjekovne utvrde Paka kod Varaždina (Šimek 2010: sl. 3).

\section{Sjekire s rupom za nasad drška}

Među analiziranim nalazima ustanovljena je 21 sjekira s rupom za nasad drška, i to sa 16 lokacija. ${ }^{14}$ Nalaz iz Bede-
29-30; Špoljar 2014: 28; 2015: 96, 101, Fig. 15), but all of these are chance surface finds. One trapezoidal axe was found in the medieval Paka castle near Varaždin (Šimek 2010: Fig. 3).

\section{Axes with holes for hafting}

The analysed material yielded 21 axes with holes for haf-

\begin{tabular}{|c|c|c|c|c|c|c|c|}
\hline $\begin{array}{l}\text { Lokalitet/ } \\
\text { Site }\end{array}$ & $\begin{array}{l}\text { Inv. br./ } \\
\text { Inv. no. }\end{array}$ & $\begin{array}{c}\text { Dužina/ } \\
\text { length }(\mathrm{cm})\end{array}$ & $\begin{array}{l}\text { Širina/ } \\
\text { width } \\
(\mathrm{cm})\end{array}$ & $\begin{array}{c}\text { Debljina/ } \\
\text { thickness } \\
(\mathrm{cm})\end{array}$ & $\begin{array}{c}\text { Rupa/ } \\
\text { hole } \\
\text { (cm) }\end{array}$ & $\begin{array}{c}\text { Težina/ } \\
\text { weight } \\
\text { (g) }\end{array}$ & $\begin{array}{l}\text { Stanje/ } \\
\text { State }\end{array}$ \\
\hline Bedekovčina & P-1714 & 7,3 & 6,2 & 2,4 & $\begin{array}{l}\text { ulomak/ } \\
\text { fragment }\end{array}$ & 184 & oštećena/damaged (T./PI. 8: 4) \\
\hline Bojačno selo & P-11693 & 9 & 3,4 & 2,4 & $\begin{array}{c}\text { nema/ } \\
\text { none }\end{array}$ & 151 & $\begin{array}{l}\text { znatno oštećen/ } \\
\text { highly damaged }\end{array}$ \\
\hline Cerje & P-4226 & 9,3 & 6,1 & 2,7 & $\begin{array}{l}\text { ulomak/ } \\
\text { fragment }\end{array}$ & 241 & $\begin{array}{c}\text { oštećenja/indents } \\
\text { (T./PI. 8: 1) }\end{array}$ \\
\hline Cvetlin & P-14929 & 12,9 & 3,9 & 5,7 & 2,4 & 393 & $\begin{array}{l}\text { znatno oštećen/ } \\
\text { highly damaged }\end{array}$ \\
\hline \multirow{2}{*}{ Drenov bok } & P-21297 & 12,5 & 3,3 & 3,5 & 2,2 & 238 & $\begin{array}{l}\text { sitna oštećenja/ } \\
\text { tiny indents }\end{array}$ \\
\hline & P-21298 & 7 & 2,6 & 4 & 1,6 & 122 & $\begin{array}{l}\text { dobro očuvana/ } \\
\text { well-preserved }\end{array}$ \\
\hline Gotalovec & P-1702 & 6,6 & 4,8 & 2,8 & 2,1 & 136 & $\begin{array}{l}\text { sitna oštećenja/ } \\
\text { tiny indents }\end{array}$ \\
\hline Hum & P-4214 & 5,7 & 5,3 & 5,8 & $\begin{array}{l}\text { ulomak/ } \\
\text { fragment }\end{array}$ & 244 & $\begin{array}{c}\text { sitna oštećenja/ } \\
\text { tiny indents }\end{array}$ \\
\hline Jakovlje & P-5776 & 21,3 & 6,2 & 7,3 & 2,4 & 1714 & očuvana/preserved (T./PI. 8: 3) \\
\hline Jakuševec & P-16075 & 8,1 & 3,6 & 4,7 & 2,1 & 199 & $\begin{array}{c}\text { oštećenje/indent } \\
\text { (T./PI. 8: 5) }\end{array}$ \\
\hline \multirow{2}{*}{ Jamno } & P-4223 & 6,6 & 4,9 & 6,8 & $\begin{array}{l}\text { ulomak/ } \\
\text { fragment }\end{array}$ & 365 & $\begin{array}{l}\text { sitna oštećenja/ } \\
\text { tiny indents }\end{array}$ \\
\hline & P-6473 & 7,5 & 3,2 & 6,6 & $\begin{array}{l}\text { ulomak/ } \\
\text { fragment }\end{array}$ & 228 & $\begin{array}{c}\text { mala oštećenja/ } \\
\text { small indents }\end{array}$ \\
\hline Jazbina & P-4225 & 15,7 & 7,6 & 6,8 & $\begin{array}{c}\text { nema/ } \\
\text { none }\end{array}$ & 1400 & $\begin{array}{l}\text { sitna oštećenja/ } \\
\text { tiny indents }\end{array}$ \\
\hline \multirow{2}{*}{ Kašina } & P-1814 & 15 & 4,9 & 6,2 & 2,6 & 691,5 & $\begin{array}{l}\text { dobro očuvan/ } \\
\text { well-preserved }\end{array}$ \\
\hline & P-1815 & 11,4 & 7,5 & 4,8 & 2,4 & 652 & $\begin{array}{l}\text { znatno oštećen/ } \\
\text { highly damaged }\end{array}$ \\
\hline Lobor & P-21310-1 & 4,8 & 6,3 & 8,4 & $\begin{array}{l}\text { ulomak/ } \\
\text { fragment }\end{array}$ & 294 & $\begin{array}{l}\text { sitna oštećenja/ } \\
\text { tiny indents }\end{array}$ \\
\hline Mače & P-1716 & 11,1 & 7,8 & 5,2 & $\begin{array}{c}\text { nema/ } \\
\text { none }\end{array}$ & 819,5 & $\begin{array}{l}\text { dobro očuvana/ } \\
\text { well-preserved }\end{array}$ \\
\hline Marija Bistrica & P-1810 & 10,8 & 6,7 & 4,9 & $\begin{array}{c}\text { početak ru- } \\
\text { pe/start of } \\
\text { hole }\end{array}$ & 654,5 & $\begin{array}{c}\text { znatno oštećen/ } \\
\text { highly damaged } \\
\text { (T./PI. 8: 2) }\end{array}$ \\
\hline \multirow{3}{*}{ Zlatar } & P-1734 & 7,1 & 3,4 & 4,6 & $\begin{array}{c}\text { ulomak/ } \\
\text { fragment }\end{array}$ & 175 & $\begin{array}{l}\text { dobro očuvana/ } \\
\text { well-preserved }\end{array}$ \\
\hline & P-1737 & 4,8 & 4,1 & 3,9 & $\begin{array}{l}\text { ulomak/ } \\
\text { fragment }\end{array}$ & 111,5 & očuvana/preserved (T./PI. 8: 6) \\
\hline & P-1781 & 6,9 & 3,6 & 4,3 & $\begin{array}{l}\text { ulomak/ } \\
\text { fragment }\end{array}$ & 156 & $\begin{array}{l}\text { oštećenja/indents } \\
\text { (T./PI. 7: 4) }\end{array}$ \\
\hline
\end{tabular}

Tab. 4 Dimenzije i zatečeno stanje glačanih kamenih sjekira s rupom za nasad drška (autorica: Đukić 2017) Tab. 4 Dimensions and state of polished stone axes with holes for hafting (author: Đukić 2017) 
kovčine (P-1714; T. 8: 4) treba posebno izdvojiti jer se radi o predmetu koji je dva puta obrađivan i korišten. Prvotno je bio sjekira s rupom za nasad drška koja je kasnije prepolovljena po dužini i sekundarno korištena kao kalup za lijevanje metalnih šila ili nekih drugih izduženih predmeta. Predmet je izrađen od pješčenjaka kakvoga ima na Medvednici, a koji je bogat organskim tvarima što ga čini tamnijim u presjeku. $\mathrm{U}$ ovoj se skupini ističe nalaz iz Jazbine (P-4225) jer se radi o predmetu koji ima vidljive početke bušenja rupe na dvije nasuprotne strane, odnosno o predmetu koji nikada nije dovršen. U prilog tome govori i činjenica da na njemu nema ni vidljivih tragova korištenja, a koji su prisutni na svim ostalim cjelovito sačuvanim nalazima. P-21298 iz Drenovog Boka na jednoj strani ima početak bušenja druge rupe koja je postavljena bliže stražnjem dijelu predmeta. P-1810 iz Marije Bistrice (T. 8: 2; Škiljan 2009b: 5, br. 10) također je nedovršeni predmet - sjekira kojoj se oba kraja sužavaju u oštrice koje nisu finalno oblikovane. Osim toga, na predmetu nije probušena rupa. Sjekira iz Gotalovca (P-1702) izrađena je od dijabaza, a sjekira iz Zlatara (P-1781; T. 7: 4), od bazalta kakvoga ima na Medvednici; predmet iz Kašine (P-1814) izrađen je od silicificiranoga sedimenta ili efuziva (površinska magmatska stijena) lokalnoga porijekla; predmet iz Drenovog Boka (P21297) od mramoriziranoga vapnenca lokalnoga porijekla, a predmet iz Jamnog (P-6473) od metamorfiziranoga sedimenta (površinske magmatske stijene) lokalnoga porijekla. Možda najzanimljiviji predmet je onaj iz Viničnog (P-1697) koji je izrađen od kamena nelokalnoga porijekla, odnosno od serpentiniziranoga ultrabazita kakvog ima na području granice današnje Slovenije i Austrije te sjevernijim predjelima. Sirovina je na ovaj prostor vjerojatno došla nekom od rijeka u obliku valutice. Navode se i nalazi kamenih sjekira iz Brdovca, Sv. Ivana Zeline, Mihovljana, Biškupca, Jazbine Cvetlinske, Jazbine Višnjičke, Klenovnika, Koškovca, Lepoglave, Ivanca Križevačkog, Kalinovca, Kuzminca i Vojakovca (Šimek 1997: br. 11, br. 91, br. 164, br. 262, br. 317, br. 318, br. 328 , br. 334 , br. 346 , br. 542 , br. 548 , br. 628 , br. 759 ), kao i 27 sjekira koje se čuvaju u Muzeju Međimurja Čakovec (Marciuš 2017: 28, kat. br. 1-27).

\section{Čekići}

U ovoj se kategoriji nalazi 20 predmeta s 13 lokacija koji su podijeljeni u dvije skupine - čekiće bez i čekiće s rupom za nasad drška.

U skupini čekića bez rupe nalazi se pet predmeta. ${ }^{15} \mathrm{U}$ četiri se slučaja radi o ovalnim predmetima koji se šire na jednom kraju tako da dobivaju blago trapezasti oblik. Peti čekić, onaj iz Jamnog (P-4222; T. 4: 4), ovalnoga je oblika, a oba kraja su mu blago zaobljena. Na svim predmetima vidljivi su tragovi upotrebe, i to na oba kraja. Čekić iz Krapine (P4065) izrađen je od pješčenjaka, onaj iz Koškovca (P-4229) od siltita, a čekići iz Jamnog (P-6471, T. 4: 3; P-4222, T. 4: 4) od bioklastičnoga vapnenca kakvog ima na Medvednici. Osim ovih nalaza, valja spomenuti i površinski nalaz čekića iz Vukovoja na Ravnoj Gori koji je otkriven speleološkim rekognosciranjem (Ozimec et al. 2012: 24, sl. 12) te dva nalaza iz Kamenog Vrha kod Lepoglave, od kojih jedan svojim ovalnim oblikom podsjeća na P-4222 iz Jamnog (T. 4: 4; Šimek 1985: 64, T. IV: 5). Osim ovih, objavljena su još dva čekića s

15 Po dva s dvije zastupljene lokacije, Jamno i Koškovec, te jedan iz Krapine. ting from 16 locations. ${ }^{14}$ The find from Bedekovčina (P-1714; PI. 8: 4) should be highlighted because it was processed and used twice. Originally it was an axe with a hole for hafting, and was later split longitudinally and used as a mould for casting metal awls or similar elongated objects. The find is made of sandstone that can be found on the Medvednica and that is rich in organic matter, making it darker in the cross-section. The find from Jazbina (P-4225) also stands out because of the visible beginnings of perforations on opposite sides, meaning that it is an artefact that was never completed. Additionally, the find does not display any traces of use that are present on all other completely preserved finds. P-21298 from Drenov Bok has the beginnings of a second perforation on one side that is placed closer to the end part of the find. P-1810 from Marija Bistrica (PI. 8: 2; Škiljan 2009b: 5, no. 10) is also an unfinished artefact, as both sides of the axe narrow into blades that were never finalized. Apart from that, the find does not have a hole. The axe from Gotalovec (P-1702) is made of diabase, and the axe from Zlatar (P-1781; PI. 7: 4) of basalt that can be found on the Medvednica; the find from Kašina (P-1814) is made of local silicified sediment or extrusive rock (surface magnetic rock), the find from Drenov Bok (P-21297) of local marbled limestone, and the find from Jamno (P-6473) of local metamorphosed sediment (surface magnetic rock). Perhaps the most interesting find comes from Vinično (P-1697). It is made of non-local rock, i.e. of serpentinized ultrabasite that can be found on the current border of Slovenia and Austria and areas north of it. The raw material probably reached this territory by river in the form of a volute. The finds of stone axes from Brdovec, Sveti Ivan Zelina, Mihovljan, Biškupec, Jazbina Cvetlinska, Jazbina Višnjička, Klenovnik, Koškovec, Lepoglava, Ivanec Križevački, Kalinovac, Kuzminec, and Vojakovci (Šimek 1997: no. 11, no. 91, no. 164, no. 262, no. 317, no. 318 , no. 328 , no. 334 , no. 346 , no. 542 , no. 548 , no. 628 , no. 759), are also mentioned, along with the 27 axes that are kept at the Museum of Međimurje in Čakovec (Marciuš 2017: 28 , cat. no. 1-27).

\section{Hammers}

This category includes 20 finds from 13 locations that are divided into two groups - hammers without a hole for hafting and hammers with the hole.

The group of hammers without the hole includes five finds. ${ }^{15}$ In four cases the finds are oval and slightly trapezoidal, widening towards one end. The fifth find, from Jamno (P-4222; PI. 4: 4), is oval with slightly curved ends. All of the finds display traces of use on both ends. The hammer from Krapina (P-4065) is made of sandstone, the one from Koškovec ( $P$-4229) of siltstone, and the hammers from Jamno ( $P$ 6471 , PI. 4: 3; P-4222, PI. 4: 4) of bioclastic limestone that can be found on the Medvednica. Apart from these, a surface find of a hammer was discovered at Vukovoj on the Ravna Gora Mountain during a speleological survey (Ozimec et al. 2012: 24, Fig. 12), two were found at Kameni Vrh near Lepoglava, one of which is oval like P-4222 from Jamno (PI. 4: 4;

14 Most locations yielded one, Drenov Bok, Jamno and Kašina yielded two, and Zlatar yielded three finds.

15 Two each from Jamno and Koškovec, and one from Krapina. 


\begin{tabular}{|c|c|c|c|c|c|c|}
\hline $\begin{array}{c}\text { Lokalitet/ } \\
\text { Site }\end{array}$ & $\begin{array}{c}\text { Inv. br./ } \\
\text { Inv. no. }\end{array}$ & $\begin{array}{c}\text { Dužina/ } \\
\text { length } \\
(\mathrm{cm})\end{array}$ & $\begin{array}{c}\text { Širina/ } \\
\text { width }(\mathrm{cm})\end{array}$ & $\begin{array}{c}\text { Debljina/ } \\
\text { thickness } \\
(\mathrm{cm})\end{array}$ & $\begin{array}{c}\text { Težina/ } \\
\text { weight }(\mathrm{g})\end{array}$ & $\begin{array}{c}\text { Stanje/ } \\
\text { State }\end{array}$ \\
\hline \multirow{2}{*}{ Jamno } & $\mathrm{P}-4222$ & 15,3 & 4,9 & 4,5 & 515 & oštećenja/indents (T./Pl. 4: 4) \\
\cline { 2 - 6 } & $\mathrm{P}-6471$ & 12 & 7 & 4,6 & 615 & oštećenja/indents (T./Pl. 4: 3) \\
\hline \multirow{2}{*}{ Krapina } & $\mathrm{P}-4065$ & 12,8 & 6,4 & 6,5 & 786 & veća oštećenja/larger indents \\
\hline \multirow{2}{*}{ Koškovec } & $\mathrm{P}-4228$ & 10,9 & 4,2 & 4,7 & 417,5 & sitna oštećenja/tiny indents \\
\cline { 2 - 6 } & $\mathrm{P}-4229$ & 12,5 & 5,5 & 4,2 & 432 & znatno oštećen/significantly damaged \\
\hline
\end{tabular}

Tab. 5 Dimenzije i zatečeno stanje glačanih kamenih čekića (autorica: Đukić 2017)

Tab. 5 Dimensions and state of the polished stone hammers (author: Đukić 2017)

područja Zagorja (Balen-Letunić 1981), jedan iz Biškupca (Šimek 1997: br. 261) i tri s prostora Međimurja (Marciuš 2017: 29, kat. br. 41-43).

\begin{tabular}{|c|c|c|c|c|c|c|c|}
\hline $\begin{array}{l}\text { Lokalitet/ } \\
\text { Site }\end{array}$ & $\begin{array}{l}\text { Inv. br./ } \\
\text { Inv. no. }\end{array}$ & $\begin{array}{l}\text { Dužina/ } \\
\text { length } \\
\text { (cm) }\end{array}$ & $\begin{array}{c}\text { Širina/ } \\
\text { width }(\mathrm{cm})\end{array}$ & $\begin{array}{c}\text { Debljina/ } \\
\text { thickness } \\
(\mathrm{cm})\end{array}$ & $\begin{array}{c}\text { Težina/ } \\
\text { weight (g) }\end{array}$ & $\begin{array}{c}\text { Rupa/ } \\
\text { hole } \\
\text { (cm) }\end{array}$ & $\begin{array}{l}\text { Stanje/ } \\
\text { State }\end{array}$ \\
\hline Cerje Tužno & P-8367 & 10,2 & 7,4 & 4,7 & 564 & 2,7 & $\begin{array}{c}\text { mala oštećenja/ } \\
\text { small indents }\end{array}$ \\
\hline Jamno & P-6404 & 11,2 & 6 & 8,9 & 929 & 2,5 & $\begin{array}{l}\text { mala oštećenja/ } \\
\text { small indents }\end{array}$ \\
\hline Jerovec & P-8369 & 9,5 & 5,3 & 4,2 & 302 & 2,1 & $\begin{array}{c}\text { oštećenja/indents } \\
\text { (T./PI. 5: 3) }\end{array}$ \\
\hline Klenovnik & P-6724 & 10,4 & 3,5 & 4,5 & 220 & $\begin{array}{l}\text { ulomak/ } \\
\text { fragment }\end{array}$ & $\begin{array}{c}\text { oštećenja/indents } \\
\text { (T./PI. 5: 1) }\end{array}$ \\
\hline $\begin{array}{l}\text { Kloštar Iva- } \\
\text { nić }\end{array}$ & P-1674 & 10,9 & 5,7 & 6,8 & 683 & 2,8 & $\begin{array}{c}\text { oštećenja/indents } \\
\text { (T./PI. 5: 2) }\end{array}$ \\
\hline \multirow{3}{*}{ Mače } & P-1717 & 8,1 & 6,3 & 3 & 201,5 & $\begin{array}{l}\text { ulomak/ } \\
\text { fragment }\end{array}$ & $\begin{array}{c}\text { sitna oštećenja/ } \\
\text { tiny damage }\end{array}$ \\
\hline & P-1718 & 5,3 & 5,7 & 3,2 & 142 & $\begin{array}{l}\text { ulomak/ } \\
\text { fragment }\end{array}$ & $\begin{array}{l}\text { mala oštećenja } \\
\text { /small indents }\end{array}$ \\
\hline & P-1719 & 3,3 & 6,3 & 8 & 265 & $\begin{array}{l}\text { ulomak/ } \\
\text { fragment }\end{array}$ & $\begin{array}{c}\text { sitna oštećenja/ } \\
\text { tiny indents }\end{array}$ \\
\hline Mihovljan & P-1723 & 6,2 & 5,1 & 4,4 & 145 & $\begin{array}{l}\text { ulomak/ } \\
\text { fragment }\end{array}$ & $\begin{array}{c}\text { sitna oštećenja/ } \\
\text { tiny indents }\end{array}$ \\
\hline Podsused & P-5185 & 10,7 & 6,2 & 6,4 & 635 & 2,3 & $\begin{array}{l}\text { mala oštećenja } \\
\text { /small indents }\end{array}$ \\
\hline \multirow{2}{*}{ Poljanica } & P-1803 & 8,6 & 5 & 4,1 & 259,5 & $\begin{array}{l}\text { ulomak/ } \\
\text { fragment }\end{array}$ & $\begin{array}{c}\text { mala oštećenja/ } \\
\text { small indents }\end{array}$ \\
\hline & P-21316 & 5,7 & 5,2 & 2,5 & 131,5 & $\begin{array}{l}\text { ulomak/ } \\
\text { fragment }\end{array}$ & $\begin{array}{c}\text { manja oštećenja/ } \\
\text { smaller indents }\end{array}$ \\
\hline Sv. Šimun & P-1801 & 8,1 & 3,2 & 5,5 & 147 & 2,8 & $\begin{array}{c}\text { sitna oštećenja/ } \\
\text { tiny indents }\end{array}$ \\
\hline \multirow{3}{*}{ Zlatar } & P-1732 & 7,2 & 4,8 & 5,2 & 226,5 & 2,4 & $\begin{array}{l}\text { sitna oštećenja/ } \\
\text { tiny indents }\end{array}$ \\
\hline & P-1736 & 8,9 & 5 & 6 & 411,5 & 2,4 & $\begin{array}{c}\text { manja oštećenja/ } \\
\text { smaller indents }\end{array}$ \\
\hline & P-1779 & 8,2 & 4 & 2,6 & 138 & $\begin{array}{l}\text { ulomak/ } \\
\text { fragment }\end{array}$ & $\begin{array}{l}\text { mala oštećenja/ } \\
\text { small indents }\end{array}$ \\
\hline
\end{tabular}

Tab. 6 Dimenzije i zatečeno stanje glačanih kamenih čekića s rupom za nasad drška (autorica: Đukić 2017) Tab. 6 Dimensions and state of polished stone hammers with holes for hafting (author: Đukić 2017)

U skupini čekića s rupom za nasad drška nalazi se 14 predmeta s devet lokacija. ${ }^{16}$ Svi primjerci čekića imaju razli-

$16 \mathrm{~S}$ većine lokacija potječe po jedan predmet, s lokacije Poljanica dva, a s lokacija Mače i Zlatar po tri predmeta.
Šimek 1985: 64, PI. IV: 5). Two additional hammers from the territory of Zagorje (Balen-Letunić 1981), one from Biškupec (Šimek 1997: no. 261) and three from Međimurje (Marciuš Š 
čit oblik, ali zaobljene krajeve na kojima su vidljivi tragovi korištenja (izuzev P-1718, Mače, kojem krajevi nisu očuvani). Na primjerku iz Klenovnika (P-6724; T. 5: 1) rupa nije do kraja probušena, a predmet nije do kraja oblikovan. Izrađen je od vapnenca. U ovoj kategoriji valja izdvojiti i P-1723 iz Mihovljana jer se radi o ulomku čekića koji je pukao i bio naknadno korišten na neodredivi način. Osim ovih, objavljen je i nalaz iz Brlekovog Sela, P-11671 (Pavišić 1990: 7, br. 7; T. III: 2) te četiri predmeta s područja Hrvatskoga zagorja koji su definirani kao motike s rupom (Balen-Letunić 1981), a koji se oblikom, ako ne i namjenom, uklapaju u ovdje analiziranu kategoriju čekića s rupom za nasad drška. Čekić iz Kloštar Ivanića (P-1674; T. 5: 2) izrađen je od bazaltne stijene kakve ima na Medvednici, Moslavačkoj Gori i Papuku. Predmet iz Mihovljana (P-1723) izrađen je od gabroidne stijene kakve ima na Medvednici.

\section{Sjekire-čekići s rupom za nasad drška}

U ovoj kategoriji nalazi se 26 predmeta s 22 lokacije $^{17}$ koji su, prema zajedničkim karakteristikama, podijeljeni u četiri podskupine.

U prvoj podskupini je 18 potpuno očuvanih predmeta, a radi se o tipu sjekire-čekića s rupom za nasad drška kojoj je stražnji kraj blago zaobljen, a tijelo gotovo ravno sve do prednjega kraja gdje se naglo sužava u oštricu. Treba istaknuti P-1698 iz Biškupca jer se radi o predmetu na kojemu rupa za nasad drška nije do kraja probušena. P-1695 iz Huma Svetog Martina je objavljen kao sjekira (T. 6: 2; Škiljan 2009b: 5, br. 3), ali oštećenja na stražnjem dijelu sugeriraju da je bio korišten i kao sjekira i kao udarač. Sjekira-čekić iz Zlatara, P-1780 (T. 6: 3) izrađena je od tamnijeg bazalta kakvog ima na Medvednici.

Druga podskupina sadrži pet potpuno očuvanih predmeta, a radi se o sjekirama-čekićima kojima je stražnji dio djelomično ili u potpunosti zaravnjen, a tijelo znatno šire oko rupe odakle se oštro sužava prema prednjem kraju, odnosno oštrici. U ovoj grupi predmeta valja izdvojiti sjekiru-čekić iz Novaka, P-1802, jer je znatno veća od ostalih, a i stražnji kraj joj je zaobljeniji nego ostalim predmetima. Izrađena je od gabroidne stijene kakve ima na Medvednici, kao i P-21323 iz Sv. Ivana Zeline. Objavljen je još jedan nalaz ovoga tipa iz Stubice, P-1811 (Pavišić 1990: 7, br. 6; T. III: 1; Škiljan 2009b: 5, br. 11).

U trećoj podskupini samo je jedan predmet, P-1700, sjekira-čekić iz Sv. Ilije Obreža. Ovaj predmet izdvojen je od ostalih jer mu je sječivo postavljeno okomito na rupu, što je slučaj na još samo jednome predmetu s područja Zagorja koji je predstavljen niže u tekstu. Osim toga, ovaj predmet oblikom podsjeća i na gore prikazane sjekire trapezastoga oblika koje se, kao i kalupasti klinovi, ponekad pojavljuju u inačici s rupom bušenom poprijeko na oštricu (Težak-Gregl 1991: 19).

Četvrtu podskupinu čine dva predmeta s dva lokaliteta, ${ }^{18}$ a izdvojeni su jer se radi o većim primjercima kojima je stražnji dio blago zaobljen, tijelo znatno izduženo i sužava se

$17 \mathrm{~S}$ većine lokacija potječe po jedan, dok iz Zajezde i Zlatara potječu po tri predmeta.

18 Sutinsko i Zajezda. shape, but have curved edges with visible traces of use (apart from P-1718, Mače, that has no preserved ends). The find from Klenovnik (P-6724; PI. 5: 1) does not have a completely perforated hole, is not fully shaped and is made of limestone. P-1723 from Mihovljan should also be pointed out because it is a hammer fragment that broke and was subsequently used in an indeterminable manner. Apart from these, a find from Brlekovo Selo, P-11671 (Pavišić 1990: 7, no. 7; T. III: 2),, and four finds from the Hrvatsko Zagorje region were published. The latter were defined as hoes with holes for hafting (Balen-Letunić 1981), but their shape, if not their purpose, places them into the analysed group of hammers with holes for hafting. The hammer from Kloštar Ivanić ( $P$ $1674 ; \mathrm{PI} .5: 2$ ) is made of basalt rock that can be found on the Medvednica, Moslavačka Gora and Papuk Mountains. The find from Mihovljan (P-1723) is made of gabbroid rock that can be found on the Medvednica.

\section{Axe-hammers with holes for hafting}

This category includes 26 finds from 22 locations $^{17}$ that were divided into four sub-groups based on common characteristics.

The first subgroup contains 18 fully-preserved finds, the type of axes-hammers with a hole for hafting with a slightly curved back end as well as an almost straight body that abruptly narrows into a blade. P-1698 from Biškupec should be highlighted because it does not have a fully perforated hole. P-1695 from Hum Sveti Martin was published as an axe (PI. 6: 2; Škiljan 2009b: 5, no. 3), but the indentations on the back end suggest that the find was used as both an axe and a hammer. The axe-hammer from Zlatar, P-1780 (PI. 6: 3), is made of darker basalt that can be found on the Medvednica.

The second sub-group contains five fully-preserved finds, axe-hammers that have a slightly or completely straightened back end; a body that is significantly wider than the hole and that abruptly narrows towards the front, i.e. the blade. The axe-hammer from Novaki, P-1802, stands out because it is significantly larger and has a more curved back end than the other finds. It is made of gabbroid rock that can be found on the Medvednica, as is P-21323 from Sveti Ivan Zelina. Another find of this type from Stubica, P-1811, has been published (Pavišić 1990: 7, no. 6; PI. III: 1; Škiljan 2009b: 5, no. 11).

The third sub-group includes only one find, P-1700, an axe-hammer from Sveti Ilija Obrež. This find was so defined because its blade is perpendicular to the hole, a case that was only recorded in one other find from Zagorje that is described below. Additionally, the shape of this find is reminiscent of the aforementioned trapezoidal axes that, just like mould-shaped wedges, sometimes have a perforation perpendicular to the blade (Težak-Gregl 1991: 19).

The fourth sub-group includes two finds, one from each of the locations, ${ }^{18}$ which were grouped together due to their size, a slightly curved back end, and a highly elongated

yielded three finds each.

17 Most locations yielded one, while Zajezda and Zlatar yielded three finds each.

18 Sutinsko and Zajezda. 
tek blizu oštrice. Za razliku od ostalih predmeta u ovoj kategoriji, rupa je postavljena bliže stražnjem dijelu. Rupa na P-1711 iz Zajezde nije do kraja probušena.

Uz navedene primjerke, objavljena je jedna sjekira-čekić iz Klanjca (P-1687), zatim jedna iz Krapinske Podgore (P6750; Pavišić 1990: 6, br. 1; T. II: 1), te jedna iz potoka Reke kod Donje Stubice (Škiljan 2009a: 29, 31), kao i dodatnih 26 predmeta ovoga tipa (Balen-Letunić 1981) te P-1690 iz Mirkovca (Pavišić 1990: 6, br. 2; T. II: 2). ${ }^{19}$ body that narrows near the blade. Unlike the other finds in this category, the hole on these finds is closer to the back end. P-1711 from Zajezda does not have a fully perforated hole. Along with the listed finds, one axe-hammer from Klanjec (P-1687), one from Krapinska Podgora (P-6750; Pavišić 1990: 6, no. 1; PI. II: 1), and one from the Reka stream near Donja Stubica (Škiljan 2009a: 29, 31), have been published, as well as 26 other finds (Balen-Letunić 1981), and P-1690 from Mirkovec (Pavišić 1990: 6, no. 2; PI. Il: 2). ${ }^{19}$

\begin{tabular}{|c|c|c|c|c|c|c|c|}
\hline $\begin{array}{l}\text { Lokalitet/ } \\
\text { Site }\end{array}$ & $\begin{array}{l}\text { Inv. br./ } \\
\text { Inv. no. }\end{array}$ & $\begin{array}{c}\text { Dužina/ } \\
\text { length }(\mathrm{cm})\end{array}$ & $\begin{array}{l}\text { Širina/ } \\
\text { width } \\
(\mathrm{cm})\end{array}$ & $\begin{array}{c}\text { Debljina/ } \\
\text { thickness } \\
(\mathrm{cm})\end{array}$ & $\begin{array}{l}\text { Rupa/ } \\
\text { hole } \\
\text { (cm) }\end{array}$ & $\begin{array}{c}\text { Težina/ } \\
\text { weight } \\
\text { (g) }\end{array}$ & $\begin{array}{l}\text { Stanje/ } \\
\text { State }\end{array}$ \\
\hline Biškupec & P-1698 & 11,6 & 4,8 & 3,7 & 1,8 & 349 & oštećena/damaged \\
\hline Blaguše & P-14910 & 9,5 & 5,4 & 3,3 & 1,5 & 257 & oštećena/damaged \\
\hline Brdovec & P-11704 & 10,8 & 4,4 & 4,8 & 2,1 & 395 & oštećena/damaged \\
\hline Hum Sv. Martin & P-1695 & 12,1 & 4,2 & 4,8 & 2,1 & 402 & $\begin{array}{c}\text { oštećena/damaged } \\
\text { (T./PI. 6: 2; Škiljan 2009b: 5, br. 3) }\end{array}$ \\
\hline Jalševec & P-6187 & 8,9 & 4,4 & 4,9 & 2,1 & 310 & oštećenja/indents \\
\hline Jamno & P-6406 & 12,5 & 5,9 & 5,8 & 2,3 & 622 & oštećena/damaged \\
\hline Konjšćina & P-1708 & 9,8 & 5,8 & 4,4 & 1,8 & 373 & oštećena/damaged \\
\hline Kršćenovec & P-1707 & 7,2 & 4,2 & 3,5 & 1,3 & 148 & oštećena/damaged \\
\hline Oštri vrh & P-4212 & 11,4 & 4,8 & 4 & 1,9 & 346 & oštećena/damaged \\
\hline Radoboj & P-1689 & 14 & 5,8 & 6,2 & 2,4 & 779 & $\begin{array}{l}\text { oštećena/damaged } \\
\text { (T./PI. 6: 1) }\end{array}$ \\
\hline Ratkovec & P-1729 & 10,8 & 5,8 & 4,3 & $\begin{array}{l}\text { ulomak/ } \\
\text { fragment }\end{array}$ & 420 & oštećena/damaged \\
\hline Šemnica & P-1726 & 8 & 4,5 & 3,4 & 1,5 & 189 & $\begin{array}{l}\text { oštećena/damaged } \\
\text { (T./PI. 6: 4) }\end{array}$ \\
\hline Štefanec & P-1701 & 10,4 & 2,6 & 4,4 & 2 & 211 & oštećena/damaged \\
\hline \multirow{2}{*}{ Zajezda } & P-1709 & 9,1 & 4,9 & 3,8 & 1,4 & 255 & oštećena/damaged \\
\hline & P-1710 & 12,8 & 4,8 & 6,2 & 2,1 & 599 & oštećena/damaged \\
\hline \multirow{3}{*}{ Zlatar } & P-1733 & 9,8 & 5 & 5,6 & 1,9 & 411 & oštećena/damaged \\
\hline & P-1780 & 10,7 & 5,4 & 5,9 & 2,2 & 580 & $\begin{array}{c}\text { oštećena/damaged } \\
\text { (T./PI. 6: 3) }\end{array}$ \\
\hline & $\mathrm{P}-1782$ & 11,8 & 4,4 & 5,4 & 2,1 & 461 & oštećena/damaged \\
\hline Hrašćina & P-4231 & 10,8 & 5,7 & 7,2 & 2,5 & 777,5 & $\begin{array}{l}\text { oštećena/damaged } \\
\text { (T./PI. 7: 1) }\end{array}$ \\
\hline Novaki & P-1802 & 15,7 & 6,9 & 7,4 & 2,7 & 1425 & oštećena/damaged \\
\hline $\begin{array}{l}\text { Sutinske } \\
\text { Toplice }\end{array}$ & P-8368 & 10,2 & 5,6 & 7,4 & $\begin{array}{l}\text { ulomak/ } \\
\text { fragment }\end{array}$ & 424 & $\begin{array}{l}\text { znatno oštećen/ } \\
\text { highly damaged }\end{array}$ \\
\hline Sv. Ivan Zelina & P-21323 & 12,1 & 5,7 & 6,9 & 2,3 & 751 & $\begin{array}{l}\text { sitna oštećenja/ } \\
\text { tiny indents }\end{array}$ \\
\hline Vinično & P-1697 & 9,7 & 3,8 & 6,7 & 2,3 & 349,5 & oštećena/damaged \\
\hline Sv. Ilija Obrež & P-1700 & 9 & 6,3 & 2,9 & 1,9 & 224 & $\begin{array}{c}\text { oštećena/damaged } \\
\text { (T./PI. 7: 2) }\end{array}$ \\
\hline Sutinsko & P-1720 & 19,3 & 5,8 & 4,4 & 2,1 & 895 & očuvana/preserved (T./PI. 7: 3) \\
\hline Zajezda & P-1711 & 14,8 & 5,7 & 4,8 & $\begin{array}{c}\text { nema/ } \\
\text { none }\end{array}$ & 699 & nedovršena/unfinished \\
\hline
\end{tabular}

Tab. 7 Dimenzije i zatečeno stanje glačanih kamenih sjekira-čekića s rupom za nasad drška (autorica: Đukić 2017)

Tab. 7 Dimensions and state of polished stone axe-hammers with holes for hafting (author: Đukić 2017)

19U Pavišić 1990 došlo je do pogreške. Table I i II su zamijenjene i pogrešno popisane, tako da Tabla I zapravo sadrži predmete iz Klanjca (popisan kao T. II: 1), Topličice (popisan kao T. II: 2) i Kraljevog vrha (popisan kao T. II: 3), a Tabla 2 predmete iz Krapinske Podgore (popisan kao T. I: 1) i Mirkovca (popisan kao T. I: 2).
19 There is a mistake in Pavišić 1990. Plates I and II are interchanged and incorrectly listed, so that Plate I displays finds from Klanjec (listed as Pl. II: 1), Topličica (listed as Pl. II: 2) and Kraljev vrh (listed as Pl. II: 3), and Plate II finds from Krapinska Podgora (listed as Pl. I: 1) and Mirkovec (listed as P1. I: 2). 


\section{Neodredivi tipovi oruđa (čekić ili sjekira)}

U kategoriji neodredivih tipova oruđa nalazi se 21 predmet sa 16 lokacija. ${ }^{20}$ Predmeti su podijeljeni u dvije podskupine. Prva uključuje predmete koji su sličniji čekićima, a druga one koji više nalikuju sjekirama. Predmet iz Marije Bistrice, P-1808, opisan je kao ulomak sjekire s rupom za nasad (Škiljan 2009b: 5, br. 8), a ovdje je uvršten u kategoriju neodredivog oruđa jer oblik sačuvanog ulomka sugerira da se moglo raditi o oruđu dvostruke namjene. Predmetima koji nalikuju čekićima sačuvani su stražnji ulomci na kojima su vidljivi tragovi upotrebe (izuzev P-1812, Vučak, gdje su oštećenja prevelika da bi se takvi tragovi mogli ustanoviti).

Predmetima koji su sličniji sjekirama sačuvani su prednji ulomci (osim u slučaju P-6400 iz Brezove gore gdje se radi o polovici, P-18834 iz Kuzminca gdje se radi o većem dijelu i P-18837 iz Klenovca, gdje se radi o središnjem ulomku predmeta). Predmet iz Lobora izrađen je od pješčenjaka, predmet iz Koškovca od vapnenca, predmet iz Brezove gore od kvarcnoga pješčenjaka, a predmet iz Ivanca kod Križevaca od krednoga pješčenjaka kakvog ima na Medvednici, ali i drugim višim lancima.

\begin{tabular}{|c|c|c|c|c|c|c|}
\hline $\begin{array}{l}\text { Lokalitet/ } \\
\text { Site }\end{array}$ & $\begin{array}{l}\text { Inv. br./ } \\
\text { Inv. no. }\end{array}$ & $\begin{array}{l}\text { Dužina/ } \\
\text { length } \\
\text { (cm) }\end{array}$ & $\begin{array}{c}\text { Širina/ } \\
\text { width } \\
(\mathrm{cm})\end{array}$ & $\begin{array}{c}\text { Debljina/ } \\
\text { thickness } \\
(\mathrm{cm})\end{array}$ & $\begin{array}{c}\text { Težina/ } \\
\text { weight } \\
\text { (g) }\end{array}$ & $\begin{array}{l}\text { Stanje/ } \\
\text { State }\end{array}$ \\
\hline Marija Bistrica & P-1808 & 3,6 & 8 & 3,7 & 192 & $\begin{array}{c}\text { sitna oštećenja/tiny indents } \\
\text { (Škiljan 2009b: 5, br. 8) }\end{array}$ \\
\hline \multirow{2}{*}{ Mihovljan } & P-1722 & 6,4 & 6,1 & 5,4 & 297 & veća oštećenja/larger indents \\
\hline & $\mathrm{P}-1724$ & 6,1 & 6,6 & 4,8 & 220 & veća oštećenja/larger indents \\
\hline Peršaves & P-1715 & 5,9 & 6 & 7,5 & 372 & sitna oštećenja/tiny indents \\
\hline Tkalec & P-6656 & 8,5 & 4,8 & 5,2 & 333 & mala oštećenja/small indents \\
\hline Vučak & P-1812 & 5,3 & 3 & 4,3 & 108 & znatno oštećen/significantly damaged \\
\hline Zlatar & P-1735 & 4,3 & 6,9 & 3,5 & 153 & sitna oštećenja/tiny indents \\
\hline Brezova gora & P-6400 & 7,6 & 3,2 & 3,9 & 183 & sitna oštećenja/tiny indents \\
\hline Brezova gora & P-6401 & 5,1 & 3,9 & 3,5 & 97 & mala oštećenja/small indents \\
\hline \multirow{3}{*}{ Ivanec (Križevci) } & P-4243 & 5,7 & 4 & 3,2 & 99 & mala oštećenja/small indents \\
\hline & P-4244 & 4 & 3,9 & 2,8 & 60 & mala oštećenja/small indents \\
\hline & P-4245 & 9 & 3,2 & 5 & 140 & znatno oštećen/highly damaged \\
\hline Jamno & P-6405 & 8,5 & 4,3 & 3,5 & 205 & sitna oštećenja/tiny indents \\
\hline Klenovec & P-18837 & 10,3 & 5,6 & 4 & 239,5 & znatno oštećen/highly damaged \\
\hline Koškovec & P-4227 & 6,1 & 6 & 4,2 & 199 & sitna oštećenja/tiny indents \\
\hline Kuzminec & P-18834 & 8,3 & 3,9 & 2,3 & 121 & sitna oštećenja/tiny indents \\
\hline Lipovac & P-6609 & 6,5 & 3,9 & 3,9 & 172 & sitna oštećenja/tiny indents \\
\hline Lobor & P-21310-2 & 10,5 & 4,4 & 4,2 & 324 & $\begin{array}{c}\text { mala oštećenja/ } \\
\text { small indents }\end{array}$ \\
\hline Marija Bistrica & P-1809 & 2,9 & 4,8 & 4,7 & 128 & $\begin{array}{c}\text { mala oštećenja/small indents } \\
\text { (Škiljan 2009b: 5, br. 9) }\end{array}$ \\
\hline Marija Gorica & P-21313 & 9,3 & 5,1 & 4,7 & 360 & sitna oštećenja/tiny indents \\
\hline Sutinsko & P-1721 & 6,4 & 5,7 & 4,1 & 204 & dobro očuvana/well-preserved \\
\hline
\end{tabular}

Tab. 8 Dimenzije i zatečeno stanje neodredivih tipova oruđa (autorica: Đukić 2017)

Tab. 8 Dimensions and state of indeterminable tool types (author: Đukić 2017)

\section{Indeterminable tool types (hammer or axe)}

The category of indeterminable tool types includes 21 finds from 16 locations. ${ }^{20}$ These finds were placed in two sub-groups, the first with finds that resemble hammers, and the second with finds that resemble axes. P-1808 from Marija Bistrica was described as a fragment of an axe with a hole for hafting (Škiljan 2009b: 5, no. 8), and was placed into the indeterminable category because the shape of the preserved fragment suggests that it could have been part of a tool that was used for two different purposes. The back parts of the finds that resemble hammers were preserved. They display traces of use (except P-1812 from Vučak that is too severely damaged to allow for such determinations).

The front parts of the finds that resemble axes were preserved (except P-6400 from Brezova Gora that is half preserved, P-18834 from Kuzminec that is largely preserved, and $\mathrm{P}-18837$ from Klenovec that is only preserved in the central part). The find from Lobor is made of sandstone, the find from Koškovec of limestone, the find from Brezova Gora of 
Pršljenovi su podijeljeni u tri skupine (tab. 9): prva uključuje primjerke iz Kraljevog Vrha, P-1813 (Pavišić 1990: 6, br. 5; T. I: neoznačeno, dolje desno) ${ }^{21}$ i Miljane, P-21311 (T. 9: 1), druga uključuje dva nalaza iz Zlatara koji su okrugloga oblika s rupom u sredini, a treća predmete iz Martinaca i Pakasina. Pršljen iz Pakasina je gotovo pravokutnoga oblika s rupom u sredini, a napravljen je od oblutka. Nalaz iz Martinaca znatno je oštećen, pa mu nije bilo moguće odrediti izvorni oblik.

Oba definirana brusa (tab. 9) duguljastoga su pravokutnog oblika s rupom za ovjes na gornjem dijelu. Pripadaju istom tipu kao i četiri brusa s područja Hrvatskoga zagorja koji će biti prikazani niže u tekstu. Brus iz Čulinca izrađen je od kvarcita kakvih ima na Medvednici. Brus iz Kašine izrađen je od rožnjaka.

U motike su uvrštena dva predmeta (tab. 9): P-1676 iz Čulinca (T. 5: 4) i P-4248 iz Poljane. Radi se o spljoštenim predmetima većih dimenzija pravokutnoga, odnosno blago

\section{Other}

The category of other finds includes six whorls, two whetstones, two hoes, 21 stone spheres, a figurine, a handstone, a bead, a weight, a tile, a pyramidal and a rhomboidal artifact (Tab. 9).

Whorls were divided into three groups (Tab. 9): the first includes finds from Kraljev Vrh, P-1813 (Pavišić 1990: 6, no. 5; PI. I: unmarked, bottom right), ${ }^{21}$ and Miljana, P-21311 (PI. 9: 1), the second includes two round finds from Zlatar that have a perforation in the middle, and the third includes finds from Martinci and Pakasin. The whorl from Pakasin is of almost rectangular shape with a hole in the middle, and was made out of a pebble. The find from Martinci is significantly damaged so its original shape could not be defined.

Both defined whetstones (Tab. 9) are of elongated rectangular shape with a hole for hanging on the upper part. They can be ascribed to the same type as the four whetstones from the territory of Hrvatsko Zagorje that is described below. The whetstone from Čulinec is made of

\begin{tabular}{|c|c|c|c|c|c|c|c|c|}
\hline \multicolumn{9}{|c|}{ PRŠLJENI/WHORLS } \\
\hline $\begin{array}{l}\text { Lokalitet/ } \\
\text { Site }\end{array}$ & $\begin{array}{l}\text { Inv. br./ } \\
\text { Inv. no. }\end{array}$ & $\begin{array}{c}\text { Promjer 1/ } \\
\text { diameter } 1 \\
(\mathrm{~cm})\end{array}$ & \multicolumn{2}{|c|}{$\begin{array}{c}\text { Promjer 2/ } \\
\text { diameter } 2 \\
(\mathrm{~cm})\end{array}$} & \multicolumn{2}{|c|}{$\begin{array}{c}\text { Debljina/ } \\
\text { thickness } \\
(\mathrm{cm})\end{array}$} & $\begin{array}{l}\text { Težina/ } \\
\text { weight } \\
\text { (g) }\end{array}$ & $\begin{array}{l}\text { Stanje/ } \\
\text { State }\end{array}$ \\
\hline Kraljev vrh & P-1813 & 7,7 & \multicolumn{2}{|c|}{1,5} & \multicolumn{2}{|c|}{1,7} & 115 & $\begin{array}{c}\text { oštećen/damaged (Pavišić 1990: 6, br./no. } \\
\text { 5; T./PI. I: dolje desno/bottom right) }\end{array}$ \\
\hline Miljana & P-21311 & 5,3 & \multicolumn{2}{|c|}{1,2} & \multicolumn{2}{|c|}{1,9} & 56 & oštećenja (T./PI. 9: 1) \\
\hline \multirow{2}{*}{ Zlatar } & P-1738 & 4,7 & \multicolumn{2}{|c|}{1,3} & \multicolumn{2}{|c|}{1,3} & 31 & $\begin{array}{c}\text { manja oštećenja/ } \\
\text { smaller indents }\end{array}$ \\
\hline & P-1739 & 5,2 & \multicolumn{2}{|c|}{1,5} & \multicolumn{2}{|c|}{2,7} & 86 & $\begin{array}{l}\text { oštećenja/indents } \\
\text { (T./PI. 9: 2) }\end{array}$ \\
\hline Martinci & P-1728 & 4,5 & \multicolumn{2}{|c|}{1,9} & \multicolumn{2}{|c|}{1,9} & 40 & $\begin{array}{c}\text { znatno oštećen/ } \\
\text { significantly damaged }\end{array}$ \\
\hline Pakasin & P-21314 & 3,5 & \multicolumn{2}{|c|}{0,5} & \multicolumn{2}{|c|}{1,2} & 19 & $\begin{array}{l}\text { oštećenja/indents } \\
\text { (T./PI. 9: 3) }\end{array}$ \\
\hline \multicolumn{9}{|c|}{ BRUSOVI/WHETSTONES } \\
\hline $\begin{array}{l}\text { Lokalitet/ } \\
\text { Site }\end{array}$ & $\begin{array}{l}\text { Inv. br./ } \\
\text { Inv. no. }\end{array}$ & $\begin{array}{l}\text { Dužina/ } \\
\text { length }(\mathrm{cm})\end{array}$ & $\begin{array}{c}\text { Širina/ } \\
\text { width }(\mathrm{cm})\end{array}$ & \multicolumn{2}{|c|}{$\begin{array}{c}\text { Debljina/ } \\
\text { thickness } \\
(\mathrm{cm})\end{array}$} & $\begin{array}{l}\text { Rupa/ } \\
\text { hole } \\
(\mathrm{cm}) \\
\end{array}$ & $\begin{array}{l}\text { Težina/ } \\
\text { weight } \\
\text { (g) }\end{array}$ & $\begin{array}{l}\text { Stanje/ } \\
\text { State }\end{array}$ \\
\hline Kašina & P-1816 & 7,4 & 2,2 & \multicolumn{2}{|c|}{1,4} & 0,6 & 42 & $\begin{array}{c}\text { oštećenje/indent } \\
\text { (T./PI. 9: 7) }\end{array}$ \\
\hline Konjšćina & P-21309 & 15,4 & 3,1 & \multicolumn{2}{|c|}{1,7} & 1,1 & 157 & $\begin{array}{l}\text { oštećenja/indents } \\
\text { (T./PI. 9: 6) }\end{array}$ \\
\hline \multicolumn{9}{|c|}{ MOTIKE/HOES } \\
\hline $\begin{array}{l}\text { Lokalitet/ } \\
\text { Site }\end{array}$ & $\begin{array}{l}\text { Inv. br./ } \\
\text { Inv. no. }\end{array}$ & $\begin{array}{c}\text { Dužina/ } \\
\text { length }(\mathrm{cm})\end{array}$ & $\begin{array}{c}\text { Širina/ } \\
\text { width }(\mathrm{cm})\end{array}$ & \multicolumn{2}{|c|}{$\begin{array}{c}\text { Debljina/ } \\
\text { thickness } \\
(\mathrm{cm})\end{array}$} & $\begin{array}{l}\text { Težina/ } \\
\text { weight } \\
\text { (g) }\end{array}$ & \multicolumn{2}{|r|}{$\begin{array}{c}\text { Opis/ } \\
\text { Description }\end{array}$} \\
\hline Čulinec & P-1676 & 21,9 & 9,1 & & & 889 & & $\begin{array}{l}\text { apezastog' oblika/of 'trapezoidal' shape } \\
\text { (T./PI. 5: 4) }\end{array}$ \\
\hline Poljana & P-4248 & 21,2 & 14,1 & & & 1434 & uloma & $\begin{array}{l}\text { k pravokutnog oblika/ fragment of rectan- } \\
\text { gular shape }\end{array}$ \\
\hline
\end{tabular}

Tab. 9 Dimenzije, zatečeno stanje i opisi pršljena, brusova i motika iz kategorije 'Ostalo' (autorica: Đukić 2017)

Tab. 9 Dimensions, state and descriptions of whorls, whetstones and hoes from the 'Other' category (author: Đukić 2017)

21 Predmet se u Pavišić 1990 pogrešno navodi. Naime, predmet je opisan kao sjekira s rupom za nasad u sredini a radi se o kamenom prršljenu. Osim toga, u Pavišić 1990 navodi se da je predmet prikazan na T. II: 3, a zapravo je prikazan na T. I i nije označen zasebnim brojem (predmet se nalazi u desnom donjem uglu T. I.).
21 The find is inaccurately listed in Pavišić 1990. Namely, the find is described as an axe with a hole for hafting, but is, in fact, a whorl. Additionally, Pavišić 1990 states that the find is shown on Pl. II: 3, but it is actually shown on Pl. I and is not numbered (the find is depicted on the bottom right of Pl. I.). 
trapezastoga oblika. Oba predmeta vrlo su dobro uglačana i izrađena od pješčenjaka.

Osim predmeta prikazanih u tab. 8, definirano je još nekoliko tipova glačanoga kamenog oruđa. Iz Marije Bistrice potječe 13 glačanih kamenih kugli (P-21312) nepoznate funkcije koje se razlikuju u dimenzijama. Promjera su od 2,7 do $8 \mathrm{~cm}$, a težina ima varira od 26 do 252 grama. Iz Zlatara potječe osam kugli istoga tipa (P-21349) koje se također razlikuju u dimenzijama. Promjer im varira od 3,8 do 7,7 cm, a težina od 72 do 593,5 grama. S područja Hrvatskoga zagorja potječe još jedan nalaz ove vrste, a objavljen je i nalaz ovakve kugle iz Jalkovca koji nije detaljnije opisan (Šimek 1997: br. 310). Na jednoj kugli iz Marije Bistrice i na dvije kugle iz Zlatara izrazito su vidljiva udubljenja nastala korištenjem predmeta - plitki žljebovi na poprečnim dijelovima predmeta. Rezultati analize dvaju predmeta ove vrste (P-213491 iz Zlatara i P-21312-9 iz Marije Bistrice) pokazuju kako su predmeti izađeni od pješčenjaka s velikim udjelom kvarca koji potječe s Medvednice. Osim toga, ustanovljeno je da oba predmeta na površini imaju pravilna četverokutna udubljenja nastala raspadanjem željeznoga oksida pirita te da su predmeti postupno zagrijavani na visokoj temperaturi, zbog čega im je površina ostakljena.

Iz Gotalovca potječe jedina zastupljena kamena perla, P-1704. Cilindričnoga je oblika s rupom u sredini. Dugačka je $3 \mathrm{~cm}$, a promjer joj je 1,5 cm. Osim perle, iz Gotalovca potječe i jedini primjerak rastirača, P-21303. Radi se o ulomku glačanoga kamenog rastirača okrugloga presjeka s jednom zaravnjenom stranom.

Iz Huma Svetog Martina potječe kameno oruđe romboidnoga oblika s rupom za nasad drška, P-1694 (Škiljan 2009b: 5, br. 2). Oštećenja na prednjem i stražnjem dijelu sugeriraju da je predmet bio korišten kao čekić, a manja oštećenja vidljiva su na svim bridovima. Predmet je dug $8,7 \mathrm{~cm}$, širok 5,1 cm i težak 405,5 grama.

Iz Koškovca potječe glačana kamena pločica nepravilnoga oblika, P-4230 (T. 9: 5). Predmet nije u potpunosti očuvan, a ima i mnogo manjih oštećenja na cijeloj površini, osobito na bridovima. Pločica je duga $7,5 \mathrm{~cm}$, debela $0,7 \mathrm{~cm}$ i teška 53 gram.

Iz Laza potječe oruđe stožastoga oblika s jednom zaravnjenom plohom i jednom oštricom, P-4215. Vjerojatno je riječ o dijelu veće sjekire koja je sekundarno korištena kao čekić (Škiljan 2009b: 6, br. 12). Predmet je dug 7,8 cm, širok $5,5 \mathrm{~cm}$ i težak $221 \mathrm{gram}$.

Jedini glačani kameni uteg (P-1705) potječe iz Topličice. Izduženoga je pravokutnog oblika s rupom na vrhu. Dugačak je 9,1 cm, širok 5,4 cm i težak 252 grama (Pavišić 1990: 6, br. 4 ; T. I: 2 ). ${ }^{22}$

Iz Radoboja potječe predmet (P-21327) koji je originalno zaveden kao dio inventarnoga broja P-1688. Kamen je oblikovan u stiliziranu ljudsku figuru s naglašenim vratom $\mathrm{i}$ licem. Na figuri se nalazi i niz urezanih linija koje vjerojatno prikazuju odjeću. Površina predmeta je oštećena. Figura je visoka 9,5 cm, debljine 3,7 cm, i teška 170 grama. Prema tipu oštećenja, vjerojatno se radi o recentnoj intervenciji na ka-

22Predmet je kod Pavišić pogrešno definiran kao sjekira. Radi se o utegu koji je u Pavišić 1990 prikazan na T. I: 2. quartzite that can be found on the Medvednica, and the one from Kašina is made of chert.

Two hoes were defined (Tab. 9): P-1676 from Čulinec (PI. 5: 4) and P-4248 from Poljana. These are larger flat finds of rectangular and slightly trapezoidal shapes. Both finds are well-polished and made of sandstone.

Apart from the finds presented in Tab. 8, several other polished stone tool types were defined. Marija Bistrica yielded 13 polished stone spheres (P-21312) of different sizes and of unknown function. Their diameter varies from 2.7 to $8 \mathrm{~cm}$, and their weight ranges from 26 to 252 grams. Zlatar yielded eight equivalent spheres (P-21349) that also differ in size. Their diameter varies from 3.8 to $7.7 \mathrm{~cm}$, and their weight ranges from 72 to 593.5 grams. The territory of $\mathrm{Hr}$ vatsko Zagorje yielded one find of this type, and another from Jalkovec was published without a detailed description (Šimek 1997: no. 310). One sphere from Marija Bistrica and two from Zlatar have highly pronounced indentations resulting from use - shallow gauges on the lateral sides of the artifacts. The results of the analysis conducted on two of the finds (P-21349-1 from Zlatar and P-21312-9 from Marija Bistrica) show that they are made of sandstone with numerous inclusions of quartz that can be found on the Medvednica. Additionally, it was established that both finds have regular square indentations on the surface, made by the decomposing of the iron oxide pyrite, and that the artefacts were gradually heated to high temperatures, giving their surface a glass-like appearance.

Gotalovec yielded the only defined stone bead, P-1704. It is cylindrical and has a hole in the middle. It is $3 \mathrm{~cm}$ long, and measures $1.5 \mathrm{~cm}$ in diameter. Apart from the bead, Gotalovec yielded the only handstone, $\mathrm{P}-21303$. It is a fragment of a handstone of circular cross-section with one straightened side.

Hum Sveti Martin yielded a rhomboidal stone tool with a hole for hafting, P-1694 (Škiljan 2009b: 5, no. 2). The indentations on both the front and the back end suggest that the artifact was used as a hammer, and some minor damage was also noted on all lateral edges. The find measures 8.7 $\mathrm{cm}$ in length, $5.1 \mathrm{~cm}$ in width and weighs 405.5 grams.

Koškovec yielded an irregularly-shaped stone tile, P-4230 (PI. 9: 5). The find is not completely preserved and has many smaller indentations on the entire surface, especially the edges. The tile is $7.5 \mathrm{~cm}$ long, $0.7 \mathrm{~cm}$ thick, and weighs 53 grams.

Laz yielded a conical artefact with one straightened side and one blade, P-4215, probably a part of a larger axe that was secondarily used as a hammer (Škiljan 2009b: 6, no. 12). The find is $7.8 \mathrm{~cm}$ long, $5.5 \mathrm{~cm}$ wide and weighs $221 \mathrm{grams}$.

The only polished stone weight (P-1705) comes from Topličica. It is of elongated rectangular shape with a hole on the top. The find is $9.1 \mathrm{~cm}$ long, $5.4 \mathrm{~cm}$ wide, and weighs 252 grams (Pavišić 1990: 6, no. 4; PI. I: 2).22

Radoboj yielded a find (P-21327) that was originally recorded under inventory number P-1688. The stone was formed into a stylized human figure with an accentuated neck

22 Pavišić (1990) inaccurately defines the find as an axe. It is a weight, and it is shown on Pl. I: 2 in Pavišić 1990. 


\begin{tabular}{|c|c|c|c|c|c|c|}
\hline $\begin{array}{c}\text { Lokalitet/ } \\
\text { Site }\end{array}$ & $\begin{array}{c}\text { Inv. br./ } \\
\text { Inv. no. }\end{array}$ & $\begin{array}{c}\text { Dužina/ } \\
\text { length } \\
\text { (cm) }\end{array}$ & $\begin{array}{c}\text { Širina/ } \\
\text { width } \\
\text { (cm) }\end{array}$ & $\begin{array}{c}\text { Debljina/ } \\
\text { thickness } \\
\text { (cm) }\end{array}$ & $\begin{array}{c}\text { Težina/ } \\
\text { weight } \\
(\mathrm{g})\end{array}$ & $\begin{array}{c}\text { Opis/ } \\
\text { Description }\end{array}$ \\
\hline Bojačno selo & P-11702 & 5,5 & 4 & 3,2 & 71 & $\begin{array}{c}\text { ulomak s ravnom plohom/ } \\
\text { fragment with a straight plane }\end{array}$ \\
\hline Kalinovac & P-21307 & 8 & 6,8 & 5 & 447,5 & $\begin{array}{c}\text { ulomak pravokutnog oblika/ } \\
\text { fragment of rectangular shape }\end{array}$ \\
\hline \multirow{2}{*}{ Tkalec } & P-6657-1 & 8,5 & 4,6 & 3,4 & 118 & 2 ulomka pravokutnog oblika/ \\
\cline { 2 - 6 } & P-6657-2 & 5,5 & 4,6 & 2,9 & 67,5 & 2 fragments of rectangular shape \\
\hline
\end{tabular}

Tab. 10 Dimenzije i opisi kamenih žrvnjeva (autorica: Đukić 2017) Tab. 10 Dimensions and descriptions of grindstones (author: Đukić 2017)

menu s abrazivnim svojstvima koji je mogao, ali nije nužno morao biti oruđe.

\section{Kameno oruđe s abrazivnim svojstvima - žrvnjevi}

U ovoj kategoriji nalaze se četiri predmeta s tri lokacije (tab. 10). ${ }^{23}$ Svi predmeti su znatno oštećeni, a razlikuju se i po obliku. Ulomak žrvnja iz Bojačnog sela izrađen je od neogene stijene sastavljene od valutica kvarca povezanih karbonatnim vezivom; predmeti iz Tkalca izrađeni su od pješčenjaka s primjesama kvarca koje su povezane karbonatnim vezivom, a predmet iz Kalinovca izrađen je od kvarca. Ležišta spomenutih vrsta stijena su na Medvednici. Predmeti iz Tkalca možda su sekundarno korišteni kao brusovi jer se na njima vide uske i plitke paralelne linije kakve nastaju brušenjem šiljatih predmeta, primjerice šila.

\section{Nepoznati lokaliteti}

S nepoznatih lokaliteta potječu tri nalaza. U inventarnim knjigama nema dodatnih podataka o točnom mjestu pronalaska ovih predmeta, osim pretpostavke da potječu iz Hrvatskoga Zagorja (tab. 1), zbog čega su i uključeni u ovaj rad. P-1795 je dlijeto s jednom zaravnjenom stranom. Tragovi upotrebe vide se na oba kraja, a predmet je dug 8,6 $\mathrm{cm}$, širok 5,1 cm, i težak 162 grama. P-1796 je stražnji ulomak sjekire s rupom za nasad drška. Predmet je dug $8,9 \mathrm{~cm}$, širok $5,1 \mathrm{~cm}$ i težak 222,5 grama. P-1797 (T. 9: 4) je kamena perla koja ima širu rupu u sredini i dvije uže oko nje. Rupe tvore oblik trokuta. Promjer perle je 3,6 cm, a predmet je težak 29 grama.

\section{Nepoznati lokaliteti u Hrvatskome zagorju}

U fundusu Arheološkoga muzeja u Zagrebu nalazi se 46 nalaza glačanoga kamenog oruđa s područja Hrvatskoga zagorja koje ne može biti preciznije kartirano. Hrvatsko zagorje određeno je kao geografska cjelina u sjeverozapadnoj Hrvatskoj, omeđena planinama Medvednicom na jugu i Ivančicom na sjeveru, odnosno rijekom Sutlom na zapadu (Pavišić 1990: 5). Za većinu nalaza, od inventarnoga broja P-1740 do P-1777, kao okvirna se lokacija spominje kotar Zlatar (tab. 1). Ovi su nalazi važni jer pokazuju visoku gustoću glačanoga kamenog oruđa u sjeverozapadnoj Hrvatskoj, a pružaju uvid i u različite tipove oruđa koje su se koristile na spomenutome području u prapovijesti. Analizirani pred-

23 Iz Bojačnog i Kalinovca potječe po jedan predmet, dok iz Tkalca potječu dva. and face. The figurine also displays a series of incised lines that probably denote clothing. The figurine is $9.5 \mathrm{~cm}$ tall, $3.7 \mathrm{~cm}$ thick, and weighs 170 grams. Based on the type of indentations, this was probably a more recent intervention made on an abrasive rock that might, but did not have to be a tool.

\section{Abrasive stone tools - grindstones}

This category includes four finds from three locations (Tab. 10). ${ }^{23}$ All of the finds are greatly damaged, and are of different shapes. The fragment from Bojačno Selo is made of neogene rock made up of quartz valves linked by carbonate binder; the find from Tkalec is made of sandstone with quartz inclusions, and the find from Kalinovec is made of quartz. These raw materials can be found on the Medvednica. The finds from Tkalec might have been reused as whetstones because they display narrow and shallow parallel lines that can be made by honing pointed objects such as awls.

\section{Unknown sites}

Unknown sites yielded three finds. The inventory books do not provide additional data about the exact place of discovery, other than the assumption that they were found in Hrvatsko Zagorje (Tab. 1), which is why they were included in this analysis. P-1795 is a chisel with one straight side that has visible traces of use on both ends. The find is $8.6 \mathrm{~cm}$ long, $5.1 \mathrm{~cm}$ wide and weighs 162 grams. P-1796 is the back end of an axe with a hole for hafting. It is $8.9 \mathrm{~cm}$ long, $5.1 \mathrm{~cm}$ wide and weighs 222.5 grams. P-1797 (T. 9: 4) is a stone bead with a wider hole in the middle, and two narrower ones around it. The holes form a triangle. The bead measures 3.6 $\mathrm{cm}$ in diameter and weighs 29 grams.

\section{Unknown sites in the Hrvatsko Zagorje region}

The Archaeological Museum in Zagreb keeps 46 polished stone tools from the territory of Hrvatsko Zagorje that cannot be mapped more precisely. Hrvatsko Zagorje is defined as a geographical region in northwestern Croatia, bordered by the Medvednica Mountain in the south, the Ivančica Mountain in the north, and the Sutla River in the west (Pavišić 1990: 5). Most of the finds, from inventory number P-1740 to P-1777, are generally attributed to the area of Zlatar (Tab. 1). These finds are important because they indicate a very large frequency of polished stone tools 23 Bojačno and Kalinovac yielded one each, and Tkalec yielded two finds. 
meti razvrstani su u sedam kategorija: tri trapezaste sjekire, jedno dlijeto, 13 sjekira-čekića s rupom za nasad drška, jedna sjekira s rupom za nasad drška, sedam čekića s rupom za nasad drška, sedam sjekira ili sjekira-čekića s rupom za nasad drška, šest čekića ili sjekira-čekića s rupom za nasad drška, jedan čep od bušenja rupe na nepoznatoj vrsti oruđa, četiri brusa s rupama za ovjes, dva pršljena s rupom i jedna glačana kugla nepoznate funkcije (tab. 11).

Dvije od tri trapezaste sjekire potpuno su sačuvane, P-1742 i P-1783 (T. 10: 2), dok je jednoj, P-1743, sačuvan samo prednji ulomak. Na oštricama svih triju sjekira vidljivi su tragovi upotrebe.

Dlijeto s jednom zaravnjenom stranom, P-1741, pripada istome tipu koji je zabilježen na ostalim lokalitetima, a kao i kod drugih primjeraka, tragovi upotrebe vidljivi su na oba kraja.

S područja Zagorja sačuvano je 13 sjekira-čekića s rupom za nasad drška. Ova kategorija definirana je na temelju tragova korištenja vidljivih i na oštrici i na stražnjem dijelu, što znači da su predmeti korišteni i kao sjekire i kao čekići. Većina predmeta potpuno je sačuvana, dok je P-1740 spojen od dva ulomka. Nalazi pod inventarnim brojevima P-1754, P-1755, P-1757 i P-21355 ulomci su različitih dijelova oruđa, a P-1745 je nedovršeni artefakt kojemu rupa nikada nije probušena. Slično je i s P-1747, predmetu na kojem se vidi tek trag početka bušenja rupe. Svi predmeti imaju zaobljen stražnji dio, a prednji se sužava u oštricu. Ipak, u prvu od četiri podskupine svrstani su primjerci pod inventarnim brojevima P-1740, P-1751 (T. 10: 4), P-1752, P-1754, P-1784 i $\mathrm{P}-1785$ jer su oblikom međusobno sličniji (širi oko rupe nego preostali primjerci koji su jednake širine gotovo cijelom dužinom). U drugoj skupini su P-1745 i P-1746 jer se radi o najvećim i međusobno najsličnijim primjercima sjekira-čekića. U trećoj skupini su P-1747, P-1756, P-1757 i P-21355. U četvrtoj skupini je samo jedan predmet, P-1753 (T. 10: 3), kojemu se oko rupe nalazi zadebljanje, a stražnji dio je izdužen i zaravnjen, kao i na sjekiri-čekiću iz Križevaca, P-4245.

Sačuvan je samo jedan stražnji ulomak glačane kamene sjekire s rupom za nasad drška (P-1769), a na njemu su vidljive i tri paralelne kratke linije koje su vjerojatno posljedica korištenja oruđa.

Sačuvano je sedam čekića s rupom za nasad drška. Gotovo svi primjerci potpuno su sačuvani, osim P-1762 i P-1767 kojima je sačuvan samo stražnji ulomak. Na svim nalazima vidljivi su tragovi upotrebe, na P-1772 samo na jednoj, a na ostalim primjercima na obje strane. Većina predmeta ima zaravnjenu stražnju stanu (P-1748, P-1749, P-1750, P-1762 i P-1770, T. 10: 5), a dva imaju zaobljeni stražnji kraj (P-1767 i P-1772).

Sačuvano je 13 predmeta neodredivih tipova. Na svim prednjim i stražnjim ulomcima ovih predmeta vidljivi su tragovi upotrebe. Treba izdvojiti P-1771, prednji ulomak kojemu je oštrica postavljena okomito na rupu, što je slučaj samo još na P-1700, sjekiri-čekiću iz Sv. Ilije Obreža (T. 7: 2).

Sačuvan je jedan čep od bušenja rupe na glačanom kamenom oruđu (P-1774). Sačuvana su četiri brusa s rupom za ovjes (P-1775, T. 10: 6; P-1776, T. 10: 7; P-1777 i P-1786). U sva četiri slučaja radi se o predmetima izduženoga oblika, kva- in northwestern Croatia, and provide insight into the different tool types used in the region during prehistory. The analysed finds were distributed into seven categories: three trapezoidal axes, one chisel, 13 axe-hammers with holes for hafting, one axe with a hole for hafting, seven hammers with holes for hafting, seven axes or axe-hammers with holes for hafting, six hammers or axe-hammers with holes for hafting, one cork from the perforation of an indeterminable tool type, four whetstones with holes for hanging, two perforated whorls, and one polished stone sphere of unknown function (Tab. 11).

Two out of the three trapezoidal axes, $\mathrm{P}-1742$ and $\mathrm{P}-1783$ (PI. 10: 2), are completely preserved, while one, P-1743, is only partially preserved. The blades on all three axes display traces of use.

The chisel with one straight side, P-1741, can be ascribed to the same type recorded at the other studied locations, and it also has visible traces of use on both ends.

The territory of Hrvatsko Zagorje yielded 13 axehammers with holes for hafting. The category was defined based on traces of use visible on both the blade and the back end, indicating that the finds were used as both axes and hammers. Most finds are completely preserved, but P-1740 was pieced together from two fragments. The finds with inventory numbers P-1754, P-1755, P-1757, and P-21355, are fragments of different parts of tools, while P-1745 is an unfinished artefact that was never perforated. P-1747 displays only the beginnings of a perforation. All of the finds have a rounded back end, and a front that narrows into a blade. However, the first of the four groups includes finds listed under inventory numbers P-1740, P-1751 (PI. 10: 4), P-1752, P-1754, P-1784 and P-1785, that were grouped together because of their similar shape (wider around the hole compared with the other finds that are of almost equal width throughout). The second group includes P-1745 and P-1746, which are the finds of axe-hammers that are the biggest and most similar to each other. The third group includes P-1747, P-1756, P-1757, and P-21355. The fourth group includes only one find, P-1753 (PI. 10: 3), which is thicker around the hole and has an elongated and straightened back end, like the axe-hammer from Križevci, P-4245.

There is only one preserved back end of a polished stone axe with a hole for hafting (P-1769), and it also displays three short parallel lines that are probably the result of tool usage.

There are seven preserved hammers with holes for hafting. Almost all of the finds are completely preserved, except P-1762 and P-1767, which only have their back ends. All of the finds display traces of use: P-1772 on one end only, and the rest on both ends. Most of the artefacts have a straightened back end (P-1748, P-1749, P-1750, P-1762 and P-1770, PI. 10: 5), but two have a rounded one (P-1767 and $\mathrm{P}-1772)$.

Thirteen indeterminable tool types were recorded. All of the front and back ends of these finds display traces of use. P-1771 is interesting because its blade is perpendicular to the hole; the only other recorded case is P-1700, an axehammer from Sveti llija Obrež (PI. 7: 2).

There is one preserved cork from the perforation of a 


\begin{tabular}{|c|c|c|c|c|c|c|c|}
\hline $\begin{array}{l}\text { Inv. br./ } \\
\text { Inv. no. }\end{array}$ & $\begin{array}{l}\text { Tip/ } \\
\text { Type }\end{array}$ & $\begin{array}{l}\text { Dužina/ } \\
\text { length } \\
\text { (cm) }\end{array}$ & $\begin{array}{l}\text { Širina/ } \\
\text { width } \\
(\mathrm{cm})\end{array}$ & $\begin{array}{c}\text { Debljina/ } \\
\text { thickness } \\
(\mathrm{cm})\end{array}$ & $\begin{array}{l}\text { Rupa/ } \\
\text { hole } \\
\text { (cm) }\end{array}$ & $\begin{array}{c}\text { Težina/ } \\
\text { weight } \\
\text { (g) }\end{array}$ & Stanje/State \\
\hline P-1742 & \multirow{3}{*}{$\begin{array}{l}\text { trapezasta } \\
\text { sjekira/ } \\
\text { trapezoidal } \\
\text { axe }\end{array}$} & 9,1 & 5,9 & 2,7 & nema/none & 235 & oštećena/damaged \\
\hline P-1743 & & 5,5 & 6,7 & 2,1 & nema/none & 118 & oštećena/damaged \\
\hline P-1783 & & 11,6 & 6,4 & 1,7 & nema/none & 185 & $\begin{array}{l}\text { oštećena/damaged } \\
\text { (T./PI. 10: 2) }\end{array}$ \\
\hline P-1741 & $\begin{array}{l}\text { dlijeto/ } \\
\text { chisel }\end{array}$ & 10,2 & 5,8 & 3,2 & $\begin{array}{c}\text { nema/ } \\
\text { none }\end{array}$ & 284 & oštećeno/damaged \\
\hline P-1740 & \multirow{13}{*}{$\begin{array}{c}\text { sjekira-čekić } \\
\text { s rupom za } \\
\text { nasad drška/ } \\
\text { axe- } \\
\text { hammers } \\
\text { with holes } \\
\text { for hafting }\end{array}$} & 10,9 & 4,3 & 5,1 & 1,9 & 330 & oštećena/damaged \\
\hline P-1751 & & 10,6 & 4 & 7 & 2,3 & 354 & $\begin{array}{l}\text { oštećena/damaged } \\
\text { (T./PI. 10: 4) }\end{array}$ \\
\hline P-1752 & & 8,2 & 6,1 & 5,5 & 2,4 & 384 & oštećena/damaged \\
\hline P-1754 & & 8,4 & 6 & 4,6 & $\begin{array}{l}\text { ulomak/ } \\
\text { fragment }\end{array}$ & 295 & oštećena/damaged \\
\hline P-1784 & & 15,6 & 5,8 & 6,6 & 2,5 & 825 & oštećena/damaged \\
\hline P-1785 & & 8,5 & 3,4 & 4,8 & 1,7 & 192 & oštećena/damaged \\
\hline P-1745 & & 15,7 & 6,6 & 5,6 & nema/none & 1028 & oštećena/damaged \\
\hline P-1746 & & 17,8 & 6,2 & 5,2 & 2,2 & 1005 & oštećena/damaged \\
\hline P-1747 & & 8,6 & 4,3 & 2,5 & nema/none & 151 & oštećena/damaged \\
\hline P-1756 & & 8,5 & 2,9 & 1,7 & $\begin{array}{l}\text { ulomak/ } \\
\text { fragment }\end{array}$ & 75 & dobro/good \\
\hline P-1757 & & 10,9 & 4,2 & 3,3 & $\begin{array}{l}\text { ulomak/ } \\
\text { fragment }\end{array}$ & 235 & oštećena/damaged \\
\hline P-21355 & & 6,3 & 4,7 & 1,1 & $\begin{array}{l}\text { ulomak/ } \\
\text { fragment }\end{array}$ & 63 & dobro/good \\
\hline P-1753 & & 13,3 & 4,3 & 4,5 & 2 & 316 & $\begin{array}{l}\text { oštećena/damaged } \\
\text { (T./PI. 10: 3) }\end{array}$ \\
\hline P-1769 & sjekira/axe & 3,3 & 5,2 & 3,9 & $\begin{array}{l}\text { ulomak/ } \\
\text { fragment }\end{array}$ & 105,5 & oštećena/damaged \\
\hline P-1748 & \multirow{7}{*}{$\begin{array}{l}\text { čekići s ru- } \\
\text { pom za na- } \\
\text { sad drška/ } \\
\text { hammers } \\
\text { with holes } \\
\text { for hafting }\end{array}$} & 10,4 & 3,9 & 4,9 & 2 & 328 & veća oštećenja/larger indents \\
\hline P-1749 & & 9,5 & 3,1 & 4,8 & 1,8 & 210 & oštećen/damaged \\
\hline P-1750 & & 8,4 & 3,2 & 5 & 2,5 & 164 & $\begin{array}{l}\text { veća oštećenja/ } \\
\text { larger indents }\end{array}$ \\
\hline P-1762 & & 5,6 & 3 & 5,4 & $\begin{array}{l}\text { ulomak/ } \\
\text { fragment }\end{array}$ & 113 & $\begin{array}{l}\text { veća oštećenja/ } \\
\text { larger indents }\end{array}$ \\
\hline P-1770 & & 9,7 & 7,1 & 3,9 & 2,7 & 391 & $\begin{array}{c}\text { oštećen/damaged } \\
\text { (T./PI. 10: 5) }\end{array}$ \\
\hline P-1767 & & 6,1 & 5,3 & 6,4 & $\begin{array}{l}\text { ulomak/ } \\
\text { fragment }\end{array}$ & 279 & oštećen/damaged \\
\hline P-1772 & & 7,5 & 5,5 & 7 & 2,4 & 47 & oštećen/damaged \\
\hline
\end{tabular}




\begin{tabular}{|c|c|c|c|c|c|c|c|}
\hline $\begin{array}{l}\text { Inv. br./ } \\
\text { Inv. no. }\end{array}$ & $\begin{array}{l}\text { Tip/ } \\
\text { Type }\end{array}$ & $\begin{array}{l}\text { Dužina/ } \\
\text { length } \\
\text { (cm) }\end{array}$ & $\begin{array}{l}\text { Širina/ } \\
\text { width } \\
(\mathrm{cm})\end{array}$ & $\begin{array}{l}\text { Debljina/ } \\
\text { thickness } \\
\qquad(\mathrm{cm})\end{array}$ & $\begin{array}{l}\text { Rupa/ } \\
\text { hole } \\
\text { (cm) }\end{array}$ & $\begin{array}{c}\text { Težina/ } \\
\text { weight } \\
\text { (g) }\end{array}$ & Stanje/State \\
\hline P-1744 & \multirow{13}{*}{$\begin{array}{c}\text { neodredivi ti- } \\
\text { povi oruđa/ } \\
\text { indeter. tool } \\
\text { types }\end{array}$} & 4,7 & 2,7 & 3,1 & $\begin{array}{l}\text { ulomak/ } \\
\text { fragment }\end{array}$ & 48 & oštećenja/indents \\
\hline P-1758 & & 6,6 & 5,3 & 4,3 & $\begin{array}{l}\text { ulomak/ } \\
\text { fragment }\end{array}$ & 219 & veća oštećenja/larger indents \\
\hline P-1761 & & 5,6 & 4,6 & 3,6 & $\begin{array}{l}\text { ulomak/ } \\
\text { fragment }\end{array}$ & 142 & oštećenja/indents \\
\hline P-1765 & & 6,1 & 6,5 & 2,9 & $\begin{array}{l}\text { ulomak/ } \\
\text { fragment }\end{array}$ & 154 & oštećenja/indents \\
\hline P-1766 & & 4,2 & 5,5 & 3,2 & $\begin{array}{l}\text { ulomak/ } \\
\text { fragment }\end{array}$ & 71 & oštećenja/indents \\
\hline P-1771 & & 4,7 & 3,1 & 3,1 & $\begin{array}{l}\text { ulomak/ } \\
\text { fragment }\end{array}$ & 73 & oštećenja/indents \\
\hline P-21356 & & 8,4 & 5,8 & 5,2 & $\begin{array}{l}\text { ulomak/ } \\
\text { fragment }\end{array}$ & 426 & oštećenja/indents \\
\hline P-1755 & & 6,5 & 5,9 & 2,9 & $\begin{array}{l}\text { ulomak/ } \\
\text { fragment }\end{array}$ & 125,5 & oštećenja/indents \\
\hline P-1759 & & 4 & 3,8 & 4,3 & $\begin{array}{l}\text { ulomak/ } \\
\text { fragment }\end{array}$ & 99 & oštećenja/indents \\
\hline P-1760 & & 6,6 & 5,4 & 4,6 & $\begin{array}{l}\text { ulomak/ } \\
\text { fragment }\end{array}$ & 292,5 & oštećenja/indents \\
\hline P-1763 & & 7 & 5,5 & 5 & $\begin{array}{l}\text { ulomak/ } \\
\text { fragment }\end{array}$ & 208 & oštećenja/indents \\
\hline P-1768 & & 4,4 & 3,8 & 2,6 & $\begin{array}{l}\text { ulomak/ } \\
\text { fragment }\end{array}$ & 42 & oštećenja/indents \\
\hline P-1764 & & 6,9 & 4,6 & 5,1 & $\begin{array}{l}\text { ulomak/ } \\
\text { fragment }\end{array}$ & 215 & oštećenja/indents \\
\hline P-1775 & \multirow{4}{*}{$\begin{array}{c}\text { brus s rupom } \\
\text { za ovjes/ } \\
\text { whetstones } \\
\text { with hole for } \\
\text { hanging }\end{array}$} & 9,2 & 2,2 & 1,9 & 0,4 & 70 & $\begin{array}{l}\text { oštećen/damaged } \\
\text { (T./PI. 10:6) }\end{array}$ \\
\hline P-1776 & & 10,1 & 2,1 & 1,8 & 1,6 & 66 & $\begin{array}{l}\text { oštećen/damaged } \\
\text { (T./PI. 10: 7) }\end{array}$ \\
\hline P-1777 & & 4,5 & 1,8 & 1,4 & 0,5 & 14 & $\begin{array}{l}\text { dobro očuvan/ } \\
\text { well-preserved }\end{array}$ \\
\hline P-1786 & & 6,5 & 1,8 & 1,8 & 0,4 & 37 & oštećen/damaged \\
\hline P-1774 & čep/cork & 5,8 & 1,8 & 1,7 & nema/none & 25 & oštećen/damaged \\
\hline P-1773 & \multirow{2}{*}{$\begin{array}{l}\text { pršljeni/ } \\
\text { whorls }\end{array}$} & 6,8 & 5 & 2,2 & 1,2 & 73,5 & oštećen/damaged \\
\hline P-1787 & & 5,8 & 5,7 & 3 & 1,5 & 95 & $\begin{array}{l}\text { oštećen/damaged } \\
\text { (T./PI. 10: 1) }\end{array}$ \\
\hline P-21354 & kugla/ball & 2,8 & 2,5 & 2,8 & nema/none & 19 & dobro/good \\
\hline
\end{tabular}

Tab. 11 Dimenzije i zatečeno stanje glačanih kamenih predmeta iz Hrvatskoga zagorja (autorica: Đukić 2017) Tab. 11 Dimensions and state of polished stone artefacts from Hrvatsko Zagorje (author: Đukić 2017) 
dratnoga presjeka s rupom na gornjem dijelu. Te ih karakteristike povezuju i s primjerkom iz Kašine, P-1816 (T. 9: 7), te onim iz Konjšćine, P-21309 (T. 9: 6). Na svim primjercima iz Zagorja vide se tragovi upotrebe i to u smislu da je predmet sužen na dijelu koji se koristi za brušenje.

Glačani kameni pršljen, P-1773, nepravilnoga je oblika s rupom, a najsličniji je pršljenu iz Pakasina, P-21314 (T. 9: 3). Drugi sačuvani pršljen, P-1787 (T. 10: 1), je okrugloga oblika s rupom u sredini, a najsličniji je pršljenima druge podskupine. Sačuvana je i jedna glačana kamena kugla nepoznate funkcije, P-21354. Ovakvi predmeti pronađeni su i u Mariji Bistrici (P-21312) i Zlataru (P-21349).

\section{RASPRAVA}

Glačana kamena dlijeta i bradve (tab. 2) različito su definirane s obzirom na oblik, a pripisivana im je i različita namjena. Ovi su predmeti smatrani poljodjelskim oruđem (motike), tesarskim oruđem i oruđem za glačanje, odnosno štavljenje kože (Težak-Gregl 2001: 10). Osim toga, neka od dlijeta zbog velikih dimenzija potencijalno mogu biti smatrana statusnim simbolom, primjerice P-15000 iz Kamenskog Dola (T. 4: 1), a koje je vrlo slično ulomku pronađenom u kontekstu korenovske kulture na lokalitetu Malo Korenovo (Težak-Gregl 1993: T. 19: 7). U dlijeta je svrstano oruđe čije su bočne stranice paralelne ili gotovo paralelne (Balen 2003: 50). Prema analogijama iz Srbije valja primijetiti da su dlijeta zapravo kombinacija bradvi i sjekira, odnosno da se radi o oruđu kojem je sječivo u ravnini simetrije, što znači da im je jedna strana zaravnjena (Antonović 2003: 54). U bradve je svrstano oruđe kojemu strane nisu sasvim paralelne, već se blago šire prema oštrici (Antonović 2003: 54; Balen 2003: 50), a koje neki autori smatraju poljodjelskim alatom (Jurić et al. 2001: 1136), dok drugi ističu da oni to nisu mogli biti jer su većinom izrađeni od pješčenjaka ili silita što ih čini pogodnijima za glačanje (drugoga kamenog oruđa ili keramičkih posuda) nego za kopanje (Težak-Gregl, Burić 2002: 16). Dlijeta i bradve pronalažene su u kontekstu neolitičke starčevačke (Garašanin 1979: 123; Dizdar, Krznarić-Škrivanko 2000: 11, T. III: 4; Težak-Gregl, Burić 2002: 16), korenovske (Težak-Gregl 1993: 26) i sopotske kulture (Balen et al. 2002: 22; Krznarić-Škrivanko 2003: 66; Okroša Rožić 2014: kat. br. 31; Miklik-Lozuk 2014: 56, kat. br. 158). U prilog pripisivanju dlijeta starčevačkoj kulturi svjedoči nalaz s mađarskoga nalazišta Vörs (Kalicz et al. 1998: 166, Fig. 17), zatim dlijeto s eponimnoga lokaliteta Starčevo koje je oblikom gotovo istovjetno nalazima iz Miholečkih Mokrica i Poljane (Garašanin 1979: T. XXIII: 6) te dva nalaza s lokaliteta Starčevo-Grad (Živković et al. 2011: T. V: 6-7). U prilog pripisivanja dlijeta korenovskoj kulturi svjedoči nalaz iz Malog Korenova (Dimitrijević 1961: T. III: 19), a u prilog pripisivanja nalaza sopotskoj kulturi svjedoče dvije bradve iz Klokočevika (Dimitrijević 1968: T. XIX: 1-2) kao i dlijeto pronađeno na lokalitetu Brezovljani (Okroša-Rožić 2003: 79, sl. 6). U kategoriji dljeta svakako treba izdvojiti P-18838 iz Klenovca (T. 3: 2). Radi se o dlijetu koje je prvotno bilo glačano, a sekundarno dorađivano lomljenjem. Slični slučajevi zabilježeni su i drugdje, primjerice na neolitičkome batu iz Samatovaca (Balen et al. 2002: 23). polished stone tool (P-1774). Four whetstones with holes for hanging were recorded (P-1775, PI. 10: 6; P-1776, PI. 10: 7; P-1777 and P-1786). All four finds are of elongated shape with a square cross-section and a hole in the upper part. They share these characteristics with the finds from Kašina, P-1816 (PI. 9: 7), and Konjšćina, P-21309 (PI. 9: 6). All of the finds from Zagorje display traces of use, in the sense that they are narrower at the part that was used for honing.

The polished stone whorl, P-1773, has an irregular shape and a hole, and resembles most closely the whorl from Pakasin, P-21314 (PI. 9: 3). The other preserved whorl, P-1787 (PI. 10: 1), is round with a hole in the middle, and resembles most closely the whorls from the second sub-group. There is one preserved polished stone sphere of unknown function, P-21354. Such artefacts were also recorded in Marija Bistrica (P-21312) and Zlatar (P-21349).

\section{DISCUSSION}

Polished stone chisels and adzes (Tab. 2) were defined differently on the basis of their shape, and were also ascribed various functions. These artefacts were regarded as agricultural tools (hoes), woodworking tools, and tools used for polishing, i.e. leather tanning (Težak-Gregl 2001: 10). Additionally, some of the chisels, considering their large dimensions, might be seen as status symbols, e.g. P-15000 from Kamenski Dol (PI. 4: 1), which is very similar to a fragment found in the context of the Korenovo culture at the Malo Korenovo site (Težak-Gregl 1993: PI. 19: 7). Chisels include tools that have parallel or almost parallel lateral sides (Balen 2003: 50). Based on analogies from Serbia, it should be noted that chisels are, in fact, a combination of adzes and axes, meaning that their blades are in the plane of symmetry, giving them one straightened side (Antonovic 2003: 54). Adzes include tools with sides that are not completely parallel, but slightly wider towards the blade (Antonović 2003: 54; Balen 2003: 50). Some authors see them as agricultural tools (Jurić et al. 2001: 1136), while others point out that they could not have been used as such because they are mostly made of sandstone or silty limestone, making them more suitable for polishing (other stone tools or ceramic vessels) than digging (Težak-Gregl, Burić 2002: 16). Chisels and adzes were found in the context of the Neolithic Starčevo (Garašanin 1979: 123; Dizdar, Krznarić-Škrivanko 2000: 11, PI. III: 4; Težak-Gregl, Burić 2002: 16), Korenovo (Težak-Gregl 1993: 26) and Sopot cultures (Balen et al. 2002: 22; Krznarić-Škrivanko 2003: 66; Okroša Rožić 2014: cat. no. 31; Miklik-Lozuk 2014: 56, cat. no. 158). Additional evidence in support of earlier dating includes the find from the Hungarian site of Vörs (Kalicz et al. 1998: 166, Fig. 17), the chisel from the eponymous site of Starčevo that is almost identical in shape to finds from Miholečke Mokrice and Poljana (Garašanin 1979: PI. XXIII: 6), and two finds from the site of Starčevo-Grad (Živković et al. 2011: PI. V: 6-7). Evidence in support of ascribing the finds to the Korenovo culture was found at Malo Korenovo (Dimitrijević 1961: PI. III: 19), and dating to the Sopot culture is supported by two adzes from Klokočevik (Dimitrijević 1968: PI. XIX: 1-2) and a chisel from Brezovljani (Okroša-Rožić 2003: 79, Fig. 6). In the category of chisels, P-18838 from Klenovec (T. 3: 2) stands out becau- 
Pod pojmom sjekire trapezastoga oblika obuhvaćeno je svo glačano kameno oruđe koje se širi prema sječivu te ima zaobljenu, zaravnjenu ili zašiljenu šiju (tab. 3; Balen 2003: 50). Kamene su sjekire u funkcionalnom smislu najčešće oruđe, a u određenim slučajevima i oružje. No, pojavljuju se i kao votivne sjekire ili pak kao oznake časti ili funkcije, neka vrsta insignija ili žezla - tada mogu biti i vrlo malih dimenzija, ali i ekstremno velikih (Težak-Gregl 2001: 9). Prema analogijama s nalazima pronađenima na području Srbije (Antonović 2003: 54), ovdje zastupljeni nalazi definirani su u dva podtipa: I/1 - sjekire sa širim distalnim i užim proksimalnim krajem; l/2 - sjekire sa širim distalnim krajem i ukošenom oštricom. Na svim predmetima su oko oštrice vidljivi tragovi upotrebe (izuzev P-4221 i P-6472, Jamno, kojima dio s oštricom nije očuvan). Svi predmeti u ovoj kategoriji malih su dimenzija, odnosno dužina im rijetko prelazi $10 \mathrm{~cm}$, što je slučaj i s većinom starčevačkih te sopotskih nalaza (Dimitrijević 1979a: 291). Sjekire trapezastoga oblika pronalažene su u kontekstima neolitičke starčevačke (Garašanin 1979: 123; Zivković et al. 2001: T. V: 2, 4), korenovske (Dimitrijević 1961: T. III: 20-21) i sopotske kulture (Dimitrijević 1968: T. XIX: 3; 1979a: 291, T. XLIX: 12; Balen et al. 2002: 22; Krznarić-Škrivanko 1997: 208, T. III: 4; Rajković 2014: 25, kat. br. 45-46, 49; Marković, Botić 2014: 68, kat. br. 191; Balen 2014: 89, kat. br. 245), ali ih ima i u eneolitičkim kontekstima, osobito vezanim uz lasinjsku kulturu (Marković 1979: 37; 1986b: 95; Balen-Letunić 1981: 7; Težak-Gregl 1993: 27; 2001: 15). Primjerci iz Brezove gore vrlo su slični nalazima s korenovskih lokaliteta Staro Čiče i Malo Korenovo (Težak-Gregl 1993: T. 19: 3-6). Ovakvih sjekira ima i u ranoneolitičkim kontekstima Körös grupe u Mađarskoj (Brukner 1979: 219). Jedna sjekira ovoga tipa pronađena je na lokalitetu Varaždinske Toplice, a definirana je kao neolitička (Kušan Špalj, Nemeth-Ehrlich 2010: 110, 124, sl. 25). Objavljena je i jedna sjekira ovoga tipa s nalazišta Bojačno Selo koja je, s obzirom na ostale nalaze iz istoga kulturnog sloja, datirana u kasno brončano doba (Pavišić 1990: 7, br. 8; T. IV: 1). Osim te sjekire, u Bojačnom su pronađene brojne kamene glačalice, brusovi i noževi, i to uz vanjske rubove brončanodobnih keramičarskih peći (Pavišić 2011: 138). U prilog kasnijoj dataciji ide i činjenica da neki plosnati primjerci oblikom podsjećaju na oblike izrađivane u metalu. U prijašnjim objavama ovi nalazi nisu precizno datirani, već su smješteni u vrijeme od ranoga neolitika do brončanoga doba (Šimek 1985: 49).

Perforirano glačano kameno oruđe predstavlja najproblematičniju skupinu nalaza kada je u pitanju datacija. Naime, glačano kameno oruđe u ranome neolitiku uglavnom uključuje plosnate trapezaste sjekire, bradve, dlijeta i čekiće, ali se pojavljuje i oruđe s rupom, poput klina sa starčevačkoga lokaliteta Galovo kod Slavonskog Broda (Bunčić 2009: 299), glačanih kamenih predmeta korenovske kulture s lokaliteta Kukunjevac - Brod (Ivanković 2014: 58, kat. br. 151152) ili pak privjesaka sopotske kulture s lokaliteta Pepelana - Lug (Minichreiter 2014: 74, kat. br. 212 , Seče tip) i Stari Perkovci - Debela šuma (Balen 2014: 90, kat. br. 248). Glačano kameno oruđe s rupom pronalaženo je u kontekstima s neolitičkom sopotskom i korenovskom kulturom (Težak-Gregl 1993: 27), ali i s eneolitičkom lasinjskom (Marković 1985: 11), se it was primarily polished, and additionally processed by knapping. Similar cases have been recorded elsewhere, e.g. a Neolithic striker from Samatovci (Balen et al. 2002: 23).

The term 'trapezoidal axes' includes all polished stone tools that widen towards the blade and have a rounded, straight or pointy back end (Tab. 3; Balen 2003: 50). In a functional sense, stone axes are most often tools, but, in certain cases, also weapons. However, they also appear as votive axes or symbols of honour and function, some kind of insignia or scepters - then they can be very small, but also extremely big (Težak-Gregl 2001: 9). Based on analogies from the territory of Serbia (Antonović 2003: 54), the material studied herein was defined as belonging to two sub-types: I/1 - axes with a wider distal end and a narrower proximal end; $1 / 2$ - axes with a wider distal part and a slanted blade. All of the finds have visible traces of use around the blade (except P-4221 and P-6472 from Jamno that do not have preserved blades). All of the finds in this category are small, their length rarely exceeding $10 \mathrm{~cm}$, as is the case with most finds of the Starčevo and Sopot cultures (Dimitrijević 1979a: 291). Trapezoidal axes have been discovered in the context of the Neolithic Starčevo (Garašanin 1979: 123; Zivković et al. 2001: PI. V: 2, 4), Korenovo (Dimitrijević 1961: PI. III: 20-21), and Sopot cultures (Dimitrijević 1968: PI. XIX: 3; 1979a: 291, PI. XLIX: 12; Balen et al. 2002: 22; Krznarić-Škrivanko 1997: 208, PI. III: 4; Rajković 2014: 25, cat. no. 45-46, 49; Marković, Botić 2014: 68, cat. no. 191; Balen 2014: 89, cat. no. 245.), but they also appear in Copper Age contexts, especially relating to the Lasinja culture (Marković 1979: 37; 1986b: 95; Balen-Letunić 1981: 7; Težak-Gregl 1993: 27; 2001: 15). The finds from Brezova Gora are very similar to finds from the Korenovo culture sites of Staro Čiče and Malo Korenovo (Težak-Gregl 1993: PI. 19: 3-6). These axes also appear in the early Neolithic contexts of the Körös group in Hungary (Brukner 1979: 219). One axe of this type was found at the site of Varaždinske Toplice, and was ascribed to the Neolithic period (Kušan Špalj, Nemeth-Ehrlich 2010: 110, 124, Fig. 25). Another axe of this type from Bojačno Selo was also published, and considering the rest of the material from the same cultural layer, was dated to the Late Bronze Age (Pavišić 1990: 7, no. 8; T. IV: 1). Apart from this axe, Bojačno yielded numerous stone polishers, whetstones and knives that were discovered along the edges of Bronze Age pottery kilns (Pavišić 2011: 138). A later dating is supported by the fact that some flat finds resemble metal forms. In previous publications, this material was not precisely dated, but was ascribed to the period between the Early Neolithic and the Bronze Age (Šimek 1985: 49).

Perforated stone tools have proven to be the most difficult to date. In the Early Neolithic, polished stone tools mostly include flat trapezoidal axes, adzes, chisels and hammers, but there are also perforated tools such as the wedge from the Starčevo culture site of Galovo near Slavonski Brod (Bunčić 2009: 299), the polished stone implements from the Korenovo culture site of Kukunjevac - Brod (Ivanković 2014: 58, cat. no. 151-152), or the pendants from the Sopot culture sites of Pepelane - Lug (Minichreiter 2014: 74, cat. no. 212) and Stari Perkovci - Debela Šuma (Balen 2014: 90 , cat. no. 248). Perforated stone tools with holes for hafting were discovered in Neolithic contexts of the Sopot and 


\begin{tabular}{|c|c|c|}
\hline Tip predmeta/Type of find & Razdoblje/Period & Lokacija/Location \\
\hline $\begin{array}{c}\text { dlijeta i bradve/ } \\
\text { chisels and adzes (tab. 2) }\end{array}$ & $\begin{array}{c}\text { Neolitik/Neolithic - starčevačka k./Starče- } \\
\text { vo c., korenovska k./Korenovo c., sopotska } \\
\text { k./Sopot c.; }\end{array}$ & \begin{tabular}{|c|} 
Čulinec, Drenov bok \\
Jazbina, Samobor, Kamenski dol (korenovska k./Koreno- \\
vo c.?), Klenovec (sopotska k./Sopot c.?), Miholečke Mo- \\
krice (starčevačka k./Starčevo c.?), Poljana (starčevačka \\
k./Starčevo c.?), Tkalec
\end{tabular} \\
\hline $\begin{array}{l}\text { trapezaste sjekire/ } \\
\text { trapezoidal axes (tab. 3) }\end{array}$ & $\begin{array}{c}\text { Neolitik/Neolithic - starčevačka k./Starče- } \\
\text { vo c., korenovska k./Korenovo c., sopotska } \\
\text { k./Sopot c.; } \\
\text { Eneolitik/Copper Age - lasinjska k./Lasinja } \\
\text { c.; } \\
\text { Brončano doba/Bronze Age }\end{array}$ & $\begin{array}{c}\text { Brezova gora (korenovska k./Korenovo c.?), Črnec, } \\
\text { Druškovec, Golubovec, Hum, Ivanec (Križevci), Ivanec } \\
\text { (Varaždin), Jamno, Jazbina, Kuzminec, Lepoglava, Marija } \\
\text { Bistrica, Oslavec, Pakasin, Tkalec }\end{array}$ \\
\hline $\begin{array}{l}\text { sjekire s rupom za nasad } \\
\text { drška/ } \\
\text { axes with holes for hafting } \\
\text { (tab. 4) }\end{array}$ & \begin{tabular}{|} 
Neolitik/Neolithic - starčevačka k./Starče- \\
vo c., korenovska k./Korenovo c., sopotska \\
k./Sopot c.; \\
Eneolitik/Copper Age - lasinjska k./Lasinja \\
c., retzgajarska k./Retz gajary c., vučedol- \\
ska k./Vučedol c.; \\
Brončano doba/Bronze Age; \\
Željezno doba/Iron Age \\
\end{tabular} & $\begin{array}{l}\text { Bedekovčina, Bojačno selo (brončano doba/Bronze } \\
\text { Age), Cerje, Cvetlin, Drenov bok, Gotalovec, Hum, Ja- } \\
\text { kovlje, Jakuševec, Jamno, Jazbina, Kašina, Lobor, Mače, } \\
\text { Marija Bistrica, Zlatar }\end{array}$ \\
\hline čekići/hammers (tab. 5) & $\begin{array}{c}\text { Neolitik/Neolithic; } \\
\text { Eneolitik/Copper Age } \\
\end{array}$ & $\begin{array}{c}\text { Jamno (eneolitik/Copper Age?), Krapina, Koškovec (ene- } \\
\text { olitik/Copper Age?) }\end{array}$ \\
\hline $\begin{array}{l}\text { čekići s rupom za nasad drš- } \\
\qquad \mathrm{ka/} \\
\text { hammers with holes for haf- } \\
\quad \text { ting (tab. 6) }\end{array}$ & $\begin{array}{c}\text { Neolitik/Neolithic - sopotska k./Sopot c.; } \\
\text { Eneolitik/Copper Age - lasinjska k./Lasinja } \\
\text { c., retzgajarska k./Retz-Gajary c., vučedol- } \\
\text { ska k./Vučedol c.; } \\
\text { Brončano doba/Bronze Age; } \\
\text { Željezno doba/Iron Age }\end{array}$ & $\begin{array}{l}\text { Cerje Tužno (lasinjska k./Lasinja c.?), Jamno, Jerovec, } \\
\text { Klenovnik, Kloštar Ivanić, Mače, Mihovljan, Podsused } \\
\text { (sopotska k./Sopot c.?), Poljanica, Sv. Šimun, Zlatar }\end{array}$ \\
\hline $\begin{array}{l}\text { sjekire-čekići s rupom za na- } \\
\text { sad drška/ } \\
\text { axe-hammers with holes for } \\
\text { hafting (tab. 7) }\end{array}$ & $\begin{array}{l}\text { Neolitik/Neolithic; } \\
\text { Eneolitik/Copper Age; } \\
\text { Brončano doba/Bronze Age; } \\
\text { Željezno doba/Iron Age }\end{array}$ & $\begin{array}{l}\text { Biškupec, Blaguše, Brdovec, Hum Sv. Martin, Jalševec, } \\
\text { Jamno, Konjšćina, Kršćenovec, Oštri vrh, Radoboj, Ratko- } \\
\text { vec, Šemnica, Štefanec, Zajezda, Zlatar, Hrašćina, Novaki, } \\
\text { Sutinske Toplice, Sv. Ivan Zelina, Vinično, Sv. Ilija Obrež, } \\
\text { Sutinsko, Zajezda }\end{array}$ \\
\hline pršljeni/whorls (tab. 9) & Neolitik/Neolithic & $\begin{array}{l}\text { Kraljev vrh (sopotska k./Sopot c., korenovska k./Kore- } \\
\text { novo c.?), Miljana (sopotska k./Sopot c., korenovska k./ } \\
\text { Korenovo c.?), Zlatar, Martinci, Pakasin }\end{array}$ \\
\hline $\begin{array}{l}\text { brusovi/whetstones } \\
\text { (tab. 9) }\end{array}$ & $\begin{array}{c}\text { Neolitik/Neolithic - starčevačka k./Starče- } \\
\text { vo c., sopotska k./Sopot c.; } \\
\text { Brončano doba/Bronze Age }\end{array}$ & Kašina, Konjšćina \\
\hline motike/hoes (tab. 9) & $\begin{array}{c}\text { Eneolitik/Copper Age - lasinjska k./Lasinja } \\
\text { c. }\end{array}$ & Čulinec (lasinjska k./Lasinja c.?), Poljana \\
\hline
\end{tabular}

Tab. 12 Okvirna datacija proučavanih lokacija na temelju tipova nalaza i analogija s dobro datiranim nalazištima (autorica: Đukić 2017) Tab. 12 Approximate dating of the studied locations based on find types and analogies from well-dated sites (author: Đukić 2017)

retzgajarskom i vučedolskom kulturom (Dimitrijević 1979b: 162, 296, 357). Ipak, i u kasnijim se razdobljima pojavljuje oruđe bez rupe za nasad drška, kao što pokazuju nalazi sjekire i raznih gladilica s brončanodobne gradine Špičak kod Bojačnog (Pavišić 2011: 135).

Glačane kamene sjekire s rupom za nasad druga su skupina nalaza po brojnosti među analiziranim nalazima (tab. 4). U ovoj kategoriji nalaze se predmeti kojima je stražnji dio zaravnjen ili zaobljen, a prednji sužen u oštricu. Predmeti su uvršteni u ovu kategoriju jer na njihovim stražnjim ulomcima nije bilo tragova koji bi ukazivali na to da se predmet
Korenovo cultures (Težak-Gregl 1993: 27), but also in the Copper Age Lasinja, Seče (Marković 1985: 11), Retz-Gajary and Vučedol cultures (Dimitrijević 1979b: 162, 296, 357). However, non-perforated tools also appear in later periods, as demonstrated by the finds of axes and various polishers from the Bronze Age hill fort of Špičak near Bojačno (Pavišić 2011: 135).

Polished stone axes with holes for hafting are the second most numerous group of finds in the analysed material (Tab. 4). This category includes finds that have a straight or rounded back end, and a front end that narrows down into a blade. The finds were placed in this category because 
koristio i kao sjekira i kao čekić. Ove sjekire su, osim u neolitiku (Balen et al. 2002: 23), rabljene i u eneolitiku (Dimitrijević 1961: T. XIII: 93; Balen 2003: 50; Šimek 1986: 80; Kušan Špalj, Nemeth-Ehrlich 2010: 110, 124, sl. 26; Kovačević 2010: 74, T. 11: 7), a moguće ih je pratiti u ranome brončanom dobu (Tkalčec 1999: 19) i kasnijim razdobljima. Primjerice, lokalitet Bojačno Selo kod Klanjca je gradinsko naselje koje je, na temelju keramike i naseobinskih pokazatelja, datirano u vrijeme od kasnoga brončanoga do mlađega željeznoga doba (Pavišić 1986: 80). Ovo je najzanimljivija kategorija nalaza u smislu reupotrebe predmeta jer je nekoliko primjeraka dorađivano ili pak sasvim prenamijenjeno. Primjerice, nalazi iz Jazbine (P-4225), Marije Bistrice (P-1810; T. 8: 2) i Drenovog Boka (P-21298) nikada nisu dovršeni, a sjekira $\mathrm{S}$ rupom za nasad iz Bedekovčine (P-1714; T. 8: 4) naknadno je pretvorena u kalup za lijevanje šila ili sličnih predmeta. Glačani kameni čekići vrlo su čest nalaz na prapovijesnim lokalitetima, a osnovna im je namjena bila udaranje (tab. 5-6; Antonović 2003: 56). Kao i u Hrvatskoj, čekići bez rupe za nasad drška pojavljuju se i u neolitiku Srbije, a i ondje se razlikuju oblikom te nisu zastupljeni u velikom broju, što se objašnjava na dva načina: a) nije bilo potrebe za čekićima u sklopu naselja; b) u tu svrhu su korišteni amorfni oblutci i drugi čvrsti materijali (Antonović 2003: 56). Dataciju ovih predmeta dodatno otežava i činjenica da izostanak rupe ne znači nužno da se radi o neolitičkim nalazima kao što pokazuju, primjerice, čekići bez rupe za nasad pronađeni u eneolitičkim slojevima špilje Vindije (Šimek et al. 2002: T. 1: 1-2, 6), a koji su tipološkim obilježjima gotovo istovjetni P-6471 (T. 4: 3) iz Jamnog i P-4228 iz Koškovca. lako bi se čekiće s rupom za nasad drška na temelju istraživanja lokaliteta Cerje Tužno, a gdje je pronađeno nekoliko glačanih kamenih sjekira i čepova od bušenja rupa na kamenome oruđu (Šimek 1978: 5), moglo pripisati eneolitičkoj lasinjskoj kulturi (Šimek 1986: 80-81; Šimek et al. 2002: T. 2), takvo se oruđe javlja i u neolitiku (Težak-Gregl 2001: 10), primjerice, glačani kameni čekići s rupom, poput P-5185 iz Podsuseda, pronađeni su i u kontekstu sopotske kulture na lokalitetu Otok kod Vinkovaca (Dimitrijević 1968: T. XIX: 26; 1979a: 291, T. XLIX: 9). Posebno valja istaknuti reupotrebu ovoga tipa predmeta. Primjerice, na probušenome čekiću iz Mihovljana (P-1723) uočena je sekundarna obrada u vidu dodatnoga glačanja i niza kratkih paralelnih linija na dijelu predmeta gdje je na originalnom nalazu oruđa bila rupa, što sugerira moguću reupotrebu predmeta kao brusa za brušenje duguljastih (metalnih?) predmeta.

Kategorija sjekira-čekića s rupom za nasad drška definirana je na temelju prisutnosti tragova korištenja na stražnjem i prednjem dijelu, odnosno oštrici, što znači da su predmeti korišteni i kao sjekire i kao neka vrsta udarača/čekića (tab. 7). Ovakvi predmeti nazivani su čekićastim sjekirama, kakve su pronalažene u kontekstima eneolitičke lasinjske, retzgajarske i vučedolske kulture (Dimitrijević 1979b: 162, 296, 357).

U kategoriju neodredivih tipova oruđa većinom su uvršteni necjeloviti predmeti, odnosno njihovi prednji ili stražnji ulomci (tab. 8). Izuzev ovih, važan je i nalaz čepa od bušenja takve vrste oruđa (P-1774) koji potječe s prostora there were no traces of use on their back ends that would indicate the tools were used as both axes and hammers. These axes were used not only in the Neolithic Age (Balen et al. 2002: 23), also used in the Copper Age (Dimitrijević 1961: PI. XIII: 93; Balen 2003: 50; Šimek 1986: 80; Kušan Špalj, Nemeth-Ehrlich 2010: 110, 124, Fig. 26; Kovačević 2010: 74, Pl. 11: 7), and can even be traced to the Early Bronze Age (Tkalčec 1999: 19), as well as later periods. For example, the site of Bojačno Selo near Klanjec is a hill fort settlement that was dated to the period between the Late Bronze and the Early Iron Age based on the pottery and indicators of habitation (Pavišić 1986: 80). This is the most interesting category of finds in the sense of item reuse, seeing as several finds were additionally processed, and even completely reallocated. For instance, the finds from Jazbina (P-4225), Marija Bistrica (P-1810; Pl. 8: 2) and Drenov Bok (P-21298) were never finished, and the axe with a hole for hafting from Bedekovčina (P-1714; PI. 8: 4) was subsequently turned into a mould for casting awls or similar objects.

Polished stone hammers are a very common find on prehistoric sites, and their primary function was striking (Tabs. 5-6; Antonović 2003: 56). Like in Croatia, non-perforated polished stone hammers appear in the Neolithic of Serbia, where they display a variety of shapes and are also not found in large numbers - a fact explained in two ways: a) there was no need for hammers in settlements; b) amorphous pebbles and other firm materials were used for the same purpose (Antonović 2003: 56). The dating of these finds is made even more difficult by the fact that the lack of a hole does not mean they were necessarily used in the Neolithic, as shown by the non-perforated hammers discovered in the Copper Age layers of the Vindija cave (Šimek et al. 2002: T. 1: $1-2,6)$, which display typological features almost identical to P-6471 (T. 4: 3) from Jamno and P-4228 from Koškovec. The perforated hammers discovered during the excavations of the Cerje Tužno site, that also yielded several polished stone axes and corks from making holes in stone tools (Šimek 1978: 5), could be ascribed to the Copper Age Lasinja culture (Šimek 1986: 80-81; Šimek et al. 2002: PI. 2), but such tools also appear in Neolithic contexts (Težak-Gregl 2001: 10). For example, perforated polished stone hammers, such as P-5185 from Podsused, were also discovered in the context of the Sopot culture at Otok near Vinkovci (Dimitrijevic 1968: PI. XIX: 26; 1979a: 291, PI. XLIX: 9). The reuse of these finds should be particularly emphasized. For instance, the perforated hammer from Mihovljan (P-1723) displays traces of secondary processing in the sense of additional polishi$\mathrm{ng}$, and a series of short parallel lines where the original hole was placed in the find, suggesting that it was reused as a whetstone for honing elongated (metal?) objects.

The category of axe-hammers with holes for hafting was defined on the basis of the presence of traces of use on both the back end and the front end (the blade), indicating that the finds were used both as axes and as some kind of strikers/hammers (Tab. 7). Such finds are sometimes called hammer-like axes, and have been found in the context of Copper Age Lasinja, Retz-Gajary and Vučedol cultures (Dimitrijević 1979b: 162, 296, 357).

The category of indeterminable tool types mostly includes incomplete finds, i.e. front or end fragments (Tab. 8). Apart from these, it is important to note the cork (P-1774) 
Hrvatskoga zagorja jer takvi predmeti govore o tehnologiji izrade oruđa s rupom za nasad drška (Balen 2003: 52).

Pršljeni su pronađeni na pet lokacija, a razlikuju se po obliku i dimenzijama te prisutnosti ili izostanku rupe u sredini (tab. 9). Primjerci pripisani prvoj od tri definirane skupine, P-1813 iz Kraljevog Vrha i P-21311 iz Miljane, oblikom podsjećaju na glačani kameni disk s lokaliteta Krčavina kod Novih Perkovaca koji je datiran u vrijeme sopotske kulture (Botić 2011: 228), kao i na kamene alke korenovske kulture s lokaliteta Dobrovac - Kućište I (Nodilo 2014: 60, kat. br. 155-156), kamenu alku sopotske kulture s lokaliteta Zarilac Grabaračke livade (Pavličić 2014: 113, kat. br. 314) te kameni uteg sopotske kulture s lokaliteta Selci Đakovački - KaznicaRutak (Rajković et al. 2010: 100, sl. 10a).

Kamene motike nisu čest nalaz na pretpovijesnim lokalitetima (tab. 9), a predmet sličan onome iz Čulinca pronađen je u Dubrancu, a određen je kao motika zbog plosnatoga oblika i grube obrade te datiran u vrijeme lasinjske kulture (Balen 1998: 17, T. VIII: 5).

Kamene kugle (tab. 11) mogle su biti korištene za mljevenje, udaranje ili pak kao rastirači (Garašanin 1979: 123). Plitki žljebovi ustanovljeni na poprečnim dijelovima predmeta iz Marije Bistrice i Zlatara ustanovljeni su na predmetu iz Bora u Vojvodini te na predmetima iz ranovinčanskih slojeva na Rudnoj Glavi. Predloženo je da oni nastaju prilikom korištenja predmeta kao njihala na nekoj vrsti užeta u prapovijesnim rudnicima bakra (Jovanović 1979: 45, T. IV: 5a; Antonović 2003: 62-63). Ovakvi predmeti nalaženi su u Đerdapu i istočnoj Srbiji, gdje su nazivani batovima za razbijanje tvrdih materijala poput zemlje ili kamena, a opisivani su kao obluci kojima nije mijenjan prirodni oblik, već im je samo po sredini iskucavanjem napravljen žlijeb (Antonović 2003: 62). Ovi predmeti mogli su poslužiti kao brusovi za izradu i brušenje koštanih ili metalnih šila, ili su mogli biti korišteni kao projektili za lov praćkom ili sličnim izbacivačem.

Mramorna perla slična onoj iz Gotalovca pronađena je na Vinči (Antonović 2003: 68). Različite uglačane kamene pločice mogle su služiti kao palete za drobljenje i mrvljenje školjaka i puževih kućica čiji se prah koristio u postupku inkrustiranja ukrasa na keramici ili za drobljenje različitih minerala u dobivanju boja (Težak-Gregl 2001: 8). Neki od ovih predmeta interpretirani su kao glačalice, primjerice nalaz pripisan sopotskoj kulturi s lokaliteta Stari Perkovci - Debela šuma (Balen 2014: 89, kat. br. 244).

Kameno oruđe s abrazivnim svojstvima uključuje žrvnjeve, rastirače i brusove (tab. 10-11). Kameni žrvnjevi su predmeti korišteni za drobljenje zrnja biljaka, većinom žitarica, koji imaju barem jednu zaravnjenu stranu (Antonović 2003: 61), a nalaze se među najzastupljenijim vrstama kamenih nalaza na neolitičkim i eneolitičkim nalazištima. Obično su u obliku ravne ploče ili pak imaju jednu zaravnjenu stranu. Uz njih se često nalaze i rastirači kojima se mrvi sjeme (Balen 2003: 49-50). Na lokalitetu Ivandvor - Šuma Gaj pronađeno je deset žrvnjeva koji se datiraju u vrijeme sopotske kulture (Balen et al. 2009: 30; T. 2: 2). Ipak, žrvanj istoga oblika kao i ovdje prezentirani primjerci, pronađen je na zagrebačkome Gradecu, a datiran je u kasno brončano doba (Majnarić-Pandžić 2009: 203). U Gotalovcu je pronađen i jedini definirani left after perforating a polished stone tool that originates from the Hrvatsko Zagorje region, because such finds attest to the technology of producing tools with holes for hafting (Balen 2003: 52).

Whorls were discovered at five locations, and they differ in shape, size, and the presence or lack of a hole in the middle (Tab. 9). The finds ascribed to the first out of the three defined groups, P-1813 from Kraljev Vrh and P-21311 from Miljana, have a shape similar to the polished stone disk from Krčavina site near Novi Perkovci that was ascribed to the Sopot culture (Botić 2011: 228), stone links of the Korenovo culture from Dobrovac - Kućište I (Nodilo 2014: 60, cat. no. 155-156), the stone link of the Sopot culture from Zarilac - Grabaračke Livade (Pavličić 2014: 113, cat. no. 314), and the stone weight of the Sopot culture from Selci Đakovački Kaznica-Rutak (Rajković et al. 2010: 100, Fig. 10a).

Stone hoes are not a frequent find on prehistoric sites (Tab. 9). A find similar to the one from Čulinec was discovered at the Lasinja culture site of Dubranec, and was defined as a hoe because of its flat shape and coarse processing (Balen 1998: 17, PI. VIII: 5).

Stone spheres (Tab. 11) could have been used for grinding, striking, or as handstones (Garašanin 1979: 123). The shallow gauges recorded on the lateral sides of the finds from Marija Bistrica and Zlatar were also noted on the find from Bor in Vojvodina, and on the finds from the Early Vinča culture layers at Rudna Glava, where it was suggested that such traces were created when the find was used as a pendulum on some kind of rope in prehistoric copper mines (Jovanović 1979: 45, PI. IV: 5a; Antonović 2003: 62-63). Such finds were discovered in the Đerdap region and eastern Serbia, where they were defined as strikers for crushing hard materials such as soil or stone, and were described as pebbles that were only modified by embossing a gauge around their middle (Antonović 2003: 62). These finds could have been used as whetstones for making and honing bone or metal awls, as well as projectiles for hunting with slings or similar throwing devices.

A marble bead similar to the one from Gotalovec was discovered at Vinča (Antonović 2003: 68). Various polished stone tiles could have been used as platforms for crushing and grinding shells or snail shells that could then be used as a powder for encrusting decorations on pottery, or for crushing different minerals to acquire paint (Težak-Gregl 2001: 8). Some of these finds were interpreted as polishers, such as the find ascribed to the Sopot culture from Stari Perkovci - Debela Šuma (Balen 2014: 89, cat. no. 244)

Stone tools with abrasive properties include grindstones, handstones and whetstones (Tabs. 10-11). Stone grindstones are items used to crush plant seeds, mostly cereals, that have at least one straight side (Antonović 2003: 61), and are among the most represented types of stone finds on Neolithic and Copper Age sites. Usually they are shaped as flat boards, or have one straight side, and are often found alongside handstones used to grind the seeds (Balen 2003: 49-50). The site of Ivandvor - Šuma Gaj yielded ten grindstones ascribed to the Sopot culture (Balen et al. 2009: 30; PI. 2: 2). However, a grindstone similar to the ones presented herein was discovered at Gradec in Zagreb and dated to the Late Bronze Age (Majnarić-Pandžić 2009: 203). Gotalovec yielded the only find defined as a handstone - a 
rastirač - tip koji se ne može definirati kao kameno oruđe u pravom smislu jer svoj oblik nije dobio svjesnom ljudskom obradom, već su njegove uglačane strane vjerojatno nastale upotrebom (Antonović 2003: 60). Rastirači ovoga oblika pronalaze se u kontekstu sopotske kulture, primjerice na lokalitetu Samatovci kod Osijeka (Balen et al. 2002: 20), ali i u kontekstu starčevačke kulture (Garašanin 1979: 123). Brusove izduženoga oblika i pravokutnoga presjeka s rupom za ovjes (tab. 9; 11) moguće je datirati u razdoblje neolitika, kao što pokazuju nalazi šest brusova s eponimnoga lokaliteta sopotske kulture (Krznaić-Škrivanko 2002: 38; 2003: 65), eneolitika, ali i u kasno brončano doba jer je gotovo jednaki primjerak brusa pronađen na lokalitetu Vukovar - Lijeva Bara u muškome grobu 269 koji je datiran u 2. pol. 8. st. pr. Kr. (Vinski-Gasparini 1973: 164; T. 125: 3b). Ipak, u prilog ranijoj dataciji govore i nalazi brusova iz ranovinčanskih i ranostarčevačkih slojeva s lokaliteta Petnica, Čučuge, Grivac, odnosno Velesnica u Srbiji, za koje se pretpostavlja da su korišteni za finu doradu koštanih predmeta kao i za oštrenje koštanih igala i šila (Antonović 2003: 60).

Na osnovi brojnih petrografskih analiza ustanovljeno je kako su vodeće sirovine za izradu glačanih artefakata u europskom neolitiku i eneolitiku bile zeleni škriljevac, amfibolit i bazalt, a u nešto manjoj mjeri žadeit, eklogit i serpentinit (Marciuš 2017: 24-25; Paunović 2002: 11). Većina glačanoga oruđa pronađenog na hrvatskim nalazištima izrađena je od dijabaza, serpentinita, amfibolita, bazalta, tufa, gabra, kvarca, kvarcita i rožnjaka (Marciuš 2017: 24-25; Paunović 2002: 11). Uzimajući u obzir geografske i geološke značajke, moguća izvorišta sirovinskoga materijala u Hrvatskoj uglavnom su formacije koje se pojavljuju kao izdignute erodirane jezgre megastruktura izgrađenih od kristalinskih stijena (gnajs, amfiboliti, mikašisti) okruženih pokrovom tercijarnih i kvartarnih naslaga Panonskoga bazena, odnosno stijene koje tvore magmatsku grupu Hrvatskoga zagorja. Istovremeno izvorište dijela sirovinskoga materijala su naplavine riječnih tokova (Soča, Sava, Drava, Una, Bosna, Neretva itd.) koji su nosili velike količine valutica i kamenih blokova nastalih trošenjem vulkanskih i metamorfnih stijena Slovenije, odnosno Bosne i Hercegovine (Paunović 2002: 11). Većina ovdje analiziranoga oruđa izrađena je od relativno lako dostupnih stijena koje su porijeklom s Medvednice ili obližnjih visinskih područja. ${ }^{24}$ Ipak, tek je mali broj primjeraka izrađen od kamena dostupnoga u neposrednoj bizini lokacija s kojih predmeti potječu, ukazujući na potrebu onodobnih populacija za kvalitetnom sirovinom, a samim time $\mathrm{i}$ za razvijanjem mreže trgovine i razmjene na veće ili manje udaljenosti. Među analiziranim oruđem uglavnom su zastupljene one izrađene od vapnenca, kvarcita i pješčenjaka različite starosti. Kao što je slučaj i u ostatku Hrvatske, radi se o materijalu koji potječe iz najbližih mogućih izvora (do 100 km udaljenosti), a iskorištavanja udaljenih ležišta i trgovina na daleke rute nisu uobičajeni (Težak-Gregl, Burić 2002: 17),

24Prema rezultatima petrogrfskih analiza koje je proveo pokojni dr.sc. Hrvoje Posilović iz Zavoda za geologiju Hrvatskoga geološkog instituta. type that cannot be defined as a stone tool in the proper sense, because it was not shaped by conscious human processing, but rather polished by use (Antonović 2003: 60). Handstones of this shape were discovered in the contexts of the Sopot culture, e.g. at Samatovci near Osijek (Balen et al. 2002: 20), but also the Starčevo culture (Garašanin 1979: 123). Elongated whetstones with a quadratic cross-section and a hole for hanging (Tab. 9; 11) can be dated to the Neolithic, as indicated by six finds from the eponymous site of the Sopot culture (Krznaić-Škrivanko 2002: 38; 2003: 65), the Copper Age, but also the Late Bronze Age, seeing as an almost identical whetstone was discovered in male grave 269 at Vukovar - Lijeva Bara that was dated to the second half of the $8^{\text {th }}$ century BC (Vinski-Gasparini 1973: 164; T. 125: 3b). However, an earlier dating is suppported by the finds of whetstones from the Early Vinča and Early Starčevo culture layers at Petnica, Čučuge, Grivac, and Velesnica in Serbia, which are assumed to have been used for the fine processing of bone artifacts and for honing bone awls and needles (Antonović 2003: 60).

Numerous petrographic analyses have revealed that the main raw materials used for polished artefact production in the European Neolithic and Copper Age periods include green slate, amphibolites and basalt, and to a lesser extent jadeite, eclogite and serpentine (Marciuš 2017: 24-25; Paunović 2002: 11). Most of the polished stone tools discovered at Croatian sites are made of diabase, serpentine, amphibolites, basalt, tuff, gabbro, quartz, quartzite and chert (Marciuš 2017: 24-25; Paunović 2002: 11). Considering the geographical and geological features, the possible sources of raw materials in Croatia are mostly formations that appear as elevated eroded cores of mega structures composed of crystalline rocks (gneiss, amphibolites, mica schists) surrounded by the tops of tertiary and quaternary deposits of the Pannonian basin, i.e. the rocks that form the magma group of Hrvatsko Zagorje. Contemporaneous sources of some of the raw materials include alluvial riverbeds (the Soča, Sava, Drava, Una, Bosna, Neretva, and other rivers) that transferred large amounts of clusters and stone blocks created by the erosion of volcanic and metamorphic rocks from Slovenia, or Bosnia and Herzegovina (Paunović 2002: 11). Most of the tools analysed herein are made of relatively easily available rocks originating from the Medvednica Mountain or near-by elevated areas. ${ }^{24}$ However, only a small number of finds is made of rocks that are available in the immediate vicinity of the locations of discovery, which indicates the need of those populations for high-quality raw materials, and the need to develop a network of trade and exchange spanning smaller or greater distances. The analysed material mostly includes tools made of limestone, quartzite and sandstone of different ages. As is the case in the rest of Croatia, these materials originated from the closest possible sources (up to $100 \mathrm{~km}$ ). The exploitation of more distant sources and long-distance trade routes are not common (Težak-Gregl, Burić 2002: 17), as indicated by the tool from Drenov Bok (P-21296) that is made of Triassic chert probably originating from the Papuk Mountain, or the perforated axe from Vinično (P-1697) that is made of serpentinized ultra-

24 Based on the results of petrograpic analyses conducted by the late Hrvoje Posilović, PhD, from the Department of Geology of the Croatian Geological Survey. 
kao što pokazuje oruđe iz Drenovog Boka (P-21296) koje je izrađeno od rožnjaka trijaske starosti koji bi porijeklom mogao biti s Papuka ili pak bušena sjekira iz Viničnog (P-1697) koja je izrađena od serpentiniziranoga ultrabazita kakvoga ima na području granice današnje Slovenije i Austrije te sjevernijim predjelima. Osim potrebe za prelaženjem većih ili manjih udaljenosti radi pribavljanja željene sirovine, određeni nalazi dodatno pokazuju važnost koju su prapovijesne populacije sjeverozapadne Hrvatske pridavale kamenome oruđu. Tijekom prapovijesti, pogotovo u razdobljima kada se kao osnovna sirovina za oruđe koristio kamen, reciklaža slučajno pronađenoga odbačenog oruđa (posebice na višeslojnim naseljima) nije bila rijetkost (Šošić Klindžić 2017: 38). Primjerice, uočena je potreba za dorađivanjem i ponovnim korištenjem sirovine za izradu drukčijeg alata - dlijeto iz Klenovca (T. 3: 2) prvotno je glačano, a sekundarno dorađivano lomljenjem. Slični slučajevi zabilježeni su i drugdje, primjerice na nalazima sopotske kulture: bat iz Samatovaca (Balen et al. 2002: 23), tesla s lokaliteta Donji Slatnik - Gajevi (Vrkić 2014: 30, kat. br. 71) ili pak nedovršeno oruđe s lokaliteta Stari Perkovci - Debela šuma (Balen 2014: 90, kat. br. 246). Osim toga, zabilježena je sekundarna obrada u vidu dodatnoga glačanja ulomka probušenoga čekića koji je naknadno korišten kao brus (Mihovljan, P-1723), ukazujući na maksimalno iskorištavanje dostupnih resursa kroz nekoliko faza ili čak razdoblja. Slična je situacija zabilježena i na primjeru probušene sjekire iz Bedekovčine (P-1714; T. 8: 4) koja je naknadno prepolovljena po dužini i korištena kao kalup za lijevanje šila ili sličnih predmeta. Praksa reupotrebe glačanoga kamenog oruđa na prostoru sjeverozapadne Hrvatske zadržala se gotovo do današnjih dana. Naime, ti predmeti koji se, kako to pokazuju i ovdje prikazani nalazi, često mogu naći na poljima, stavljani su na nadvratnik kuće kako bi se obranila od udara groma "jer grom ne udara u isto mjesto dva puta", a za sjekire se smatralo da su nastale upravo udarom groma u zemlju (Belaj 1998; Šošić Klindžić 2017: 40). Osim reupotrebe, ovakvi tragovi mogu biti i indikatori tehnologije izrade glačanoga kamenog oruđa, odnosno procesa u kojem se određene vrste stijena prvo obrađuju lomljenjem kako bi se smanjila količina vremena potrebna za finalno oblikovanje predmeta glačanjem. Takvi su slučajevi česti u neolitiku Srbije, poglavito u kontekstu vinčanske kulture (Antonović 2014: 79, sl. 1: 80; sl. 2).

\section{ZAKLJUČNA RAZMATRANJA}

Glačano kameno oruđe dugotrajna je i česta pojava u prapovijesti sjeverozapadne Hrvatske. Većina lokaliteta, odnosno lokacija koje su zastupljene u ovome radu nisu nikada istraživane, što znači da ih je nemoguće precizno kronološki i kulturološki opredijeliti. Podaci iz inventarnih knjiga u većini slučajeva vrlo su oskudni kada je riječ o preciznome mjestu pronalaska predmeta, a podaci o nabavi više govore o broju arheologa entuzijasta i kolekcionara nego o samim predmetima. Ipak, moguće je zaključiti da se glačano kameno oruđe na prostoru sjeverozapadne Hrvatske, kao i u basite that can be found on the border of today's Slovenia and Austria and areas north of it. Apart from the need to cross smaller or larger distances to obtain the desired raw materials, certain finds additionally stress the importance given to stone tools by prehistoric communities that inhabited northwestern Croatia. During prehistory, especially in the periods when stone was used as the basic raw material for tool production, recycling previously discarded tools (especially on multi-layer sites) was not rare (Šošić Klindžić 2017: 38). For example, there was the need to re-process and reuse raw materials for producing different tools - the chisel from Klenovec (PI. 3: 2) was originally polished and subsequently knapped. Similar cases have been recorded elsewhere; for example, among the finds of the Sopot culture: a hammer from Samatovci (Balen et al. 2002: 23), an adze from Donji Slatnik - Gajevi (Vrkić 2014: 30, cat. no. 71), or an unfinished tool from Stari Perkovci - Debela Šuma (Balen 2014: 90 , cat. no. 246). Moreover, secondary processing in the sense of additional polishing has been recorded for a perforated hammer that was subsequently used as a whetstone (Mihovljan, P-1723), pointing to the maximized use of the available raw materials through several phases or even periods. Something similar was recorded for the perforated axe from Bedekovčina (P-1714; PI. 8: 4) that was additionally split length-wise and used as a mould for casting awls or similar items. The practice of reusing polished stone tools in northwestern Croatia has been around almost to this day. In fact, these finds, as demonstrated by the material presented herein, were often found on fields and placed on the crossbeams of houses as protection from lightning because "lightning never strikes the same place twice," and axes were considered to be the result of lightning hitting the ground (Belaj 1998; Šošić Klindžić 2017: 40). Apart from the reuse, the described traces can indicate polished stone tool production technology, i.e. the process wherein certain kinds of rocks were first knapped in order to reduce the amount of time necessary for the final shaping of the item by polishing. Such cases have been frequently recorded in the Serbian Neolithic, especially in the context of the Vinča culture (Antonović 2014: 79, Fig. 1: 80; Fig. 2).

\section{CONCLUDING REMARKS}

Polished stone tools are a long-lasting and common occurrence in the prehistory of northwestern Croatia. Most represented sites or locations have never been excavated, making it impossible to precisely define them chronologically and culturally. The data from inventory books is often scarce when it comes to the precise place of discovery, and the data on find acquisitions speaks more about the number of enthusiast archaeologists and collectors than about the finds. However, it is possible to conclude that polished stone tools in northwestern Croatia and other regions, including the neighbouring Serbia, appeared in completely developed forms, because the earliest sites yielded all of the tool types that also appear in later periods (Antonović 2003: 113).

Based on the distribution of finds (Map 1), it is possible to suggest narrower areas for future field surveys and archaeological research. In the Krapina-Zagorje County, the area around Marija Bistrica is the most interesting, with four defined locations, and systematic field surveys should be 
ostalim područjima, pa i u susjednoj Srbiji, javlja u potpuno razvijenom obliku, jer su i na najranijim lokalitetima zastupljeni svi oblici koji se pojavljuju i u kasnijim vremenima (Antonović 2003: 113).

Temeljem distribucije nalaza (karta 1) moguće je predložiti uže prostore za buduća sustavna rekogosciranja i arheološka istrživanja. U Krapinsko-zagorskoj županiji zanimljiv je prostor oko Marije Bistrice gdje su definirane čak četiri lokacije, a sustavna rekognosciranja valjalo bi započeti na središnjim prostorima općina Radoboj, Mihovljan i Mače, jugozapadnome dijelu općine Zlatar te u središnjem dijelu općine Marija Bistrica. U Varaždinskoj županiji najveća koncentracija nalaza uočena je na graničnome području između općina Ivanec i Maruševec (pet lokacija) te na sjevernom dijelu općine Bednja (četiri lokacije na granici sa Slovenijom), zbog čega bi upravo ta područja trebala biti polazišna točka za buduće sustavne terenske preglede i istraživanja.

Muzejska građa analizirana u ovome radu podijeljena je u osam kategorija - glačana kamena dlijeta i bradve (14), sjekire trapezastoga oblika (22), čekići (21), sjekire-čekići s rupom za nasad drška (28), sjekire s rupom za nasad drška (21), čekići i sjekire ili sjekire-čekići s rupom za nasad drška (19), žrvnjevi (4) i ostalo (38). S obzirom na vrstu i tipove glačanoga kamenog oruđa, većinom ih se može definirati kao neolitička ili eneolitička (tab. 12; Težak-Gregl 2001: 10-15; Balen-Letunić 1981), iako nalazi brusova i utega idu u prilog široj dataciji u smislu brončanoga i ranoga željeznog doba (Vinski-Gasparini 1973: 164). U prijašnjim je objavama zaključeno kako je nalaze teško kulturološki i kronološki odrediti, no da treba pretpostaviti da su ostavština nosilaca neolitičkih starčevačke, linearnotrakaste i sopotsko-brezovljanske i kasne sopotske kulture, ili pak bakrenodobnih lasinjske, retzgajarske ili vučedolske kulture (Balen-Letunić 1981). Nalazi s kasnobrončanodobnih gradina pak ukazuju i na mogućnost dužega trajanja ovoga tipa nalaza koji su mogli biti izrađeni u tom vremenu ili su pak oni iz ranijih razdoblja bili sekundarno korišteni. Nažalost, prethodne zaključke nije moguće precizirati niti proširiti zbog nedostatka, barem probnih, ako ne i sustavnih istraživanja kojima bi se dobio uvid u više vrsta pokretnih arheoloških nalaza koji bi omogućio preciznije datiranje od onoga predloženog u tab. 12.

Pravu sliku o kulturološkome i kronološkom opredjeljenju analiziranih lokaliteta sjeverozapadne Hrvatske bit će moguće uspostaviti tek nizom sustavnih rekognosciranja cijeloga, a osobito onih područja gdje je utvrđena veća frekvencija nalaza (karta 1) te nizom arheoloških i interdisciplinarnih istraživanja. U svakome slučaju, ovdje predstavljeni opisi i dimenzije svih analiziranih nalaza mogu poslužiti kao dobar temelj za proučavanje tehnologije glačanih kamenih izrađevina na prostoru sjeverozapadne, ali i ostatka Republike Hrvatske. ${ }^{25}$

25 Table je nacrtala Miljenka Galić iz Arheološkoga muzeja u Zagrebu 2013. godine, a dodatno ih je obradio Marin Mađerić 2017. godine. started in the central parts of the Radoboj, Mihovljan and Mače municipalities, the southwestern parts of the Zlatar municipality, and the central part of the Marija Bistrica municipality. In the Varaždin County, the largest concentration of finds was noted on the border between the Ivanec and Maruševec municipalities (five locations), and the northern part of the Bednja municipality (four locations on the Slovenian border), making these areas the starting point for future systematic field surveys and research.

The museum material analysed in this paper was divided into eight categories - polished stone chisels and adzes (14), trapezoidal axes (22), hammers (21), axe-hammers with holes for hafting (28), axes with holes for hafting (21), hammers and axes or axe-hammers with holes for hafting (19), grindstones (4), and other (38). Considering the kind and types of polished stone tools, they can mostly be defined as Neolithic or Copper Age finds (Tab. 12; Težak-Gregl 2001: 10-15; Balen-Letunić 1981), although whetstones and weights suggest a wider dating to the Bronze and Early Iron Age (Vinski-Gasparini 1973: 164). Previous publications noted that the finds are difficult to define in the sense of chronology and culture, but that they were probably left by the Neolithic Starčevo, Linear Pottery, Sopot-Brezovljani and Late Sopot cultures, or by the Copper Age Lasinja, RetzGajary or Vučedol cultures (Balen-Letunić 1981). Finds from Late Bronze Age hill forts, however, indicate the possibility that these types of items were in use longer and could have been produced at that time, or items from older periods could have been reused. Unfortunately, the conclusions of previous authors cannot be made more precise or wider due to the lack of test excavations, not to mention systematic excavations that would provide insights into different kinds of movable archaeological material that would enable a more precise dating than the one suggested in Tab. 12.

The full picture of the chronological and cultural attribution of the analysed locations in northwestern Croatia will be made possible only after a series of systematic field surveys of the entire area, especially those parts with a larger frequency of finds (Map 1), and after archaeological and inter-disciplinary research. In any case, the presented descriptions and dimensions of everything analysed can serve as a good foundation for the study of polished stone tool production technology in northwestern Croatia and the rest of Croatia. ${ }^{25}$

\section{Prijevod / Translation Ana Đukić \\ Lektura / Proofreading Marko Maras}

\footnotetext{
25 The plates were drawn by Miljenka Galic from the Archaeological Museum in Zagreb in 2013, and were additionally processed by Marin Mađerić in 2017.
} 


\section{LITERATURA / BIBLIOGRAPHY}

Antonović, D. 2003, Neolitska industrija glačanog kamena u Srbiji, Beograd.

Antonović, D., Đorđević, A. V. 2003, Tipologija perforiranog kamenog oruđa iz Srbije, Zbornik Narodnog muzeja, Arheologija, Vol. XX-1, 47-69.

Antonović, D. 2014, Manufacturing of stone axes and adzes in Vinča culture, in: Archaeotechnology: studying technology from prehistory to the Middle Ages, Vitezović S., Antonović D. (eds.), Srpsko arheološko društvo, Beograd, 77-88.

Balen, J. 1998, Nalazište lasinjske kulture u Dubrancu, Vjesnik Arheološkog muzeja u Zagrebu, Vol. XXX-XXXI (1997-1998), 13-31.

Balen, J. 2003, Keramika i metal - neolitik i eneolitik, in: Karavanić I., Balen J., Osvit tehnologije, katalog izložbe, Arheološki muzej u Zagrebu, Zagreb, 48-53.

Balen, J. 2014, Stari Perkovci - Debela šuma, in: Darovi zemlje - neolitik između Save, Drave i Dunava, drugi dio - kataloške jedinice, Balen J. Hršak T., Šošić-Klindžić R. (eds.), Zagreb, 89-91.

Balen, J., Balen, D., Kurtanjek, D. 2002, Kamene alatke s nalazišta Samatovci iz fundusa Arheološkog muzeja u Zagrebu, Opuscula archaeologica, Vol. 26, 19-37.

Balen, J., Bilić, T., Bunčić, M., Drnić I., Solter, A. 2009, Rezultati zaštitnih istraživanja na lokalitetu Ivandvor - Šuma Gaj, Vjesnik Arheološkog muzeja u Zagrebu, Vol. XLII, 23-72.

Balen-Letunić, D. 1981, Kameno oružje i oruđe s područja Hrvatskog zagorja - zbirka Pečornik, Godišnjak gradskog muzeja u Varaždinu, Vol. 6, 5-17.

Biró, K., 1994, The role of the lithic finds in the Neolithic archaeology of the Alföld region, Jósa András Múzeum Évkönyve, Vol. 36, 159-165.

Botić, K. 2011, O kamenom nalazu iz Novih Perkovaca kod Đakova, in: Panonski prapovijesni osviti, Zbornik radova posvećenih Korneliji Minichreiter uz 65. obljetnicu života, Dizdar M. (ed.), Institut za arheologiju, Zagreb, 227-245.

Brukner, B. 1979, Körös grupa, in: Praistorija jugoslavenskih zemalja. II: Neolitsko doba, Benac A. (ed.), Sarajevo, 213-226.

Bunčić, M. 2009, Kameni nalazi starčevačke kulture s nalazišta Galovo u Slavonskom Brodu, Prilozi Instituta za arheologiju u Zagrebu, Vol. 26, 291-308.

Dimitrijević, S. 1961, Problem neolita i eneolita u sjeverozapadnoj Jugoslaviji, Opuscula Archaeologica, Vol. 5, 5-78.

Dimitrijević, S. 1968, Sopotsko-lenđelska kultura, Monographiae Archaeologicae, Filozofski fakultet Sveučilišta u Zagrebu, Arheološki institut, Zagreb.

Dimitrijević, S. 1979a, Sjeverna zona, in: Praistorija jugoslavenskih zemalja. II: Neolitsko doba, Benac A. (ed.), Sarajevo, 229-362.

Dimitrijević, S. 1979b, Lasinjska kultura, Vučedolska kultura i vučedolski kulturni kompleks, Retz-Gajary kultura, in: Praistorija jugoslavenskih zemalja. III: Eneolitsko doba, Benac A. (ed.), Sarajevo, 137-181; 267-341; 343-379.

Dizdar, M., Krznarić-Škrivanko, M. 2000, Prilog poznavanju arhitekture starčevačke kulture u Vinkovcima, Vjesnik Arheološkog muzeja u Zagrebu, Vol. XXXII-XXXIII (1999-2000), 7-22.

Feletar, D. 1986, Geografske osobine sjeverozapadne Hrvatske, in: 40 godina arheoloških istraživanja u sjeverozapadnoj Hrvatskoj, katalog izložbe, Balen-Letunić D., Demo Ž., Homen Z., Jakovljević G., Marković Z., Sokol V., Šimek M., Tomičić Ž. (eds.), Muzejsko društvo sjeverozapadne Hrvatske, Koprivnica, 4-5.

Garašanin, M. 1979, Centralnobalkanska zona, in: Praistorija jugoslavenskih zemalja. II: Neolitsko doba, Benac A. (ed.), Sarajevo, 79-212.

Ivanković, A. 2014, Kukunjevac - Brod, in: Darovi zemlje - neolitik između Save, Drave i Dunava, drugi dio - kataloške jedinice, Balen J., Hršak T., Šošić-Klindžić R. (eds.), Zagreb, 57-58.

Jovanović, B. 1979, Rudarstvo i metalurgija neolitskog perioda Jugoslavije, in: Praistorija jugoslavenskih zemalja. III: Eneolitsko doba, Benac A. (ed.), Sarajevo, 27-54.

Jurić, I., Bogunović, M., Đikić, M., Balen, J. 2001, Značajke poljoprivredne proizvodnje u naseljima starčevačke kulture na prostoru između Vinkovaca i Slavonskog broda u Hrvatskoj, Društvena istraživanja, Vol. 10, 1131-1158.

Kalicz, N., Virág, M. Z., Biró, T. K. 1998, The northern periphery of the Early Neolithic Starčevo culture in south-western Hungary: a case study of an excavation at Lake Balaton, Documenta Praehistorica,
Vol. XXV, 151-187.

Karavanić, I., Balen, J. 2003, Osvit tehnologije, Arheološki muzej u Zagrebu, Zagreb.

Klemenc, J., Saria, B. 1939, Archaeologische Karte von Jugoslavien: Blatt Rogatec, Zagreb.

Kovačević, S. 2010, Karakteristični nalazi iz naselja kasne faze starijeg željeznog doba Zbelava-pod lipom, in: Arheologija varaždinskog kraja i srednjeg Podunavlja, Izdanja Hrvatskog arheološkog društva, Vol. 28, Varaždin, 57-105.

Kozina, D. 2007, Općina Radoboj, Općina Radoboj, Radoboj.

Krznarić-Škrivanko, M. 1997, Prapovijesno naselje na Ervenici u Vinkovcima, Opuscula Archaeologica, Vol. 21, 205-215.

Krznarić-Škrivanko, M. 2002, Peta i šesta sezona sustavnog istraživanja gradine Sopot (godina 2000. i 2001.), Obavijesti Hrvatskog arheološkog društva, Vol. XXXIV/1, 36-45.

Krznarić-Škrivanko, M. 2003, Neki naseobinski pokazatelji na eponimnom nalazištu sopotske kulture, Opuscula Archaeologica, Vol. 27, 63-69.

Kušan Špalj, D., Nemeth-Ehrlich, D. 2010, Aquae lasae - Varždinske Toplice, Arheološka istraživanja rimskog izvorišnog bazena i okolnog prostora, in: Arheologija varaždinskog kraja i srednjeg Podunavlja, Izdanja Hrvatskog arheološkog društva, Vol. 28, 107-129.

Ljubić, Š. 1890, Popis arkeologičkoga odjela Narodnog zemaljskog muzeja u Zagrebu $1 / 1$

Ljubić, Š. 1889, Popis arkeologičkoga odjela Narodnog zemaljskog muzeja u Zagrebu, Odsjek 1, Sv. 1, Prehistorička zbirka, Zagreb, 26-192.

Majnarić-Pandžić, N. 2009, Zagrebački Gradec u prapovijesti, Vjesnik Arheološkog muzeja u Zagrebu, Vol. XLII, 199-212.

Marciuš, B. 2017, Kamen na prapovijesni način, Glačane kamene alatke iz fundusa Muzeja Međimurja Čakovec, katalog izložbe, Muzej Međimurja Čakovec, Čakovec.

Marković, Z. 1979, Uz problem istraživanja neolita i eneolita u sjeverozapadnoj Hrvatskoj, Muzejski vjesnik, Vol. 2, 37-39.

Marković, Z. 1985, Problem ranog eneolita u sjeverozapadnoj Hrvatskoj, Vjesnik Arheološkog muzeja u Zagrebu, Vol. XVIII, 1-34.

Marković, Z. 1986a, Istraživanja paleolitskih, mezolitskih, neolitskih, eneolitskih i ranobrončanih lokaliteta, in: 40 godina arheoloških istraživanja u sjeverozapadnoj Hrvatskoj, katalog izložbe, BalenLetunić D., Demo Ž., Homen Z., Jakovljević G., Marković Z., Sokol V., Šimek M., Tomičić Ž. (eds.), Muzejsko društvo sjeverozapadne Hrvatske, Koprivnica, 6-8.

Marković, Z. 1986b, Koprivnički Ivanec - Piškornica, Koprivnica; Koprivnički Ivanec - Vojnik I, Koprivnica; Koprivnički Ivanec - Zasek I, Koprivnica, in: 40 godina arheoloških istraživanja u sjeverozapadnoj Hrvatskoj, katalog izložbe, Balen-Letunić D., Demo Ž., Homen Z., Jakovljević G., Marković Z., Sokol V., Šimek M., Tomičić Ž. (eds.), Muzejsko društvo sjeverozapadne Hrvatske, Koprivnica, 95.

Marković, Z., Botić, K. 2014, Novi Perkovci - Krčavina, in: Darovi zemlje neolitik između Save, Drave i Dunava, drugi dio - kataloške jedinice, Balen J., Hršak T., Šošić-Klindžić R. (eds.), Zagreb, 65-70.

Miklik-Lozuk, L. 2014, Kruševica - Njivice, in: Darovi zemlje - neolitik između Save, Drave i Dunava, drugi dio - kataloške jedinice, Balen J., Hršak T., Šošić-Klindžić R. (eds.), Zagreb, 55-56.

Minichreiter, K. 2014, Pepelane - Lug i Razlivlje, in: Darovi zemlje - neolitik između Save, Drave i Dunava, drugi dio - kataloške jedinice, Balen J., Hršak T., Šošić-Klindžić R. (eds.), Zagreb, 73-74.

Nodilo, H. 2014, Kutina - Dobrovac-Kučište, in: Darovi zemlje - neolitik između Save, Drave i Dunava, drugi dio-kataloške jedinice, Balen J., Hršak T., Šošić-Klindžić R. (eds.), Zagreb, 59-61.

Okroša Rožić, L. 2003, Arheološka istraživanja u Brezovljanima 2003. godine, Cris, Vol. 5, 75-79.

Okroša Rožić, L. 2014, Brezovljani, in: Darovi zemlje - neolitik između Save, Drave i Dunava, drugi dio - kataloške jedinice, Balen J., Hršak T., Šošić-Klindžić R. (eds.), Zagreb, 15-19.

Pavličić, M. 2014, Zarilac - Grabaračke livade, in: Darovi zemlje - neolitik između Save, Drave i Dunava, drugi dio - kataloške jedinice, Balen J., Hršak T., Šošić-Klindžić R. (eds.), Zagreb, 112-113.

Rajković, D. 2014, Čepin - Ovčara/Tursko groblje, in: Darovi zemlje - neolitik između Save, Drave i Dunava, drugi dio - kataloške jedinice, Balen J., Hršak T., Šošić-Klindžić R. (eds.), Zagreb, 22-28.

Ozimec, R., Cvitanović, H., Šincek, D. 2012, Arheološko rekognosciranje 
u okviru sustavnih speleoloških i biospeleoloških istraživanja: područje SZ Hrvatske, in: Arheologija varaždinskog kraja i srednjeg Podunavlja, Izdanja Hrvatskog arheološkog društva, Vol. 28, Varaždin, 21-30.

Paunović, M. 2002, Origins of the Neolithic raw materials in Croatia, Opuscula Archaeologica, Vol. 26, 7-11.

Pavišić, I. 1986, Bojačno - Špičakov breg, Klanjec, in: 40 godina arheoloških istraživanja u sjeverozapadnoj Hrvatskoj, katalog izložbe, BalenLetunić D., Demo Ž., Homen Z., Jakovljević G., Marković Z., Sokol V., Šimek M., Tomičić Ž. (eds.), Muzejsko društvo sjeverozapadne Hrvatske, Koprivnica, 80.

Pavišić, I. 1990, Prilog poznavanju neolitika i eneolitika u Hrvatskom zagorju, Prilozi Instituta za povijesne znanosti, Vol. 7, 5-12.

Pavišić, I. 2011, Gradina Špičak u Bojačnom - prilog poznavanju visinskih naselja u Hrvatskom zagorju, Histria Antiqua, Vol. 20, 135-144.

Rajković, D., Hršak, T., Posilović, H., Kos, K. 2010, A case analysis of the operational sequence for the production of polished stone tools at the Selci Đakovački - Kaznica-Rutak site, in: Archaeotechnology: studying technology from prehistory to the Middle Ages, Vitezović S., Antonović D. (eds.), Srpsko arheološko društvo, Beograd, 89-112.

Šimek, M. 1978, Arheološko iskopavanje na Krču, Muzejski vjesnik, Vol. 1, 4-5.

Šimek, M. 1985, Kameni vrh, Godišnak Gradskog muzeja Varaždin, Vol. 7, Varaždin, 49-79.

Šimek, M. 1986, Cerje Novo - Draguševec, Ivanec; Cerje Tužno - Krč, Ivanec; in: 40 godina arheoloških istraživanja u sjeverozapadnoj Hrvatskoj, katalog izložbe, Balen-Letunić D., Demo Ž., Homen Z., Jakovljević G., Marković Z., Sokol V., Šimek M., Tomičić Ž. (eds.), Muzejsko društvo sjeverozapadne Hrvatske, Koprivnica, 80-81.

Šimek, M. 1997, Registar arheoloških nalaza i nalazišta sjeverozapadne Hrvatske, drugo dopunjeno izdanje, Muzejsko društvo sjeverozapadne Hrvatske - Sekcija arheologa i preparatora, Bjelovar.

Šimek, M. 2010, „Kamena strela“ u srednjovjekovnoj utvrdi?, Zbornik Soboškega Muzeja, Vol. 15, 135-149.

Šimek, M., Kurtanjek, D., Paunović, M. 2002, Eneolitičke glačane kamene alatke iz špilje Vindije (SZ Hrvatska), Opuscula Archaeologica, Vol. 26, 39-54.

Škiljan, I. 2009a, Arheološka baština stubičkog kraja, in: Osam stoljeća
Stubice, Horjan G. (ed.), Muzeji Hrvatskog zagorja, Muzej seljačkih buna, Grad Gornja Stubica, Sveta Nedjelja, 28-41.

Škiljan, I. 2009b, Prapovijest, in: Osam stoljeća Stubice, Horjan G. (ed.), Muzeji Hrvatskog zagorja, Muzej seljačkih buna, Grad Gornja Stubica, Sveta Nedjelja, 5-6.

Šošić Klindžić, R. 2017. Reciklaža kamenog oruđa tijekom povijesti, in: Recikliraj, ideje iz prošlosti, katalog izložbe, Miloglav I., Kudelić A., Balen J. (eds.), Arheološki muzej u Zagrebu, Filozofski fakultet Sveučilišta u Zagrebu, Institut za arheologiju, Zagreb, 35-44.

Špoljar, D. 2012, Rezultati arheoloških rekognosciranja Ravne gore i okolnih područja, in: Arheologija varaždinskog kraja i srednjeg Podunavlja, Izdanja Hrvatskog arheološkog društva, Vol. 28, Varaždin, 31-46.

Špoljar, D. 2014, Arheološki nalazi i nalazišta na području općine Radoboj, in: Općina Radoboj, Kozina D. (ed.), Radoboj, 25-42.

Špoljar, D. 2015, Naseljenost Radoboja i okolnih područja u prapovijesti, Kaj, Vol. XLVIII(1-2), 89-122.

Špoljar, D., Šincek, D. 2013, Elaborat o provedenom arheološkom rekognosciranju na području općine Radoboj, Radoboj.

Težak-Gregl, T. 1993, Kultura linearnotrakaste keramike u središnjoj Hrvatskoj, Korenovska kultura, Disertacije i Monografije 2, Arheološki zavod Filozofskog fakulteta Sveučilišta u Zagrebu, Zagreb.

Težak-Gregl, T. 2001, Glačane kamene rukotvorine neolitičkog i eneolitičkog razdoblja u Hrvatskoj, Opuscula Archaeologica, Vol. $25,7-25$.

Težak-Gregl, T., Burić, M. 2002, Polished stone implements of the neolithic Starčevo Culture, Opuscula Archaeologica, Vol. 26, 13-17.

Tkalčec, T. 1999, Kratak pregled arheoloških nalazišta križevačkog kraja, Cris, Vol. 1, 17-21.

Vinski-Gasparini, K. 1973, Kultura polja sa žarama u sjevernoj Hrvatskoj, Filozofski fakultet u Zadru, Zadar.

Vrkić, Š. 2014, Donji Slatnik - Gajevi, in: Darovi zemlje - neolitik između Save, Drave i Dunava, drugi dio - kataloške jedinice, Balen J., Hršak T., Šošić-Klindžić R. (eds.), Zagreb, 29-30.

Živković, M., Medović, I., Jovanov, J. 2011, Okresano i glačano kameno oruđe sa zaštitnih arheoloških iskopavanja naselja Starčevo Grad u periodu od 2003. do 2008. godine, Rad vojvođanskih muzeja, Vol. 53, 23-43. 


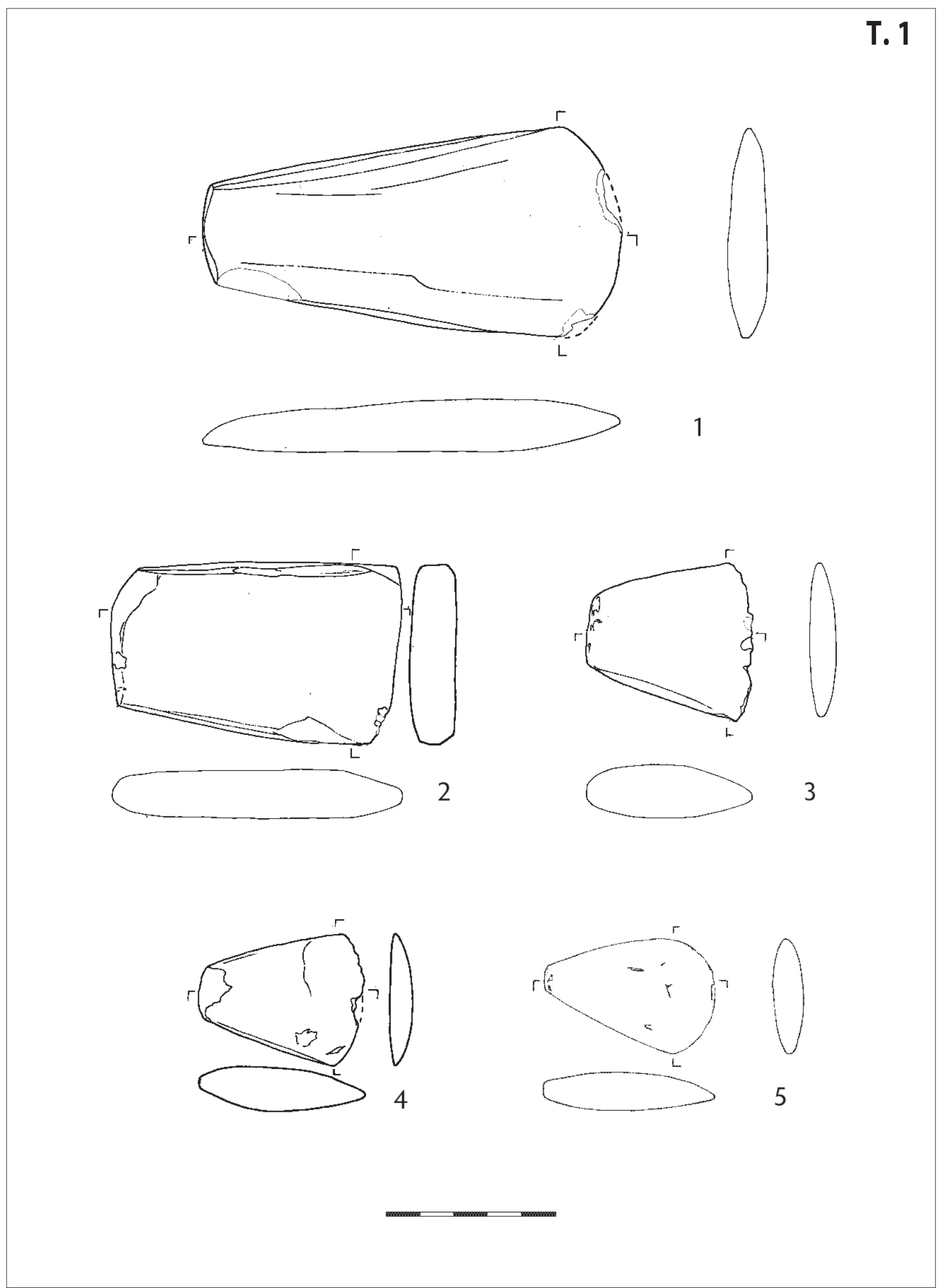

T. 1 Sjekire trapezastoga oblika: 1 Jamno (P-4218); 2 Jazbina (P-5777); 3 Hum (P-1804); 4 Druškovec (P-14945); 5 Marija Bistrica (P-1807)

PI. 1 Trapezoidal axes: 1 Jamno (P-4218); 2 Jazbina (P-5777); 3 Hum (P-1804); 4 Druškovec (P-14945); 5 Marija Bistrica (P-1807) 

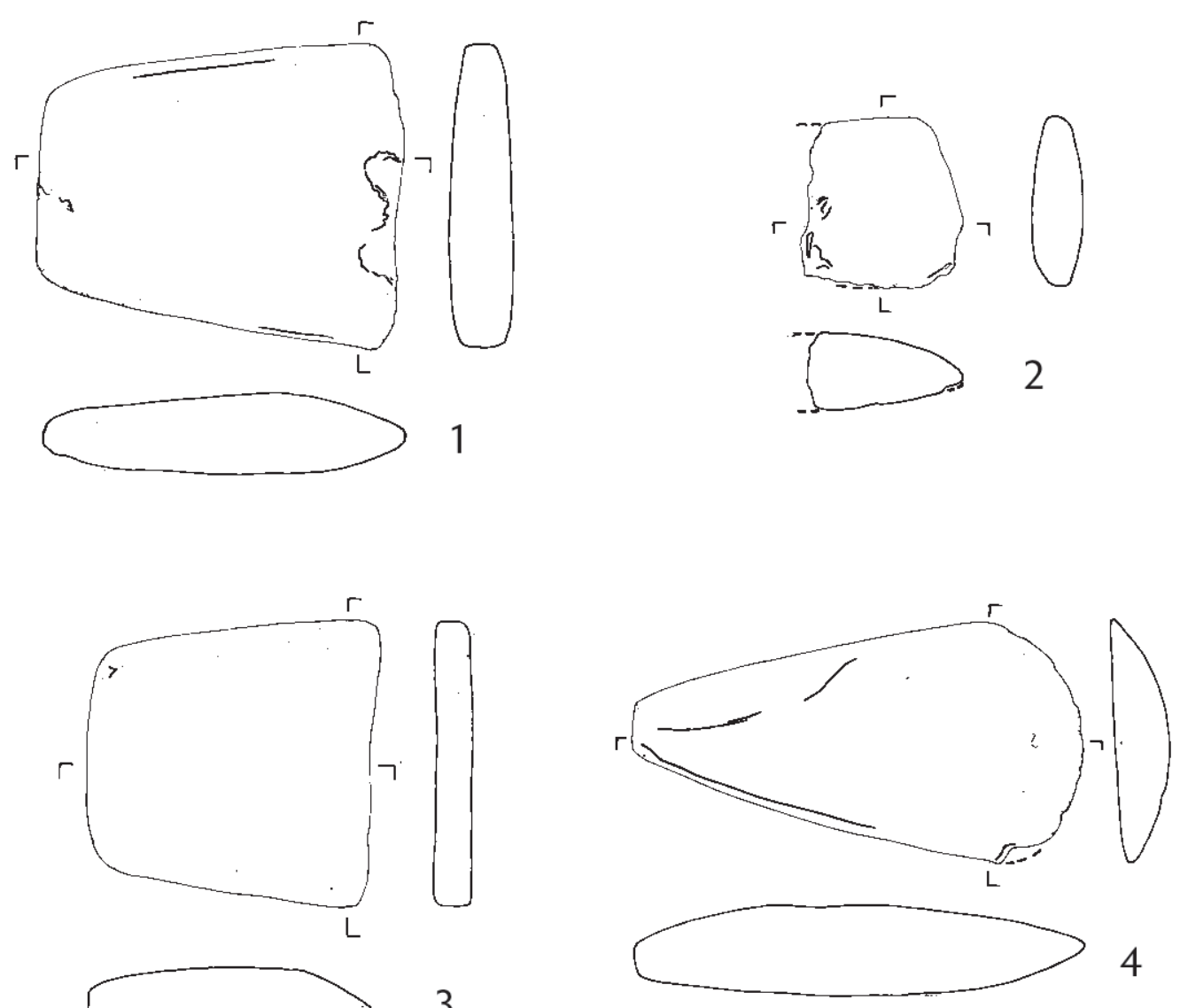

3
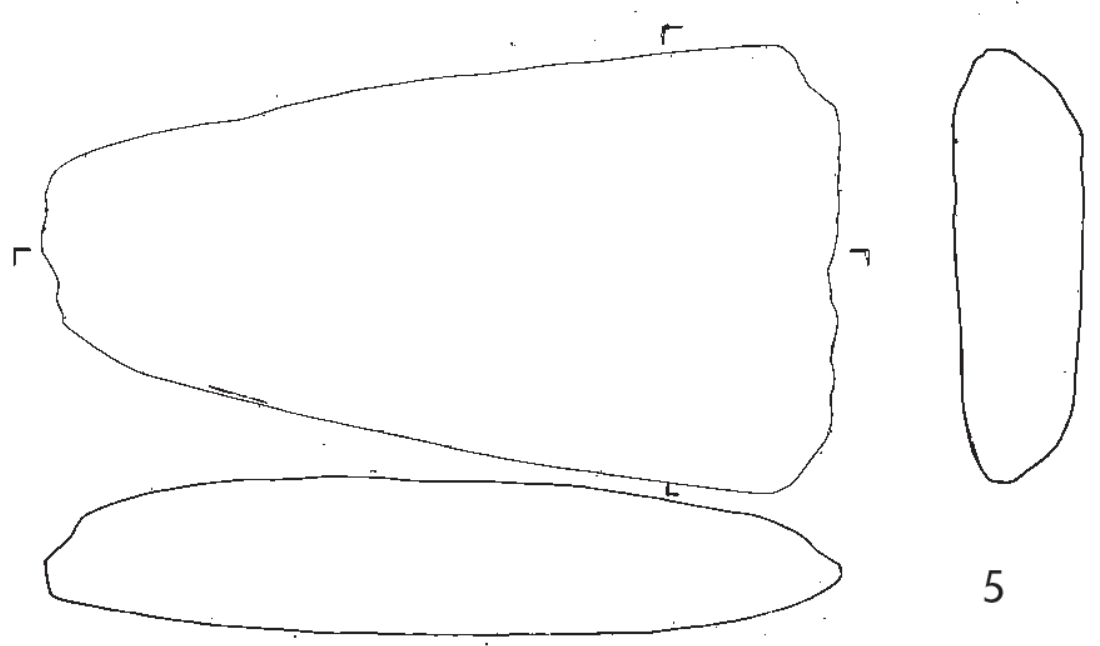

T. 2 Sjekire trapezastoga oblika: 1 Brezova Gora (P-6399); 2 Strugača; 3 Kuzminec (P-18832); Bradve: 4 Samobor (P-21318); 5 Drenov Bok (P-21299)

PI. 2 Trapezoidal axes: 1 Brezova Gora (P-6399); 2 Strugača; 3 Kuzminec (P-18832); Adzes: 4 Samobor (P-21318); 5 Drenov Bok (P-21299) 

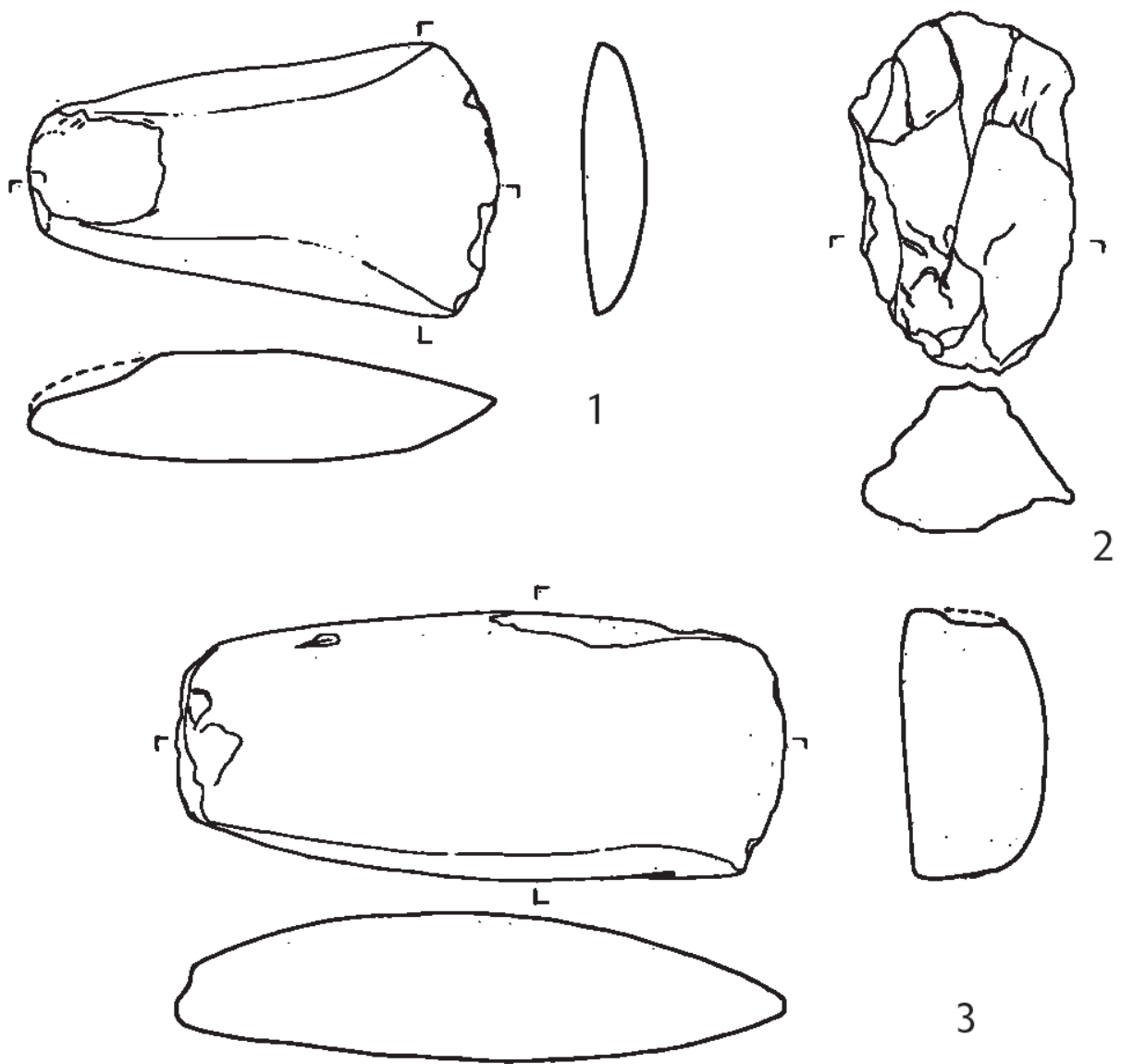

3

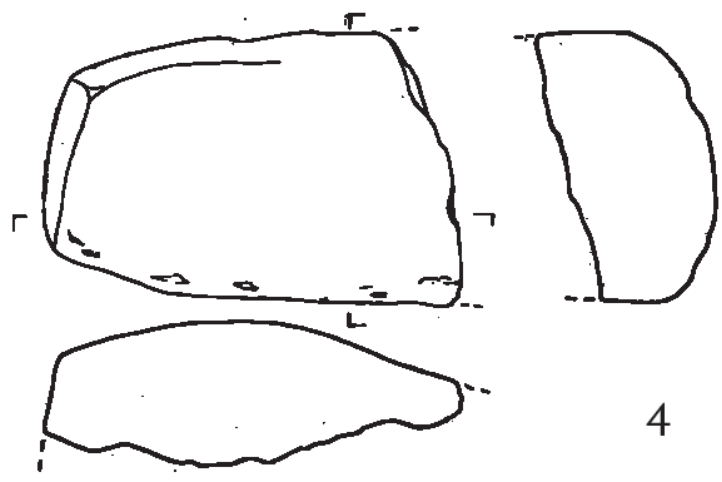

T. 3 Bradva: 1 Drenov Bok (14934); Dlijeta: 2 Klenovec (P-18838); 3 Miholečke Mokrice (P-6753); 4 Strugača

Pl. 3 Adze: 1 Drenov Bok (14934); Chisels: 2 Klenovec (P-18838); 3 Miholečke Mokrice (P-6753); 4 Strugača 


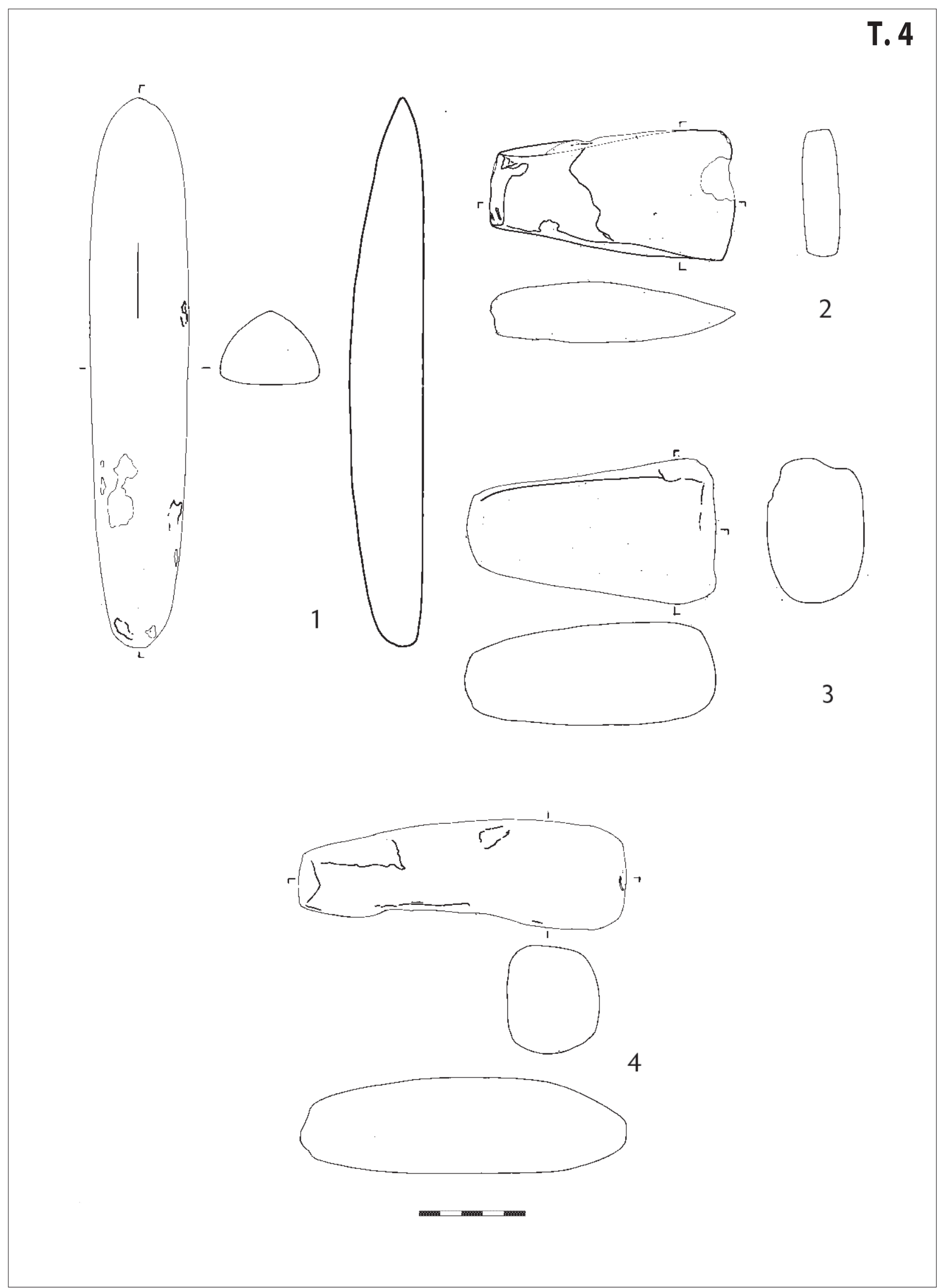

T. 4 Dlijeta: 1 Kamenski Dol (P-15000); 2 Tkalec (P-6654); Čekići: 3 Jamno (P-6471); 4 Jamno (P-4222)

PI. 4 Chisels: 1 Kamenski Dol (P-15000); 2 Tkalec (P-6654); Hammers: 3 Jamno (P-6471); 4 Jamno (P-4222) 

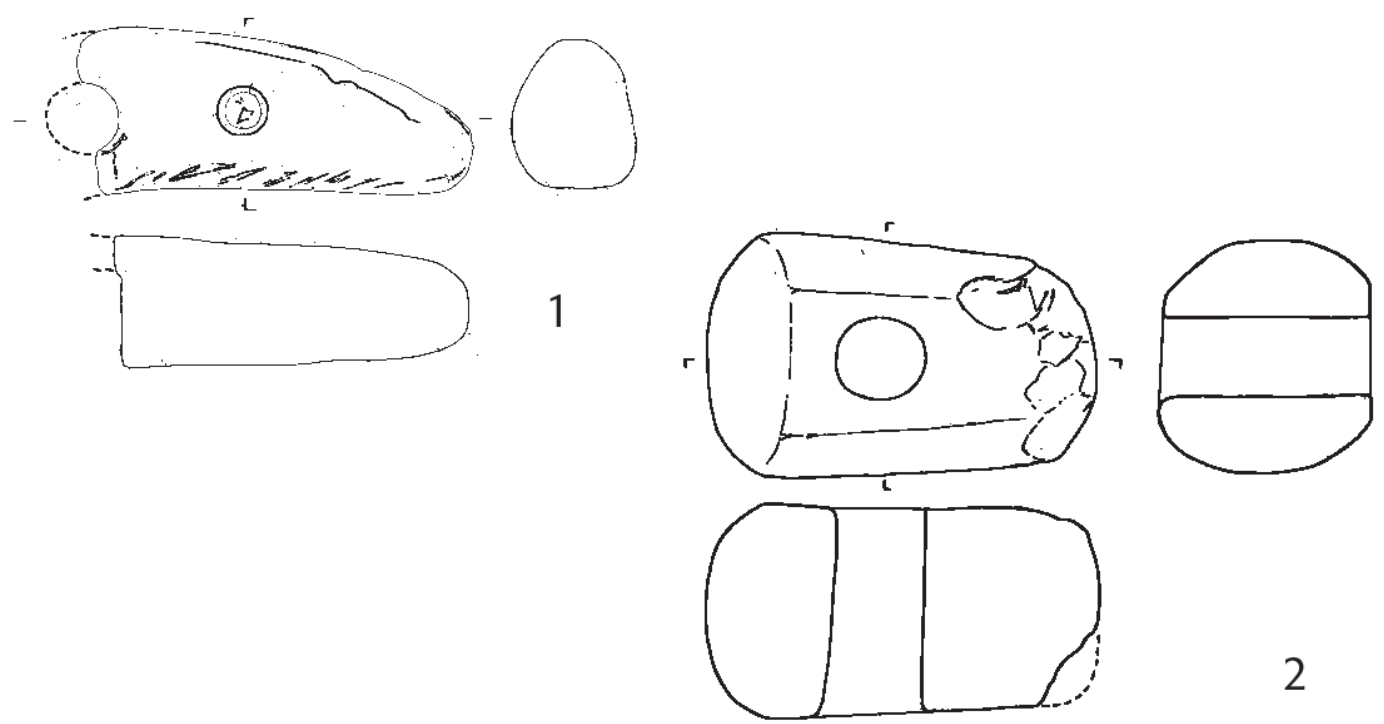

2
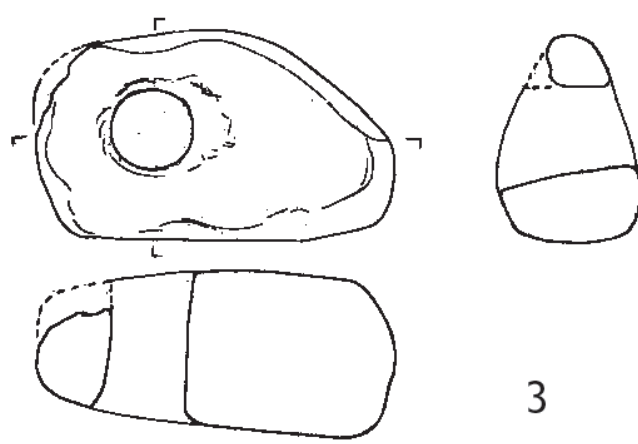

3

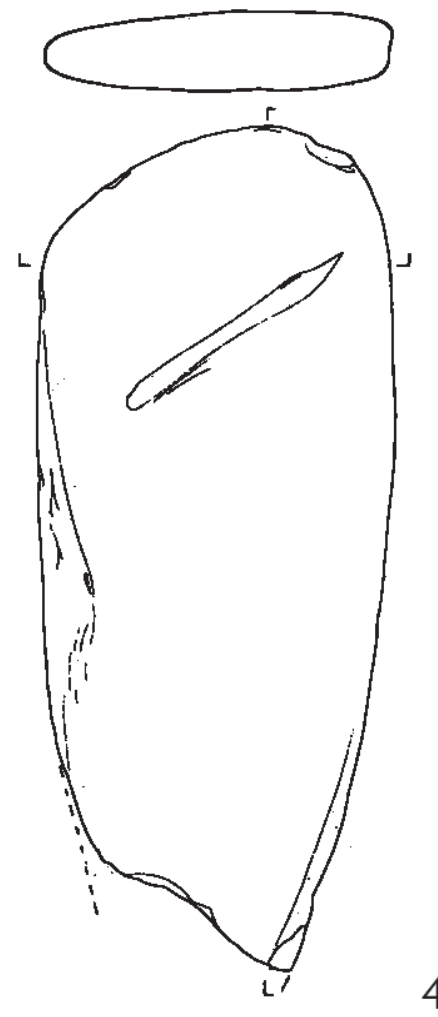

4

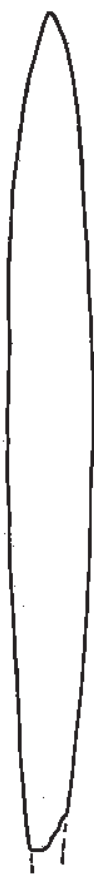

T. 5 Čekići s rupom za nasad drška: 1 Klenovnik (P-6724); 2 Kloštar Ivanić (P-1674); 3 Jerovec (P-8369); Motika: 4 Čulinec (P-1676) Pl. 5 Hammers with holes for hafting: 1 Klenovnik (P-6724); 2 Kloštar Ivanić (P-1674); 3 Jerovec (P-8369); Hoe: 4 Čulinec (P-1676) 


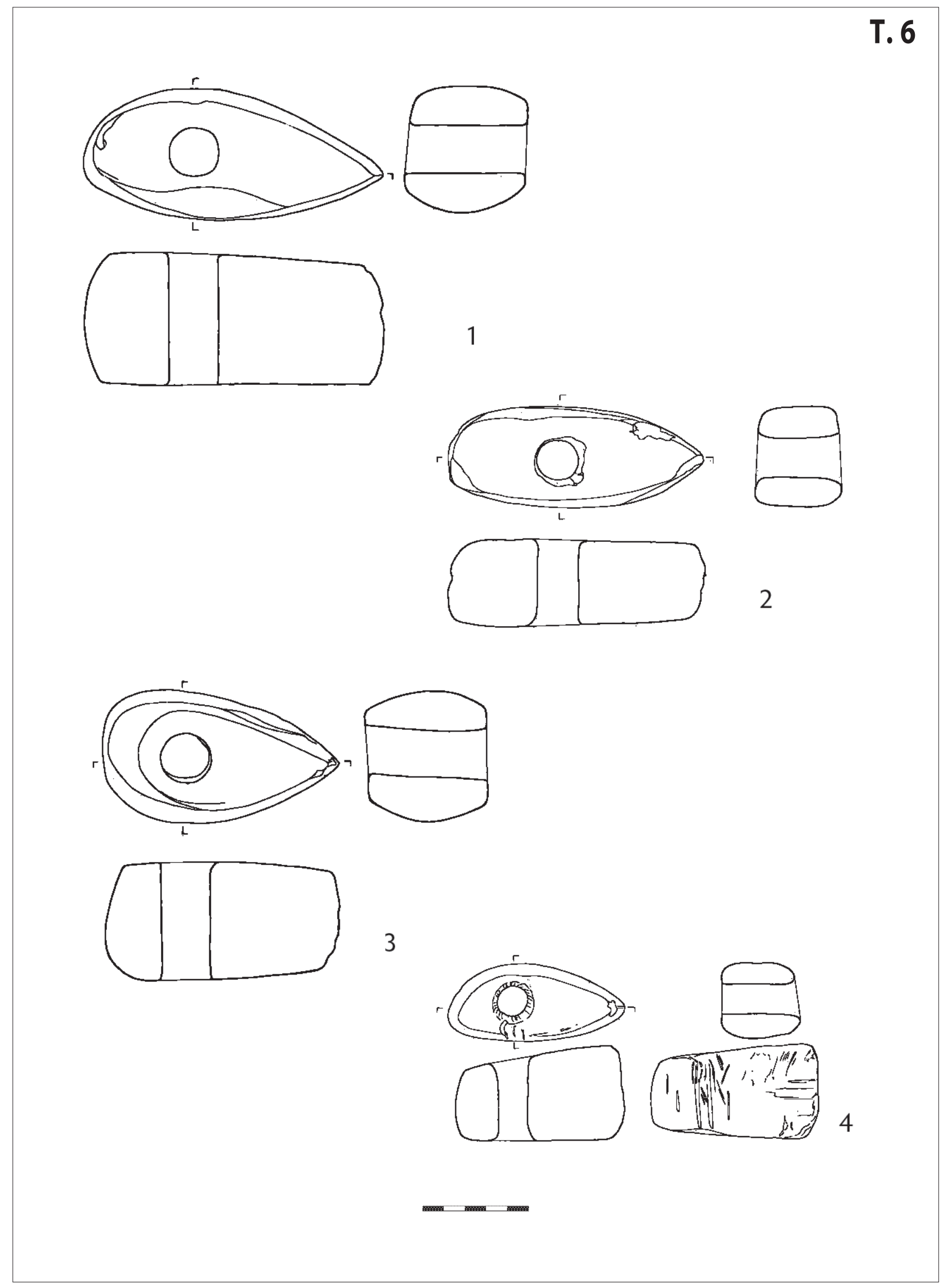

T. 6 Sjekire-čekići s rupom za nasad drška (1. grupa): 1 Radoboj (P-1689); 2 Hum sv. Martin (P-1695); 3 Zlatar (P-1780); 4 Šemnica (P-1726)

PI. 6 Axe-hammers with holes for hafting (1st group): 1 Radoboj (P-1689); 2 Hum Sv. Martin (P-1695); 3 Zlatar (P-1780); 4 Šemnica (P1726) 

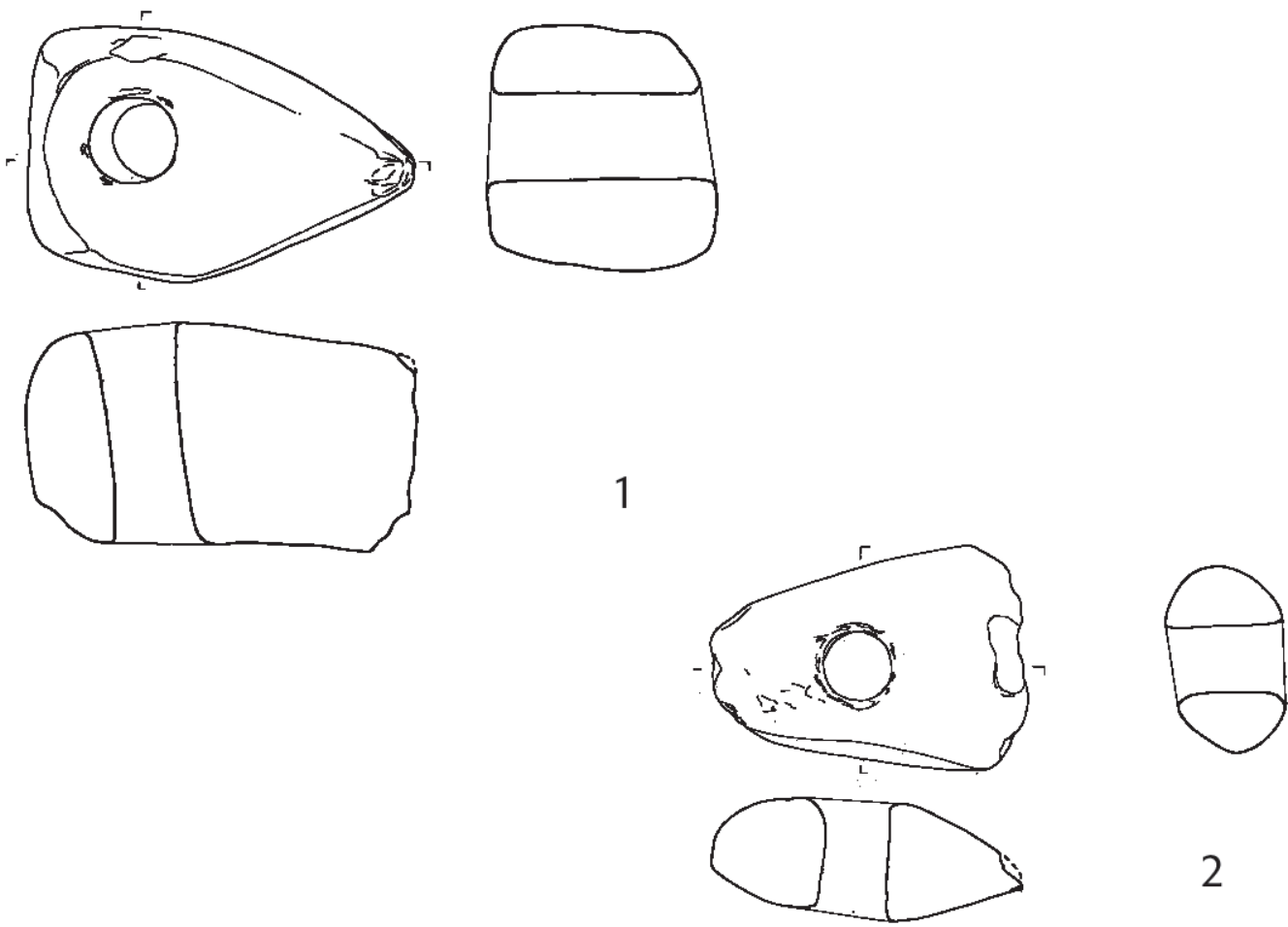

2
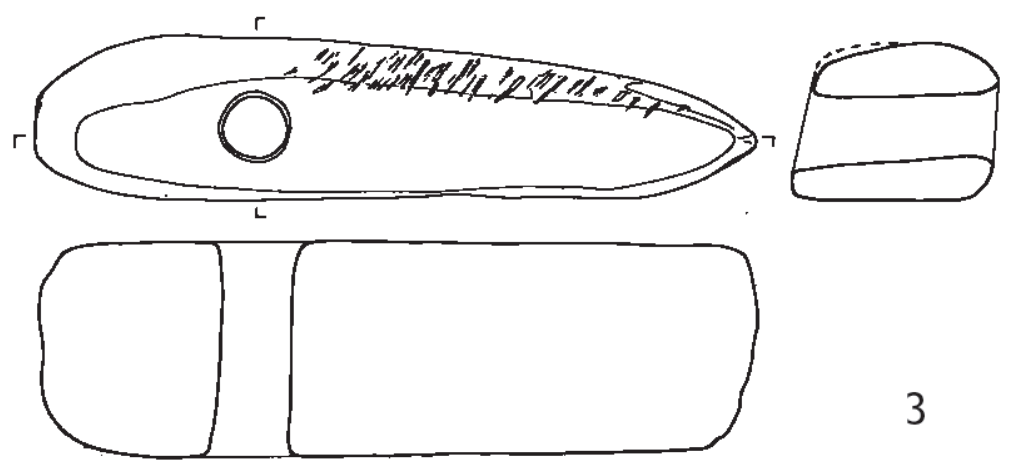

\section{3}
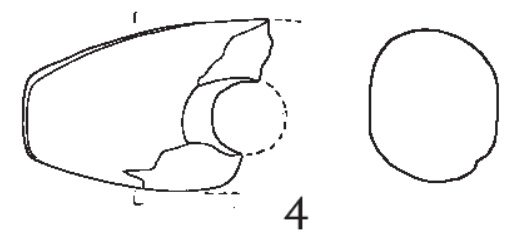

4
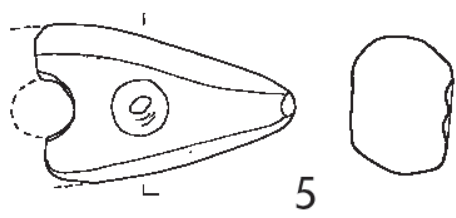

5

T. 7 Sjekira-čekić s rupom za nasad drška (2. grupa): 1 Hrašćina (P-4231); Sjekira-čekić s rupom za nasad drška (3. grupa): 2 Sv. llija Obrež (P-1700); Sjekira-čekić s rupom za nasad drška (4. grupa): 3 Sutinsko (P-1720); Sjekire s rupom za nasad drška: 4 Zlatar (P-1781); 5 Drenov Bok (P-11298)

PI. 7 Axe-hammer with a hole for hafting (2nd group): 1 Hrašćina (P-4231); Axe-hammer with a hole for hafting (3rd group): 2 Sveti llija Obrež (P-1700); Axe-hammer with a hole for hafting (4th group): 3 Sutinsko ( $P$-1720); Axes with holes for hafting: 4 Zlatar ( $(P-1781)$; 5 Drenov Bok (P-11298) 

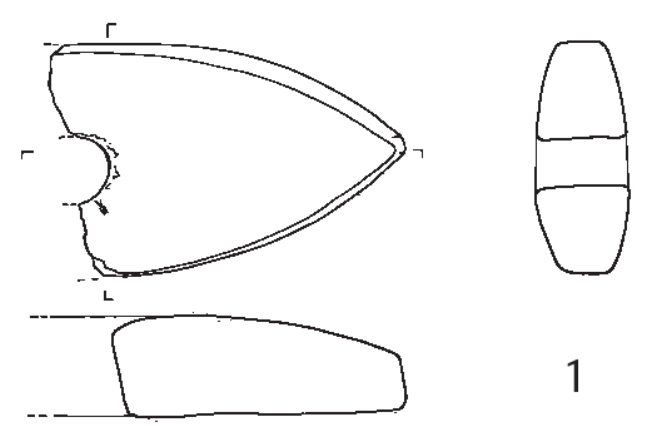

1
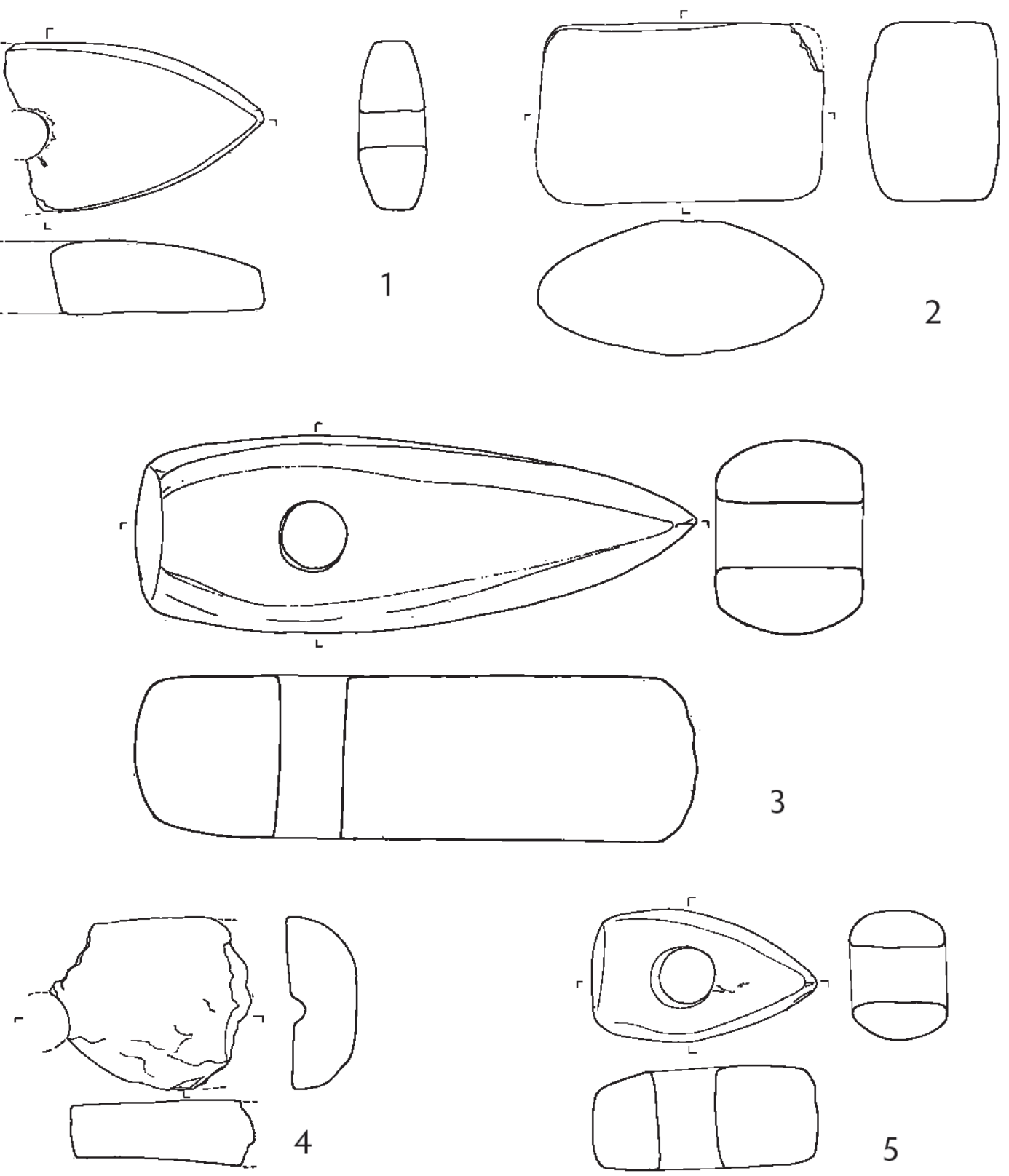

5

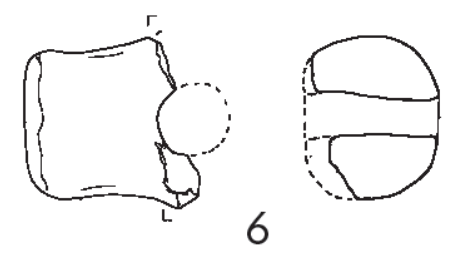

T. 8 Sjekire s rupom za nasad drška: 1 Cerje (P-4226); 2 Marija Bistrica (P-1810); 3 Jakovlje (P-5776); 4 Bedekovčina (P-1714); 5 Jakuševec (P-16075); 6 Zlatar (P-1737)

PI. 8 Axes with holes for hafting: 1 Cerje (P-4226); 2 Marija Bistrica (P-1810); 3 Jakovlje (P-5776); 4 Bedekovčina (P-1714); 5 Jakuševec (P16075); 6 Zlatar (P-1737) 


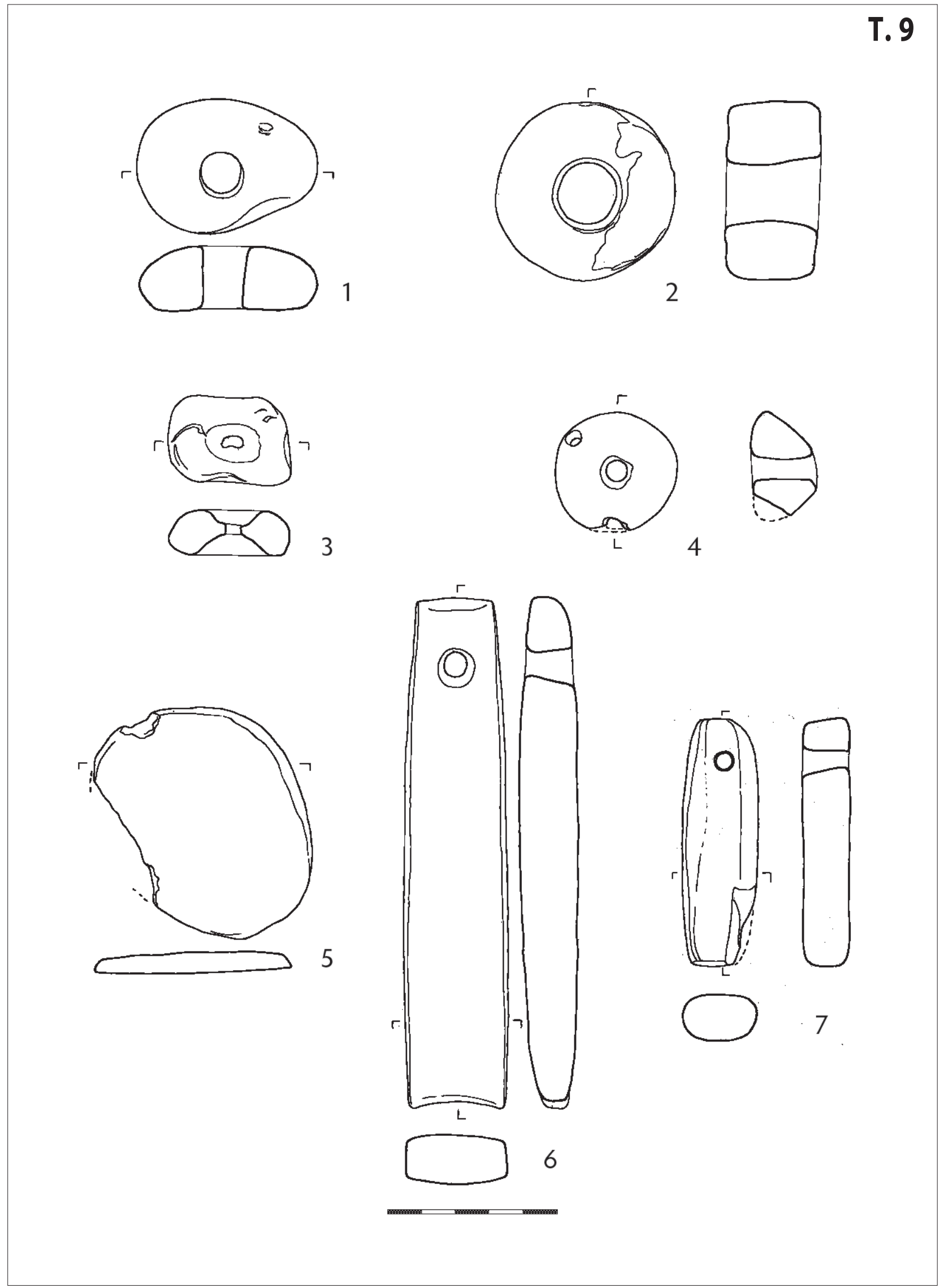

T. 9 Pršljeni (1. grupa): 1 Miljana (P-21311); Pršljen (2. grupa): 2 Zlatar (P-1739); Pršljeni (3. grupa): 3 Pakasin (P-21314); 4 Hvatska (P-1797); Pločica: 5 Koškovec (P-4230); Brusovi: 6 Konjšćina (P-21309); 7 Kašina (P-1816)

PI. 9 Whorls (1st group): 1 Miljana (P-21311); Whorl (2nd group): 2 Zlatar (P-1739); Whorls (3rd group): 3 Pakasin (P-21314); 4 Hvatska (P1797); Tile: 5 Koškovec (P-4230); Whetstone: 6 Konjšćina (P-21309); 7 Kašina (P-1816) 

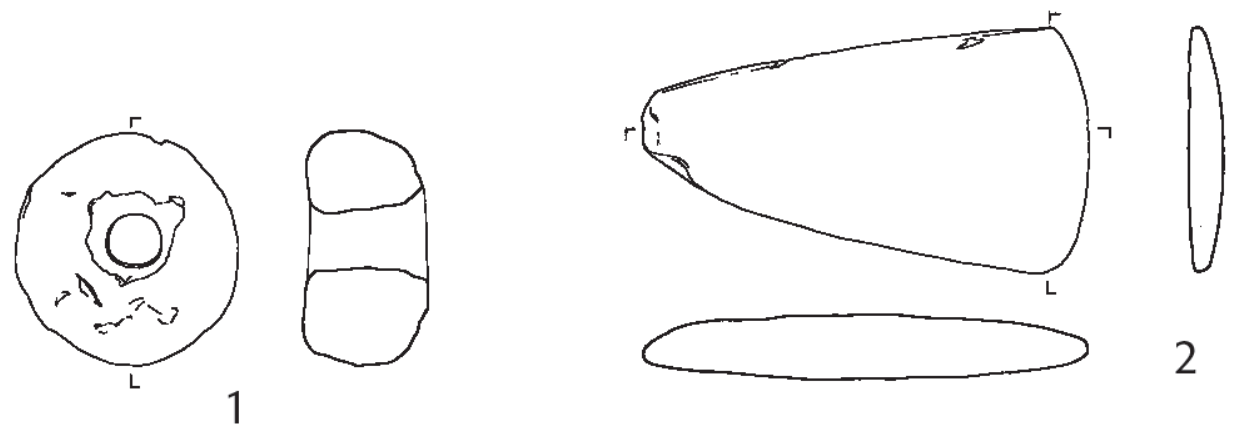

1

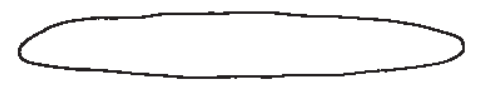

2
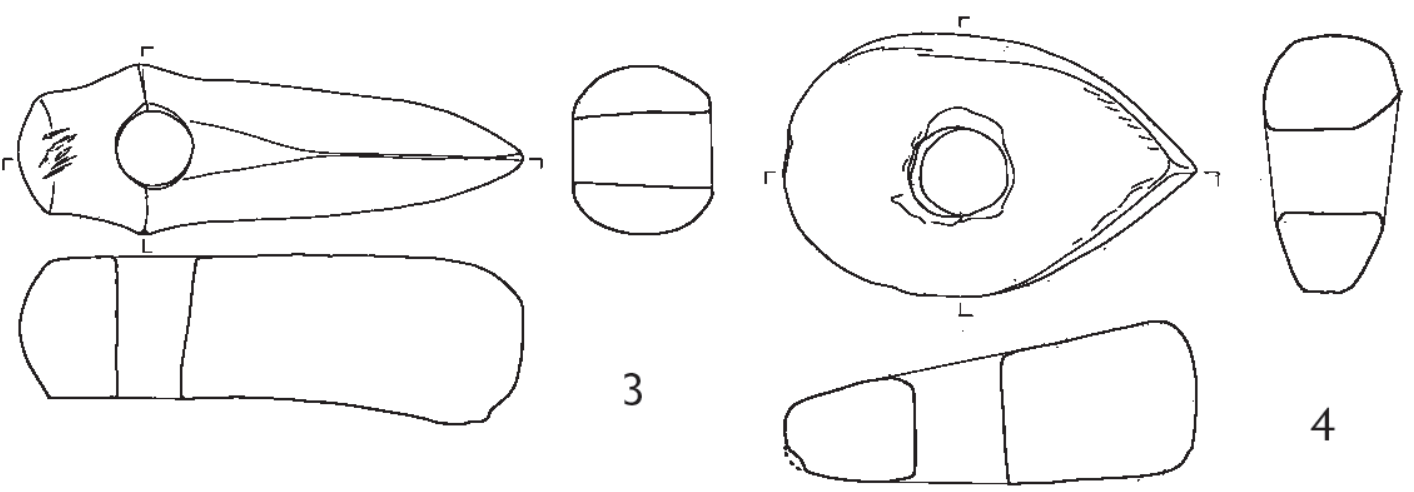

3
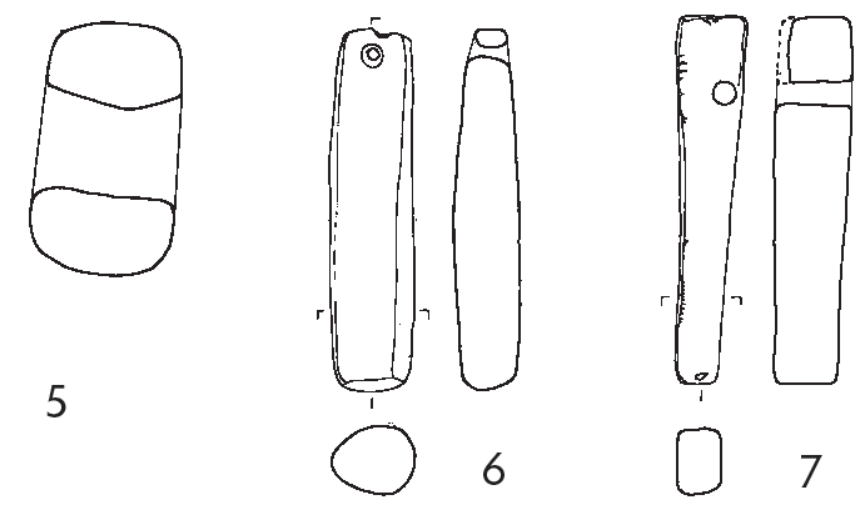

7

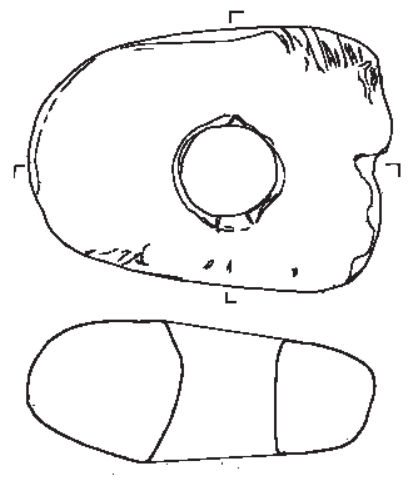

6

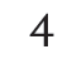

T. 10 Nalazi s područja Hrvatskoga zagorja: 1 pršljen (P-1787); 2 sjekira trapezastoga oblika (P-1783); 3 sjekira-čekić s rupom za nasad drška (4. grupa; P-1753); 4 sjekira-čekić s rupom za nasad drška (1. grupa; P-1751); 5 čekić s rupom za nasad drška (P1770); 6 brus (P-1775); 7 brus (P-1776)

PI. 10 Finds from Hrvatsko Zagorje: 1 Whorl (P-1787); 2 Trapezoidal axe (P-1783); 3 Axe-hammer with a hole for hafting (4th group; $P$-1753); 4 Axe-hammer with a hole for hafting (1st group; $P$-1751); 5 Hammer with a hole for hafting (P-1770); 6 Whetstone (P-1775); 7 Whetstone (P-1776) 